\title{
2007 National Roadside Survey of Alcohol and Drug Use by Drivers
}

\section{ALCOHOL RESULTS}
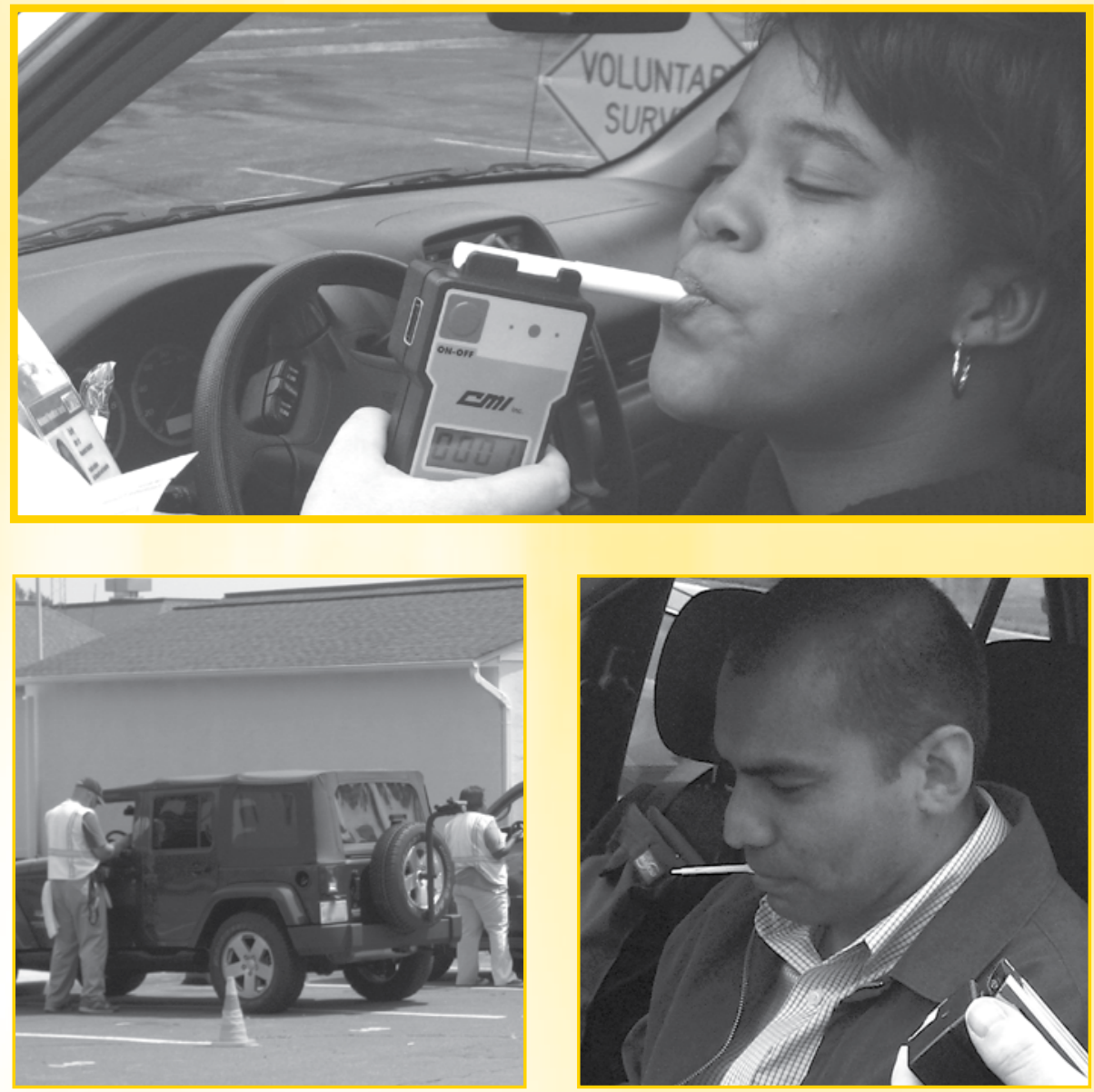
This publication is distributed by the U.S. Department of Transportation, National Highway Traffic Safety Administration, in the interest of information exchange. The opinions, findings and conclusions expressed in this publication are those of the author(s) and not necessarily those of the Department of Transportation or the National Highway Traffic Safety Administration. The United States Government assumes no liability for its content or use thereof. If trade or manufacturers' names or products are mentioned, it is because they are considered essential to the object of the publication and should not be construed as an endorsement. The United States Government does not endorse products or manufacturers. 
Technical Report Documentation Page

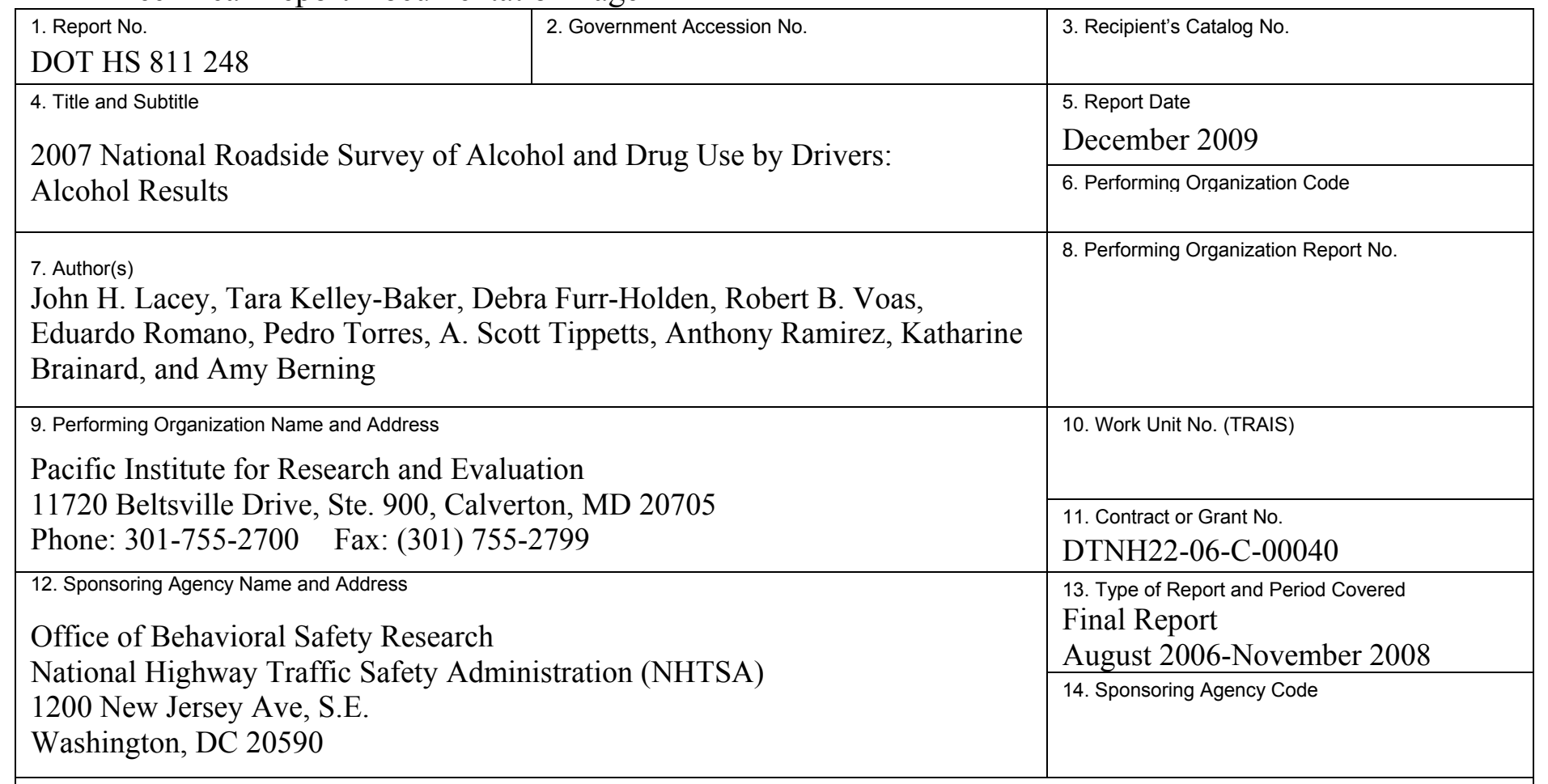

15. Supplementary Notes

Amy Berning served as the project's Contracting Officer's Technical Representative.

The National Institute on Alcohol Abuse and Alcoholism (NIAAA) provided funding and support for the assessment of alcohol use disorders.

The National Institute on Drug Abuse (NIDA) provided funding for collection of additional blood samples and the administration of the drug use disorders assessment.

The National Institute of Justice (NIJ) provided support for querying participants about interaction with the Criminal Justice System.

16. Abstract

This report presents the prevalence estimates for alcohol-involved driving derived from the recently completed U.S. national field survey of alcohol- and drug-involved driving (primarily of nighttime weekend drivers, but also daytime Friday drivers) and compares those estimates with the three previous National Roadside Surveys. This survey involved randomly stopping drivers at 300 locations across the 48 contiguous United States. Data were collected during 2-hour Friday daytime sessions (9:30 a.m. to 11:30 a.m. or 1:30 p.m. to 3:30 p.m.) at 60 locations and during four 2-hour nighttime periods (10 p.m. to midnight and 1 a.m. to 3 a.m. on Fridays and Saturdays) at 240 locations. Both self-report and biological measures were taken. Biological measures included breath-alcohol measurements on 9,413 respondents, oral fluid samples from 7,719 respondents, and blood samples from 3,276 respondents. A prior report described the sampling plan and data collection methodology and summarized the response patterns to the various stages of the multipart survey. A third report, based on analyses of the oral fluid and blood specimens collected, will present the first national prevalence estimate of drug-involved driving and of alcohol-plus-drug-involved driving. This report focuses on the alcohol breath-test results and how they relate to previous national surveys. It also summarizes response patterns to survey questions and to an alcohol-use-disorder-screening instrument. The data indicate a continuing trend over the past three decades of fewer alcohol-involved drivers on the Nation's roads during weekend nights.

17. Key Words

Alcohol and driving, drugs and driving, roadside survey, impaired driving, drugged driving, alcohol
18. Distribution Statement

Document is available to the public from the National Technical Information Service www.ntis.gov

\begin{tabular}{l|l}
\hline 19 Security Classif. (of this report) & 20. Security Classif. (of this page) \\
Unclassified & Unclassified
\end{tabular}

Form DOT F 1700.7 (8/72)

\begin{tabular}{|l|l|}
\hline 21 No. of Pages & 22. Price \\
\hline 108 & \\
\hline
\end{tabular}

Reproduction of completed page authorized 


\section{Acknowledgements}

The authors received extensive assistance from State and local officials in the conduct of this project. Our data collection procedures were not routine. The willingness of officials to help us identify cooperating local police agencies and the willingness of agencies to participate in the project were essential to our success.

To all those who helped in conducting this study, the authors express their sincere gratitude. 


\section{Table of Contents}

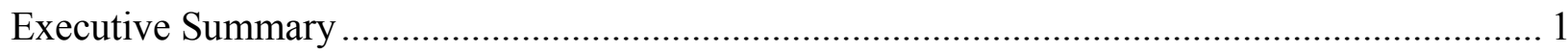

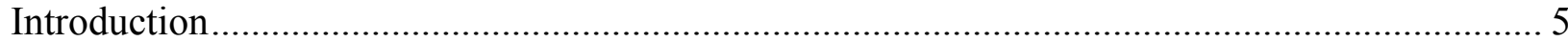

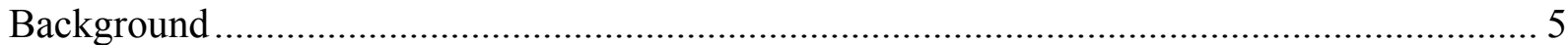

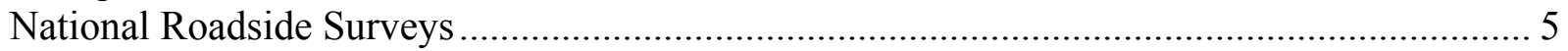

First Report: The 2007 NRS Methodology Report................................................................. 6

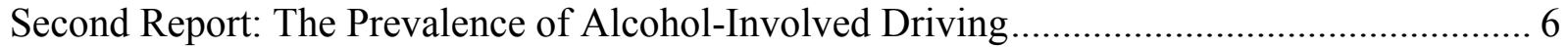

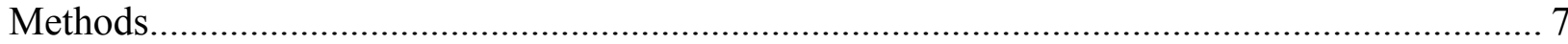

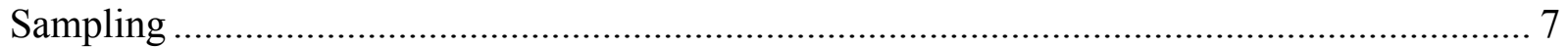

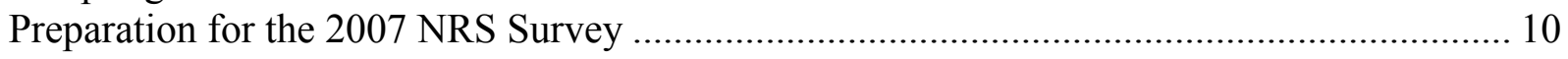

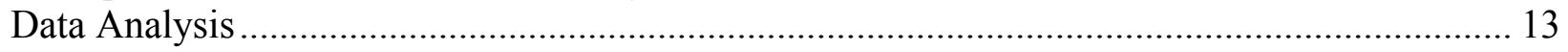

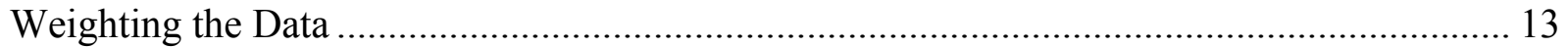

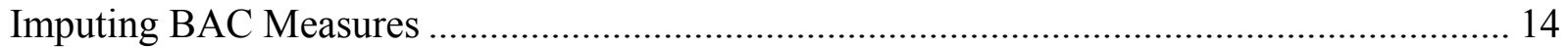

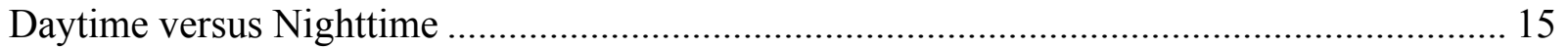

Comparing the Results of the Four National Roadside Surveys.................................................... 16

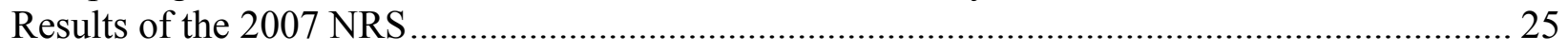

Comparison of Friday Daytime and Nighttime Results......................................................... 25

Comparison of the Demographics of Friday Daytime to Nighttime Drivers......................... 25

Comparison of the BACs of Friday Daytime to Friday Nighttime Drivers........................... 28

Nighttime Survey Results ................................................................................................ 29

Nighttime BAC by Demographics, Exposure, Trip, and Vehicle Type ............................... 29

Nighttime Drivers Reporting Contact with the Criminal Justice System .............................. 36

Nighttime Drivers Reporting Contact with the Health System ........................................... 37

Observed and Reported Safety Behaviors of Nighttime Drivers......................................... 42

Daytime Survey Results........................................................................................................ 46

Daytime BAC by Demographics, Exposure, Trip, and Vehicle Type................................... 46

Daytime Drivers Reporting Contact with the Criminal Justice System ................................ 51

Daytime Drivers Reporting Contacts with the Health System ………………………......... 52

Observed and Reported Safety Behaviors of Daytime Drivers ............................................. 56

Prevalence of Respondents with Alcohol Use Disorders (AUDs) ................................................... 59

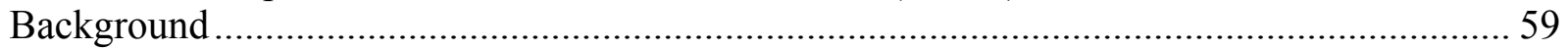

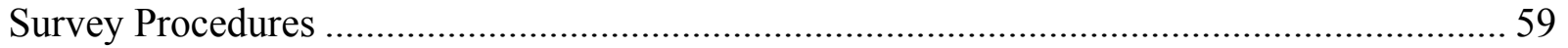

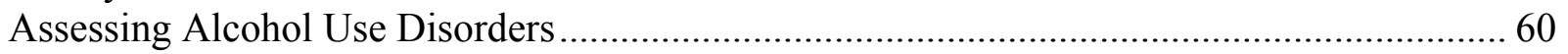

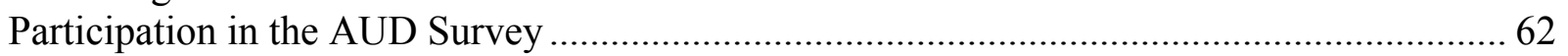

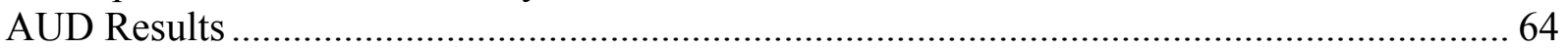

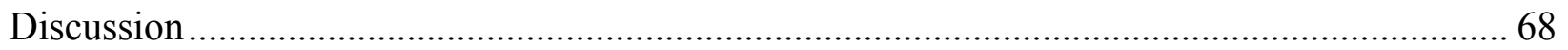

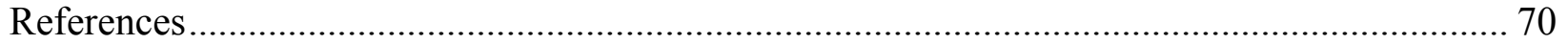

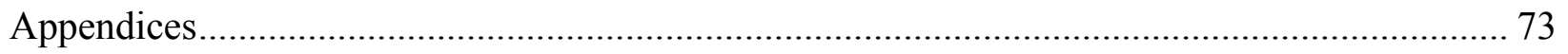

Appendix A. 2007 National Roadside Survey: Survey Instrument .......................................... 75

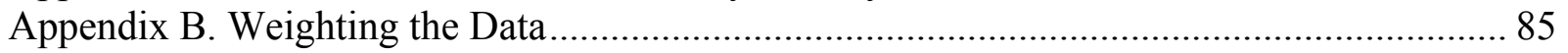

Appendix C. Imputing Blood Alcohol Concentration (BAC) ………………………............ 93 


\section{Tables}

Table 1. Percentage of Eligible Drivers Entering the Survey Sites that Provided Interviews and Breath Tests during Nighttime Data Collection Periods 2

Table 2. Proportion of Eligible Drivers Entering the Survey Sites that Provided Interviews and Breath Tests in 2007 3

Table 3. Comparison of the Percentage of Nighttime Drivers in Various BAC Categories in the Four National Roadside Surveys .............................................................................. 3

Table 4. Comparison of the Percentage of Drivers in Various BAC Categories in 2007 by Time of Day 4

Table 5. Comparison of Number of Nighttime Participants by Year in the National Roadside

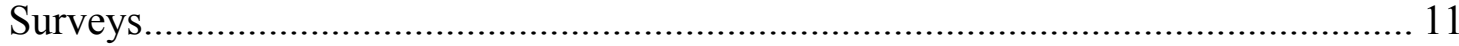

Table 6. BAC Distribution of Successfully Converted Refusers........................................... 12

Table 7. 2007 NRS Observed and Imputed BAC Levels (Daytime and Nighttime) ................... 15

Table 8. Comparison of the Percentage of Nighttime Drivers in Various BAC Categories in the Four National Roadside Surveys ........................................................................... 18

Table 9. Comparison of Driver BAC Results in Relation to Time of Night and Weekend Night 21 Table 10. Comparison of Nighttime High BAC Drivers by Demographic Characteristics......... 23 Table 11. Results of Logistic Regression Models Predicting the Odds of BAC $\geq .05$ and/or BAC

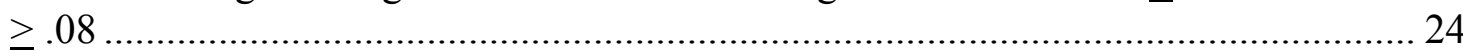

Table 12. Percentage of Friday Respondents by Age Category .............................................. 26

Table 13. Percentage of Male and Female Drivers during Friday Daytime and Nighttime ......... 26

Table 14. Percentage of Race/Ethnicity of Friday Daytime and Nighttime Drivers .................. 27

Table 15. Percentage of Educational Attainment by Friday Daytime and Nighttime Drivers ..... 27

Table 16. Employment Status of Friday Daytime and Nighttime Drivers ................................ 28

Table 17. Type of Vehicle Driven by Friday Daytime and Nighttime Drivers .......................... 28

Table 18. Percentage of Drivers in Three BAC Categories on Fridays across Three Periods ..... 29 Table 19. Nighttime: BAC Distributions of Nighttime Drivers (Friday and Saturday Combined)

Table 20. Nighttime: BAC by Demographics (Gender, Race/Ethnicity, and Age Group).......... 30 Table 21. Nighttime: Exposure (Yearly Miles and Percentage of Day and Night Driving) by BAC (Percentages Calculated by Row) ................................................................ 31

Table 22. Nighttime: Exposure (Yearly Miles and Percentage of Day and Night Driving) by BAC (Percentages Calculated by Column) .......................................................... 32

Table 23. Nighttime: Trip Origin and Destination by BAC (Percentages Calculated by Row)... 34 Table 24. Nighttime: Trip Origin and Destination by BAC (Percentages Calculated by Column)

Table 25. Nighttime: Vehicle Type by BAC (Percentages Calculated by Row) ......................... 36

Table 26. Nighttime: Vehicle Type by BAC (Percentages Calculated by Column) ................... 36

Table 27. Nighttime: Reported Sanctions Following Arrest for Previous Impaired Driving....... 37

Table 28. Nighttime: "Have you visited a medical facility in the past year?"........................... 38

Table 29. Nighttime: "In the past year, have you been told by a medical person you needed help for your drinking?" (Percentages Calculated by Row) ............................................. 38

Table 30. Nighttime: "In the past year, have you been told by a medical person you needed help for your drinking?" (Percentages Calculated by Column).......................................... 39

Table 31. Nighttime: "In the past year, have you sought help because of your drinking?" (Percentages Calculated by Row).... 
Table 32. Nighttime: "In the past year, have you sought help because of your drinking?" (Percentages Calculated by Column).

Table 33. Nighttime: "In the past year, have you been to an emergency room because of something related to your drinking?" (Percentages Calculated by Row) .................... 39

Table 34. Nighttime: "In the past year, have you been to an emergency room because of something related to your drinking?" (Percentages Calculated by Column). 40

Table 35. Nighttime: "During the past 12 months, did you ever stay at least overnight in an impatient or residential drug or alcohol treatment program, for example, detox, rehab, a therapeutic community, or a hospital?" (Percentages Calculated by Row). 40

Table 36. Nighttime: "During the past 12 months, did you ever stay at least overnight in an impatient or residential drug or alcohol treatment program, for example, detox, rehab, a therapeutic community, or a hospital?" (Percentages Calculated by Column)......... 40

Table 37. Nighttime: "Have you ever been admitted to an outpatient drug or alcohol treatment program, NOT including meetings like AA or NA?" (Percentages Calculated by Row)

Table 38. Nighttime: "Have you ever been admitted to an outpatient drug or alcohol treatment program, NOT including meetings like AA or NA?" (Percentages Calculated by Column)

Table 39. Nighttime: "During the past 12 months, have you received treatment for your drug or alcohol use in a self-help group such as AA or NA?” (Percentages Calculated by Row)

Table 40. Nighttime: "During the past 12 months, have you received treatment for your drug or alcohol use in a self-help group such as AA or NA?" (Percentages Calculated by Column) ....................................................................................... 42

Table 41. Nighttime: Safety (Designated-driver Report and Seat Belt Observation) by BAC (Percentages Calculated by Row) ....................................................................... 43

Table 42. Nighttime: Safety (Designated-driver Report and Seat Belt Observation) by BAC (Percentages Calculated by Column).....

Table 43. Nighttime: Helmet Use of Motorcycle Riders (Operators), With and Without Passengers, by Rider BAC (Percentages Calculated by Row) 45

Table 44. Nighttime: Helmet Use for Motorcycle Rider (Operators), With and Without Passengers, by Rider BAC (Percentages Calculated by Column) ........................... 45

Table 45. Daytime: BAC Distributions of Daytime Drivers ................................................... 46

Table 46. Daytime: Demographics (Gender, Race/Ethnicity, and Age Group) by BAC ............ 47

Table 47. Daytime: Exposure (Yearly Miles and Percentage if Daytime Driving) by BAC (Percentages Calculated by Row) ......................................................................... 48

Table 48. Daytime: Exposure (Yearly Miles and Percentage of Daytime Driving) by BAC (Percentages Calculated by Column)................................................................ 48

Table 49. Daytime: Trip Origin and Destination by BAC (Percentages Calculated by Row) .... 49 Table 50. Daytime: Trip Origin and Destination by BAC (Percentages Calculated by Column) 50 Table 51. Daytime: BAC Distribution by Vehicle Type (Percentages Calculated by Row)....... 51 Table 52. Daytime: BAC Distribution by Vehicle Type (Percentages Calculated by Column)... 51 Table 53. Daytime Reported Sanctions Following Arrest for Previous Impaired Driving ......... 52 Table 54. Daytime: "Have you visited a medical facility in the past year?" ............................. 52 Table 55. Daytime: "In the past year, have you been told by a medical person you needed help for your drinking?" (Percentage Calculated by Row) 
Table 56. Daytime: "In the past year, have you been told by a medical person you needed help for your drinking?" (Percentage Calculated by Column) .............................................. 53

Table 57. Daytime: "In the past year, have you sought help because of your drinking?" (Percentage Calculated by Row)..................................................................................... 53

Table 58. Daytime: "In the past year, have you sought help because of your drinking?" (Percentage Calculated by Column).

Table 59. Daytime: "In the past year, have you been to an emergency room because of something related to your drinking?" (Percentages Calculated by Row)......................................54

Table 60. Daytime: "In the past year, have you been to an emergency room because of something related to your drinking?" (Percentages Calculated by Column) ................................ 54

Table 61. Daytime: "During the past 12 months, did you ever stay at least overnight in an impatient or residential drug or alcohol treatment program, for example, detox, rehab, a therapeutic community, or a hospital?" (Percentages Calculated by Row). 54

Table 62. Daytime: "During the past 12 months, did you ever stay at least overnight in an impatient or residential drug or alcohol treatment program, for example, detox, rehab, a therapeutic community, or a hospital?" (Percentages Calculated by Column).......... 55

Table 63. Daytime: "Have you ever been admitted to an outpatient drug or alcohol treatment program, NOT including meetings like AA or NA?" (Percentages Calculated by Row)

Table 64. Daytime: "Have you ever been admitted to an outpatient drug or alcohol treatment program, NOT including meetings like AA or NA?" (Percentages Calculated by Column)

Table 65. Daytime: "During the past 12 months, have you received treatment for your drug or alcohol use in a self-help group such as AA or NA?" (Percentage Calculated by Row)

Table 66. Daytime: "During the past 12 months, have you received treatment for your drug or alcohol use in a self-help group such as AA or NA?" (Percentage Calculated by

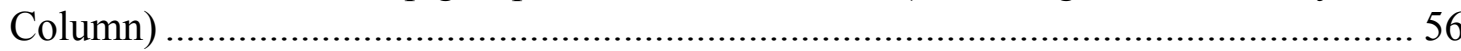

Table 67. Daytime: Designated-Driver, and Seat Belt Observation by BAC (Percentage Calculated by Row) 57

Table 68. Daytime: Designated-Driver Report, and Seat Belt Observation by BAC (Percentage Calculated by Column) ........................................................................................ 57

Table 69. Daytime: Helmet Use of Motorcycle Riders (Operators), With and Without Passengers, by Rider BAC (Percentages Calculated by Row) ..................................... 58

Table 70. Daytime: Helmet Use for Motorcycle Rider (Operators), With and Without Passengers, by Rider BAC (Percentages Calculated by Column)..................................................... 58

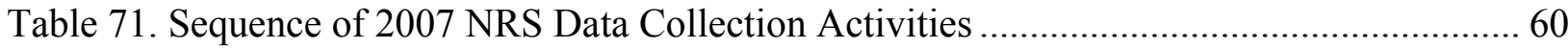

Table 72. AUDIT-C Consumption Items for Measuring Heavy Drinking Questions ........................ 61

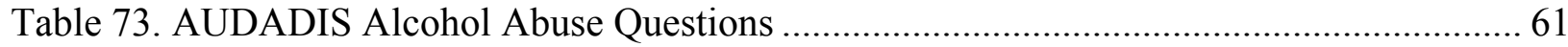

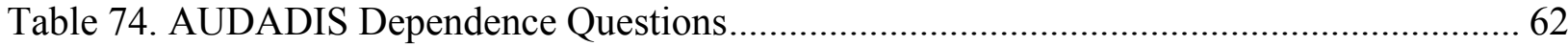

Table 75. Number and Percentage of Respondents by Drinking Category, Nighttime .................. 64

Table 76. Number and Percentage of Respondents by Drinking Category, Daytime .................... 64

Table 77. Overlap Between AUD Categories, Nighttime Respondents .........................................6 65

Table 78. Overlap between AUD Categories, Daytime Respondents ............................................. 65

Table 79. Nighttime: BAC Distribution by Drinking Category (Percentage Calculated by Row)66 
Table 80. Nighttime: BAC Distribution by Drinking Category (Percentage Calculated by

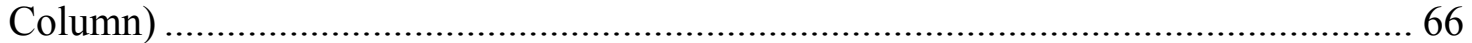

Table 81. Daytime: BAC Distribution by Drinking Category (Percentage Calculated by Row). 67

Table 82. Daytime: BAC Distribution by Drinking Category (Percentage Calculated by Column)

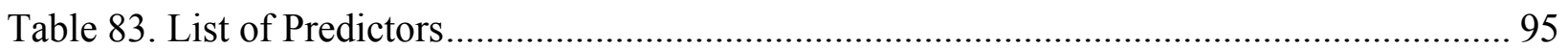

\section{Figures}

Figure 1. Percentage of Nighttime Drivers in Three BAC Categories in the Four National

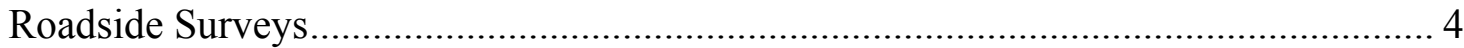

Figure 2. Map of the Sixty 2007 National Roadside Survey Sites .......................................... 9

Figure 3. Percentage of Nighttime Drivers in Three BAC Categories in the Four National

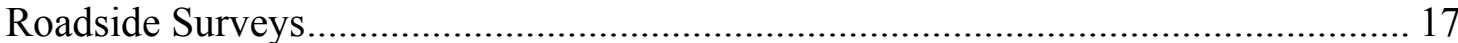

Figure 4. Comparison of FARS and National Roadside Surveys Drivers with BAC $\geq .08 \mathrm{~g} / \mathrm{dL} .19$

Figure 5. Comparison of FARS and National Roadside Surveys Underage (Age Under 21)

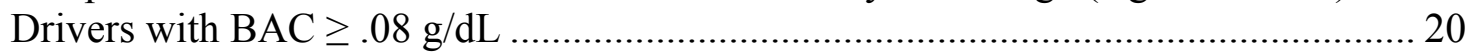

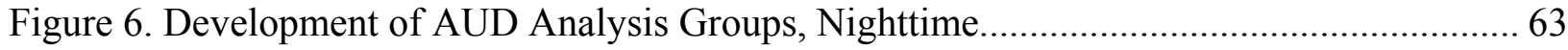

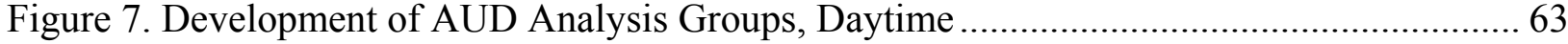




\section{Executive Summary}

This report is the second of three that summarize the results of a 2007 survey conducted by the Pacific Institute for Research and Evaluation (PIRE) for the National Highway Traffic Safety Administration (NHTSA) under Contract DTNH22-06-C-0040, "2007 National Roadside Survey of Alcohol and Drugged Driving." This report presents the prevalence estimates for alcoholinvolved driving derived from the study and compares them with the three previous National Roadside Surveys. The first report of this series (Lacey, Kelley-Baker, Furr-Holden, Voas, Moore, Brainard, Tippetts, Romano, Torres, \& Berning, 2008) describes the sampling plan and data collection methodology ${ }^{1}$ and the response patterns at the various stages of the multipart survey. A third report, based on analyses of biological specimens collected, will present the first national prevalence estimate of drug-involved driving and alcohol-plus-drug-involved driving.

Three prior National Roadside Surveys of drivers to estimate prevalence of drinking and driving and determine changes over time have been conducted in the United States. These surveys, which included a brief interview and a breath sample to determine blood alcohol concentration (BAC), were conducted on a stratified random sample of weekend nighttime drivers in the 48 contiguous States. The first National Roadside Survey (NRS), sponsored by NHTSA, was conducted in 1973 (Wolfe, 1974). The second NRS was sponsored by the Insurance Institute for Highway Safety (IIHS) and conducted in 1986 (Lund \& Wolfe, 1991), and the third, jointly funded by IIHS and NHTSA, was conducted in 1996 (Voas, Wells, Lestina, Williams, \& Greene, 1998). NHTSA sponsored the 2007 NRS described in this report, with additional funding from the National Institute on Alcohol Abuse and Alcoholism (NIAAA), the National Institute on Drug Abuse (NIDA), and the National Institute of Justice (NIJ). Like its predecessors, the 2007 NRS covered the 48 contiguous States.

In 1996 and in the current 2007 NRS, four sampling stages were applied. In the first sampling stage, we selected primary sampling units based on criteria applied by the National Automotive Sampling System/General Estimates System (NASS/GES; NHTSA, 1995). Second, we selected police jurisdictions within the NASS/GES primary sampling units. Third, we selected survey sites within law enforcement jurisdictions, and fourth, we selected drivers at random from the traffic flow at these sites.

As in previous NRS studies, the 2007 NRS data were collected during the following periods on both Friday and Saturday nights: 10:00 p.m. to midnight and 1:00 a.m. to 3:00 a.m. ${ }^{2}$ In addition, the 2007 survey also included a Friday daytime data collection period either from 9:30 a.m. to 11:30 a.m. or from 1:30 p.m. to 3:30 p.m. The prior three surveys did not include commercial vehicles and motorcycles in the sample; this survey, however, included motorcycles. In addition to a daytime survey and the inclusion of motorcycles, the 2007 NRS included other features that the prior surveys did not: (1) more data collectors per survey site to achieve a larger sample size; (2) the collection of biological samples (oral fluid and blood) to determine the presence of drugs other than alcohol in the driving population; (3) a questionnaire to allow an estimation of alcohol use disorders (AUDs) among drinking drivers; (4) a questionnaire to study drivers' patterns of drug consumption; (5) questions about interaction with the criminal justice system and the treatment system; and (6) collection of information on passengers.

\footnotetext{
${ }^{1}$ This is referred to throughout the report as the "Methodology Report."

${ }^{2}$ In this report, a "Friday night" or a "Saturday night" includes the early hours of the following day.
} 
In all four NRS studies, police officers directed vehicles into a safe location, where an interviewer approached the driver and requested participation in a survey followed by a breath test. Random selection of drivers was ensured by selecting the next vehicle when an interviewer became available. Any driver suspected of impairment was subjected to a safety protocol designed to dissuade his/her continued driving on that trip. See the Methodology Report for details (Lacey et al., 2009).

Table 1 shows the level of participation in all four nighttime surveys. Almost twice as many drivers were interviewed in the 1996 survey as in the earlier surveys, and nearly 15 percent more drivers were interviewed in the 2007 survey than in the 1996 survey. In the 2007 survey, 82.5 percent of the eligible drivers who entered each survey site were interviewed; however, even this high response rate was lower than those recorded in previous surveys. We suspect that the lower rates reflect national changes in the culture and attitudes toward survey participation (e.g., litigation concerns, nonparticipation rights). It is also possible that with the increase in computerassisted telephone surveys and computer-generated telephone marketing calls, the public may have become more resistant to survey type activities. These conjectures were tested in a small survey designed to replicate the 1996 methods. It was found that despite using procedures identical to those used in 1996, it was not possible to obtain the earlier high compliance rate of 96 percent of eligible drivers. The 2007 replication of the 1996 protocol yielded an 83.7 percent compliance rate (see Lacey et al., 2009).

Table 1. Percentage of Eligible Drivers Entering the Survey Sites that Provided Interviews and Breath Tests during Nighttime Data Collection Periods

\begin{tabular}{lcccc}
\hline & \multicolumn{4}{c}{ Year } \\
\cline { 2 - 5 } & $\mathbf{1 9 7 3}$ & $\mathbf{1 9 8 6}$ & $\mathbf{1 9 9 6}$ & $\mathbf{2 0 0 7}$ \\
\hline Entered site/eligible & 3,698 & 3,043 & 6,298 & 8,384 \\
Provided interview & 3,353 & 2,971 & 6,045 & 6,920 \\
Provided interview (\% of entered/eligible) & $90.7 \%$ & $97.6 \%$ & $96.0 \%$ & $82.5 \%$ \\
\hline Breath samples & 3,192 & 2,850 & 6,028 & 7,159 \\
Breath samples (\% of entered/eligible) & $86.3 \%$ & $93.7 \%$ & $95.7 \%$ & $85.4 \%$ \\
\hline
\end{tabular}

In this table, Ns and percentages are unweighted.

As mentioned previously, a new feature of the 2007 NRS data was the extension of the survey to daytime hours (Fridays from 9:30 a.m. to 11:30 a.m. or from 1:30 p.m. to 3:30 p.m.). This was done primarily to assess alcohol- and drug-use patterns in the daytime driving population. Table 2 shows the number of drivers who participated in the 2007 survey by daytime and nighttime survey hours. For the 2007 survey, 10,909 drivers were initially selected and eligible to participate. For the nighttime survey, the entries in Table 2 replicate those in Table 1. For the daytime survey, about 86 percent of the eligible drivers provided an interview, and about 89 percent of the eligible drivers provided a breath sample. 
Table 2. Proportion of Eligible Drivers Entering the Survey Sites that Provided Interviews and Breath Tests in 2007

\begin{tabular}{lccc}
\hline & \multicolumn{3}{c}{$\mathbf{2 0 0 7}$} \\
\cline { 2 - 4 } & Daytime & Nighttime & Total \\
\hline Eligible & 2,525 & 8,384 & 10,909 \\
Provided interview & 2,174 & 6,920 & 9,094 \\
Provided interview (\% of eligible) & $86.1 \%$ & $82.5 \%$ & $83.4 \%$ \\
\hline Breath samples & 2,254 & 7,159 & 9,413 \\
Breath samples (\% of eligible) & $89.3 \%$ & $85.4 \%$ & $86.3 \%$ \\
\hline In this table, Ns and percentages are unweighted & & &
\end{tabular}

The BAC results of the four NRS studies for nighttime drivers are shown in Table 3 . Readers should note that all States in the U.S. have per se limits of .08 BAC. In past years, when previous roadside surveys were conducted, States' per se limits were more typically .10 BAC. Results are presented here in a manner to compare to past years' surveys. As in the past surveys, results for drivers with a BAC below the legal limit are included to provide complete data records. Drivers with a BAC below the legal limit cannot be presumed to be impaired by alcohol.

Compared to the 1996 survey, there was a significant reduction in 2007 in the percentage of drivers on the road with positive BACs in the low range, between .005 and $.049 \mathrm{~g} / \mathrm{dL}$ (grams per deciliter). There were also statistically significant reductions in drivers with BACs in the .05 to $.079 \mathrm{~g} / \mathrm{dL}$ range, and .08 to $.149 \mathrm{~g} / \mathrm{dL}$ range. Reductions at BAC levels of $.15 \mathrm{~g} / \mathrm{dL}$ or higher were recorded in each successive survey, although due in part to the small sample size at these BACs, these reductions were not statistically significant.

Table 3. Comparison of the Percentage of Nighttime Drivers in Various BAC Categories in the Four National Roadside Surveys

\begin{tabular}{|c|c|c|c|c|c|c|c|c|c|c|}
\hline \multirow[b]{2}{*}{ BAC (g/dL) } & \multicolumn{4}{|c|}{ Percent by Year } & \multicolumn{3}{|c|}{$\begin{array}{l}\text { Percent Differences } \\
\text { between } 2007 \text { and } \\
\text { Previous NRS Studies }\end{array}$} & \multicolumn{3}{|c|}{$\begin{array}{c}\text { Percent Decennial } \\
\text { Differences }\end{array}$} \\
\hline & 1973 & 1986 & 1996 & 2007 & $\begin{array}{c}2007- \\
1973\end{array}$ & $\begin{array}{l}2007- \\
1986\end{array}$ & $\begin{array}{l}2007- \\
1996\end{array}$ & $\begin{array}{l}1986- \\
1973\end{array}$ & $\begin{array}{l}1996- \\
1986\end{array}$ & $\begin{array}{l}2007 \\
1996 \\
\end{array}$ \\
\hline Zero & 63.9 & 74.1 & 83.1 & 87.6 & $23.7^{*}$ & $13.5^{*}$ & $4.5^{*}$ & $10.2^{*}$ & $9.0^{*}$ & $4.5^{\star}$ \\
\hline $.005-.049$ & 22.3 & 17.6 & 9.2 & 7.9 & $-14.4^{*}$ & $-9.7^{*}$ & $-1.3^{*}$ & $-4.7^{*}$ & $-8.4^{*}$ & $-1.3^{*}$ \\
\hline $.050-.079$ & 6.1 & 3.0 & 3.4 & 2.3 & $-3.8^{*}$ & -0.7 & $-1.1^{*}$ & $-3.1^{*}$ & 0.4 & $-1.1^{*}$ \\
\hline $.080-.149$ & 6.1 & 4.4 & 3.7 & 1.8 & $-4.3^{*}$ & $-2.6^{*}$ & $-1.9^{*}$ & $-1.7^{*}$ & -0.7 & $-1.9^{*}$ \\
\hline $.150+$ & 1.4 & 1.0 & 0.6 & 0.4 & $-1.0^{*}$ & -0.6 & -0.2 & -0.4 & -0.4 & -0.2 \\
\hline $\begin{array}{l}\text { Total alcohol } \\
\text { positive }\end{array}$ & 35.9 & 26.0 & 16.9 & 12.4 & $-23.5^{\star}$ & $-13.6^{*}$ & $-4.5^{*}$ & $-9.9^{*}$ & $-9.1^{*}$ & $-4.5^{\star}$ \\
\hline
\end{tabular}

Data from 1973, 1986, and 1996 were obtained from tables in previous reports.

In all tables, zero $=.000$ to $.004 \mathrm{~g} / \mathrm{dL}$.

* Denotes that the observed difference is statistically significant $\left(p<.05^{3}\right)$.

In this table, percentages are weighted.

${ }^{3} p<.05$ indicates that the probability of encountering this difference by chance is less than 5 percent; $\mathrm{p}<.01$ indicates that the probability of encountering this difference by chance is less than 1 percent. 
Table 4 compares the percentage of daytime and nighttime drivers in various BAC categories for the 2007 NRS. During the daytime, fewer drivers had positive BACs; less than one percent of daytime drivers had a BAC of $.05 \mathrm{~g} / \mathrm{dL}$ or higher. The daytime BACs in the various categories are all significantly lower than nighttime BACs.

Table 4. Comparison of the Percentage of Drivers in Various BAC Categories in 2007 by Time of Day

\begin{tabular}{lrrc}
\hline BAC (g/dL) & Daytime & Nighttime & $\begin{array}{c}\text { Difference* } \\
\text { Night-Day }\end{array}$ \\
\hline Zero & $98.9 \%$ & $87.6 \%$ & $-11.3 \%$ \\
$.005-.049$ & $0.9 \%$ & $7.9 \%$ & $7.0 \%$ \\
$.050-.079$ & $0.0 \%$ & $2.3 \%$ & $2.3 \%$ \\
$.080-.149$ & $0.1 \%$ & $1.8 \%$ & $1.7 \%$ \\
$.150+$ & $0.0 \%$ & $0.4 \%$ & $0.4 \%$ \\
\hline Total alcohol positive & $1.0 \%$ & $12.4 \%$ & $11.4 \%$ \\
\hline
\end{tabular}

* Denotes that the percentages at nighttime are significantly different from daytime $(p<.05)$.

Column percentages may not total to $100 \%$ due to rounding. Rounding also obscures the existence of some daytime drinking drivers: $.047 \%$ and $.028 \%$ of the daytime drivers were $\mathrm{BAC}=.050-.079$ and $\mathrm{BAC}=.150+$, respectively. In this table, percentages are weighted.

Figure 1 summarizes and compares the results of the four NRS studies of weekend nighttime drivers. The figure shows that the percentage of drivers in all BAC range categories presented 4 decreased in succeeding decades, with the exception of an increase in the percentage of drivers with BACs between .050 and $.079 \mathrm{~g} / \mathrm{dL}$ between 1986 and 1996. However, the overall percentage of positive BAC drivers decreased between 1986 and 1996.

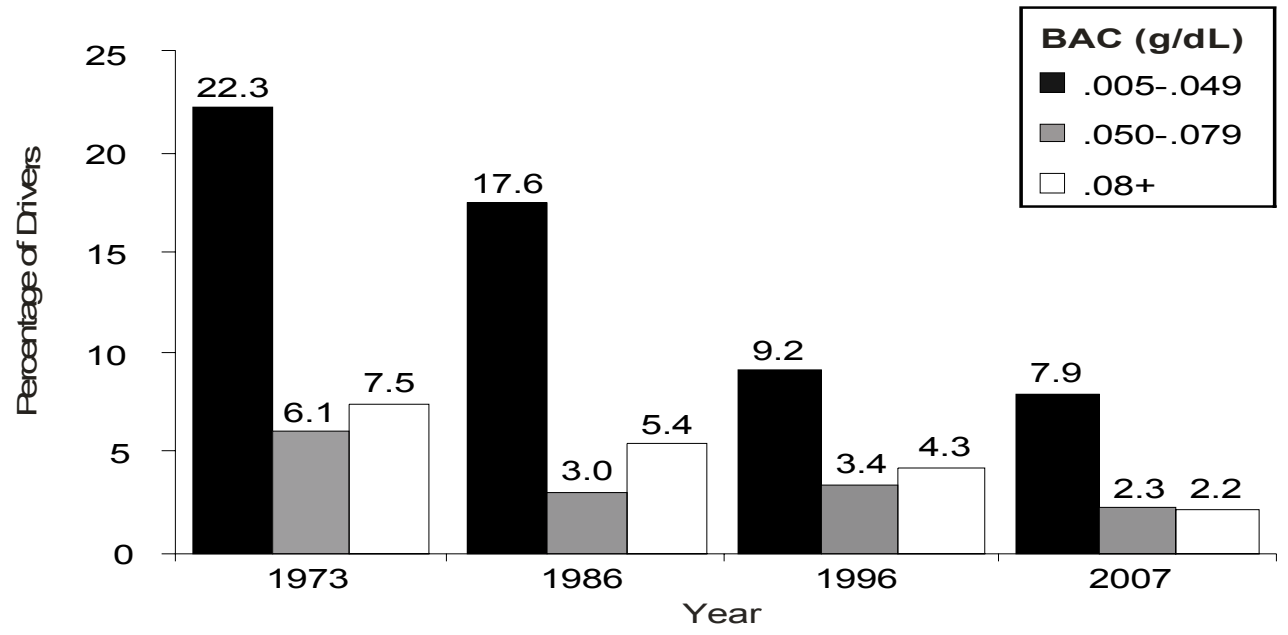

Figure 1. Percentage of Nighttime Drivers in Three BAC Categories in the Four National Roadside Surveys ${ }^{5}$

\footnotetext{
${ }^{4}$ Note: Drivers with zero BAC (i.e., BAC <.005) are not included in the figure.

${ }^{5}$ In this figure, percentages are weighted.
} 


\section{Introduction}

This report is the second of three that summarize the results of a 2007 study conducted by the Pacific Institute for Research and Evaluation (PIRE) for the National Highway Traffic Safety Administration (NHTSA) under Contract DTNH22-06-C-0040, "2007 National Roadside Survey of Alcohol- and Drug-Involved Driving." This report presents the prevalence estimates for alcohol-related driving derived from the study and compares them with the three previous National Roadside Surveys. The first report described the sampling plan and data collection methodology and summarized the response patterns at the various stages of the multipart survey (Lacey et al., 2009). A third report, based on analyses of biological specimens collected, will present the first national prevalence estimate of drug-involved driving and alcohol-plus-druginvolved driving.

\section{Background}

Blood tests for alcohol were introduced in the United States following World War II, and by the time the Department of Transportation (DOT) was established 40 years ago, it was well understood that alcohol was an important factor in traffic crashes. In 1968, the entity that was to become the "National Highway Traffic Safety Administration" delivered a report to Congress on Alcohol and Highway Safety (USDOT, 1968), pointing to the role of problem drinkers in fatal alcohol-related crashes and highlighting a need for improved data on drinking and driving. This led to the establishment of incentives for States to conduct blood alcohol concentration (BAC) tests on fatally injured drivers, riders, and pedestrians, and eventually to the establishment in 1975 of NHTSA's Fatality Analysis Reporting System ${ }^{6}$ (FARS), a census of fatal crashes occurring in the United States. The development of accurate handheld breath testers for use at the roadside in the early 1970 s provided a means for evaluating impaired-driving laws and enforcement programs and for tracking over time the progress in reducing drinking and driving. These handheld devices made it more feasible to conduct roadside surveys of randomly stopped drivers.

\section{National Roadside Surveys}

Our knowledge about the impaired-driving problem in the Nation has been augmented by a series of National Roadside Survey (NRS) studies from which we can estimate the prevalence of drinking and driving over time in the contiguous 48 States by randomly selecting drivers from the road and requesting breath samples. The first NRS, sponsored by NHTSA, was conducted in 1973 (Wolfe, 1974). The second NRS was sponsored by the Insurance Institute for Highway Safety (IIHS) in 1986 (Lund \& Wolfe, 1991), and the third was jointly funded by IIHS and NHTSA in 1996 (Voas et al., 1998). NHTSA sponsored the 2007 NRS described in this report, and additional funding was provided by the National Institute on Alcohol Abuse and Alcoholism (NIAAA), the National Institute on Drug Abuse (NIDA), and the National Institute of Justice (NIJ). Like its predecessors, the 2007 NRS covered the 48 contiguous States.

The first three surveys $(1973,1986$, and 1996) included a brief interview of randomly selected drivers, and a breath sample to measure the BAC. Together, the first three national surveys and the FARS documented the reductions in the number of drinking drivers on U.S. roadways.

\footnotetext{
${ }^{6}$ Originally called "Fatal Accident Reporting System."
} 
The fourth in this series of national surveys, conducted in 2007 , followed the general methodology of the three prior surveys in obtaining BACs for comparison with the earlier surveys, but also incorporated several new features. These included questionnaires on drivers' drug use, interaction with the criminal justice and treatment systems, drug- and alcohol-use disorders, and collecting and analyzing oral fluid and blood to determine the presence of drugs (over-the-counter, prescription, and illegal) other than alcohol.

\section{First Report: The 2007 NRS Methodology Report}

The first report stemming from the 2007 NRS focused on methodology (Lacey et al., 2009). The report described the sampling plan, the data collection procedures, and the biological specimen analysis procedures. The special equipment used and the recruiting and training of survey staff were also discussed. Additionally, the Methodology Report described the human research procedures implemented to protect the survey participants, and the quality control protocols implemented to ensure the reliability and validity of the data. The report described the efforts to convert initial survey refusers into participants and reported on a special study comparing response rates achieved using the 1996 NRS survey procedures in 2007, and then compared the participation rates with those obtained in 1996.

\section{Second Report: The Prevalence of Alcohol-Involved Driving}

This second report on the 2007 NRS covers the prevalence of alcohol-positive weekend drivers and their drinking characteristics. This report begins with a brief review of the methods, which are more fully described in the Methodology Report (Lacey et al., 2009). This report then describes the weighting system applied to ensure that the 2007 NRS sample is nationally representative of drivers' crash involvement and describes the imputation method for estimating the BACs of drivers who refused to provide a breath sample. The results related to the prevalence of drinking drivers are presented under three headings: (1) "Comparing the Results of the Four National Roadside Surveys," (2) "Results of the 2007 NRS," and (3) "Prevalence of Drivers with Alcohol Use Disorders (AUDs)." 


\section{Methods}

This section of the report briefly summarizes the methodology used in conducting the 2007 NRS, with special emphasis on sampling procedures. A separate Methodology Report (for a full discussion, see Lacey et al., 2009) provides detailed descriptions of the multiple components of the data collection process.

\section{Sampling}

This section presents an abridged description of the sampling approach we followed in conducting the 2007 NRS. Because it is infeasible to conduct surveys on all the roads in the United States, we constructed a sampling system for the 2007 NRS that represented the 48 contiguous States but required interviewing only a practical portion of the almost 203 million drivers on U.S. roads (FHWA, 2006).

For practicality, we limited locations to roadways where surveys could be performed safely and with sufficient traffic to recruit the number of participants required for valid estimates of the national prevalence of drinking drivers, as did prior NRS studies.

The past three national surveys provided information on private four-wheel vehicle operators at randomly selected locations during weekend, nighttime periods when drinking and driving is most prevalent. The 2007 NRS covered the same periods and added two Friday daytime periods. As in the three earlier surveys, the 2007 NRS excluded commercial vehicles but, unlike previous practice, included motorcycles.

The 2007 NRS followed the practice of the 1973, 1986, and 1996 national surveys by using a multistage sampling system that represented the drivers at risk for crash involvement in the 48 contiguous States in the year the roadside data were collected. In this process, the initial sample structure was taken from the National Automotive Sampling System/General Estimates System (NASS/GES) (NHTSA, 1995), which was constructed to provide a basis for making nationally representative estimates of highway crashes. The four steps included:

1. Selecting the primary sampling units (PSUs), which are cities, large counties, or groups of counties from within four regions of the United States and three levels of population density.

2. Randomly selecting 30 specific square-mile-grid areas within each PSU, and randomly numbered them to form an order of priority from among the total of all the square mile sectors comprising the PSU area. Then we attempted to recruit the cooperation of local law enforcement agencies that had jurisdiction over the selected grids. One law enforcement agency often would cover several of the selected square mile areas.

3. Identifying appropriate survey sites within the square-mile-grid areas. Appropriate sites had a safe area large enough to accommodate the survey operation and had sufficient traffic flow to generate an adequate number of subjects. In some cases, more than one such location was available within a square mile grid. In this case, the survey manager exercised her/his judgment to select the optimal location for safe data collection. This resulted in selection of five data collection or survey sites within each PSU. 
4. Selecting at random drivers to be interviewed from the traffic passing by the survey site. The total number of eligible vehicles was counted to determine the proportion of the traffic passing by each survey site that was sampled.

These sampling procedures were followed to ensure that the probability of selecting a PSU, a survey location within the PSU, and a driver at a survey location was known at each of the sample design stages. Knowing these probabilities permitted the computation of the probability that a given driver would be interviewed in the survey. This was done by multiplying the sampling probabilities at each of the four steps to obtain the final overall probability of being sampled. The weight given to each case in the final totals (sampling weight) was computed as the inverse of the sampling probability. This statistical procedure accounts for differences among PSUs in the size of the driver' population. In other words, although we sampled approximately the same number of drivers at each PSU, the actual number of individuals driving at each sampling site was not uniform. To make the sample of drivers at each site representative of the actual number of drivers we applied the above-described weights. As a result, drivers interviewed at sites with a relatively heavy traffic flow (i.e., a relatively large pool of actual drivers) carry a larger weight than drivers sampled from sites with less traffic loads. This ensured that the basic requirement of sampling theory - that every driver has an equal chance of being interviewed — was met by adjusting for the biases inherent in the selection of locations within the sampling frame.

The major barrier to carrying out this staged sampling system was obtaining law enforcement support for the survey. In some localities, city attorneys or law enforcement leadership believed legal limitations to randomly stopping vehicles, including potential liability, prevented their participation in the study. In some cases, the law enforcement agencies reported that they lacked the personnel resources to support the effort. These types of objections, where enforcement assistance could not be obtained, resulted in having to make substitutions for initially selected PSUs, as had proved necessary in all three previous NRS studies for various reasons. Replacement PSUs were chosen from within the same geographic region (GES defines four geographic strata) and the same GES category of PSU type (city, large suburban area, all others) as the unavailable PSU. For more information on PSU replacement, see Lacey et al. (2009). The 60 PSUs used in the 2007 NRS are shown in Figure 2. 


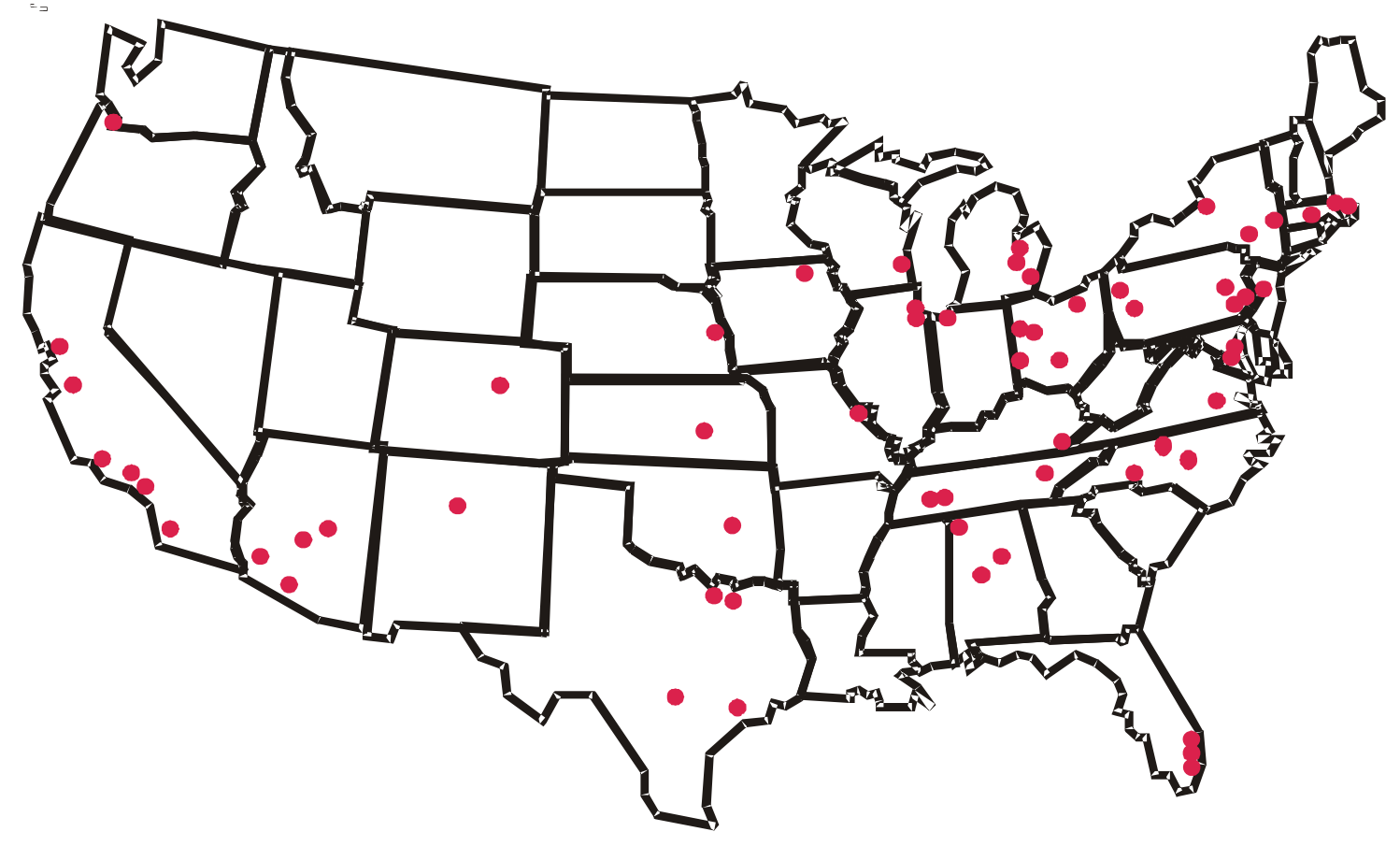

Figure 2. Map of the Sixty 2007 National Roadside Survey Sites

As mentioned, the roadside survey procedures used in the 2007 NRS followed, as closely as possible, those used in the previous three surveys (see Lacey et al., 2009; Lestina et al., 1999). However, the 2007 NRS departed from the earlier surveys in several important ways. The earlier surveys included only a brief questionnaire and a breath test that generally required less than 5 minutes of a participant's time, whereas the 2007 NRS included a more extensive set of questions (base survey, a drug questionnaire, questions about interaction with the criminal justice and treatment systems, an alcohol-use disorder and a drug-use disorder survey). The 2007 survey protocol also attempted to collect two biological samples (oral fluid and blood) from participants, as well as a breath test. The earlier surveys consisted of 3 teams of 3 interviewers; the 2007 NRS consisted of 6 teams of 10 to 12 members each. The earlier surveys were conducted at 24 PSUs, whereas the 2007 survey was conducted at 60 PSUs to exploit the use of all possible PSUs defined by the NASS/GES. The earlier surveys had four 2-hour data collection periods on weekend nights; the 2007 survey added a 2-hour survey during the daytime on Fridays, for a total of five 2-hour surveys during the weekend. Finally, the number of participants in the 2007 survey was about three times as many as in the 1973 study.

PIRE employed and trained six specialized teams of interviewers from both the East and West Coasts. All staff was trained during the summer of 2007. Surveys began the weekend of July 20 and 21, 2007, and concluded 20 weeks later on December 1, 2007. As in the three previous NRS studies, nighttime surveys were conducted between 10 p.m. and midnight, and between 1 a.m. and 3 a.m. on both Friday and Saturday. For the 2007 survey, a 2-hour Friday daytime data collection period was added, either between 9:30 a.m. and 11:30 a.m. or between 1:30 p.m. and 3:30 p.m. 
The daytime data collection period was randomly selected for each PSU. The daytime periods were added to determine whether the number of drivers using drugs and the types of drugs used differed between day and night.

Each component used in the basic roadside survey is thoroughly described in the Methodology Report (Lacey et al., 2009).

\section{Preparation for the 2007 NRS Survey}

The size and complexity of the 2007 NRS required extensive preparation that NHTSA began years before the actual survey was initiated, including a pilot test of survey procedures (Lacey, Kelley-Baker, Furr-Holden, Voas, Brainard, \& Moore, 2007). The preparation activitiesselection and testing of equipment for collecting biological samples; recording and organizing the self-report and observational data at the roadside; recruiting and training of survey staff; pretesting of survey procedures; developing procedures for protection of survey respondents and the public - are fully described in the Methodology Report (Lacey et al., 2009). Only a brief overview of this work is described here.

Survey equipment: Interviewers recorded the responses to the traditional NRS interview on a handheld, portable digital assistant (PDA). Through a special program developed for the 2007 NRS, the PDA provided a means of prompting the interviewer through each step of the data collection process.

As part of the program, to protect survey participants and the public, it was important to know the extent of the drivers' drinking. To this end, a passive alcohol sensor (PAS), attached to the PDA with Velcro ${ }^{\mathrm{TM}}$, was used to collect mixed expired air from approximately 6 inches in front of the driver's face (we used the PAS Vr. ${ }^{\mathrm{TM}}$ manufactured by PAS International, Inc. of Fredericksburg, Virginia). This small handheld unit was used because it was less obvious and intimidating than the larger flashlight-based passive sensors. We researched three available styles of PAS models: (1) the handheld unit that was used in the pilot study; (2) the flashlight PAS; and (3) a clipboard device with an alcohol sensor built into one corner. We tested the devices for accuracy, ease of use, and reliability and found that the PAS Vr. ${ }^{\mathrm{TM}}$ was best suited to the needs of this study. The PAS unit can detect alcohol in emitted breath around the face (Kiger, Lestina, \& Lund, 1993). The PAS was held within 6 inches of the participant's face, and when the subject spoke, the interviewer activated the small electrical pump, which pulled in the exhaled breath from the participant.

Data collection: To compare results from the 2007 survey to prior surveys, a strong effort was made to follow the protocol of the prior three NRS studies, despite the addition of a large number of questions and new biological specimen collections following the traditional questionnaire and breath test. As described in the Methodology Report (Lacey et al., 2009), we placed the traditional NRS interview and breath-test collection in front of the new questions and specimen collections, so that these additions to the basic survey would not affect the responses collected for comparison with the three earlier surveys. Nevertheless, we found that we were having a somewhat larger refusal rate in 2007 than in 1996 (see Table 5).

To determine whether the 2007 survey procedure accounted for producing the lower response rate, we conducted a replica of the 1996 NRS procedure in one of our 2007 sites (Knox County, Tennessee). The simpler protocol followed that used in the 1996 and earlier surveys, collecting the traditional interview and a breath sample only. About 16 percent of all drivers signaled to stop 
by the officer in the replica of the 1996 survey procedures failed to stop and/or enter the site. This is similar to the 15 percent who failed to stop (when the police signaled) in the 2007 NRS study. Among those who entered the research bay and were eligible for the survey, the proportion of refusals in the replica of the 1996 survey compared to the full 2007 NRS were also very similar $(16.3 \%$ and $17.5 \%)$. Thus, it appears that the lower response rate in the $2007 \mathrm{NRS}$ reflects a change in the driving public's willingness to be interviewed, rather than an effect of the more elaborate survey procedures implemented in 2007.

Table 5. Comparison of Number of Nighttime Participants by Year in the National Roadside Surveys

\begin{tabular}{lcccc}
\hline & $\mathbf{1 9 7 3}$ & $\mathbf{1 9 8 6}$ & $\mathbf{1 9 9 6}$ & $\mathbf{2 0 0 7}$ \\
\hline Signaled to enter site & Not reported & 3,260 & 6,480 & 9,553 \\
Did not enter site & Not reported & 217 & 182 & 1,016 \\
Stopped and entered site & 3,698 & 3043 & 6,298 & 8,537 \\
Eligible for survey & Not reported & Not reported & Not reported & $8,384^{\star}$ \\
Entered site and interviewed & $3,353(90.7 \%)$ & $2,971(97.6 \%)$ & $6,045(96.0 \%)$ & $6,920(82.5 \%)^{\bullet}$ \\
Valid breath sample" $^{*}$ & $3,192(86.3 \%)$ & $2,850(93.7 \%)$ & $6,028(95.7 \%)$ & $7,159(85.4 \%)^{\bullet}$ \\
\hline
\end{tabular}

- Commercial vehicles not eligible.

- Because previous surveys did not inform about the eligibility of the drivers, percentages for the years 1973,1986 , and 1996 are based on drivers who stopped and entered the site. Percentages for 2007 are based on drivers who not only were stopped and entered site, but also were eligible for the survey (i.e., noncommercial drivers, drivers aged 16 and older, and not constrained by language barriers). Percentages are based on nighttime drivers.

- Some drivers provided breath samples but declined to be interviewed.

In this table, Ns and percentages are unweighted.

The basic procedure in the 2007 NRS, as well as in the prior three surveys, was for the police officer working with the survey team to direct the potential respondent into the survey site without speaking to the driver. Once in the site, the driver was directed into a research bay and was approached by an interviewer and recruited to participate in the interview. Prospective participants were informed that they had done nothing wrong and that the interview concerned traffic safety and was anonymous. A PAS reading was also taken at this point. If the individual agreed to participate, the interviewer asked the 22 questions on the traditional NRS protocol and requested a breath sample. Only after the completion of the standard NRS procedure did the additional data collection for the 2007 NRS begin. A detailed description of the survey procedures is provided in the Methodology Report (Lacey et al., 2009).

A special Impaired Driver Protocol was developed to ensure the safety of both the drivers directed into the survey site and the public by ensuring that impaired drivers did not return to the highway. Impairment was determined by the interviewer's observation of the driver's behavior and by the use of a PAS. If there was any sign of possible impairment, the interviewer signaled the survey manager who administered a breath test with a preliminary breath test (PBT) device that displayed the actual BAC. If the driver's BAC was .05 g/dL (grams per deciliter) or higher, the survey manager provided the participant with several options for getting home without driving. This system has been successful in preventing identified impaired drivers from returning to the road where they could be a danger to themselves or others. A full description of the Impaired Driver Protocol is provided in Appendix E of the Methodology Report (Lacey et al., 2009). 
A significant concern for all four NRS studies was that high BAC drivers might be less likely to agree to participate, resulting in an underestimation of the number of risky drinking drivers on the road. Data from the 1996 NRS and from relative risk studies, such as that of Blomberg, Peck, Moskowitz, Burns, and Fiorentino (2001, p. 117), have suggested that drivers who refuse the breath test are likely to have higher BACs than those who agree to participate. This was corrected somewhat in the 1996 and 2007 NRS studies by using the PAS data collected as part of the consent process. To do this, a PAS was used when the driver was first approached to participate in the survey. The PAS provides a nine-unit estimate of what a true BAC measure collected by the PBT device would be. We correlated the PAS and other measures (specifically, gender and time of night) to impute the BACs of drivers who entered the site but refused to provide a breath sample. Thus, the actual BACs collected in both the 1996 and the 2007 NRS studies were corrected for nonparticipating drivers.

As presented in the Methodology Report (Lacey et al., 2009), there were 444 attempts to convert drivers who had initially refused to participate in our study (i.e., to change their minds and provide us with at least a breath sample). Drivers that refused were offered a $\$ 100$ incentive as an inducement to convert. Of the 444 total attempts, 50 percent were successfully converted. As Table 6 illustrates, of the nighttime drivers that were converted, 13 percent were alcohol positive (2.4\% had a BAC of .08 or above).

Table 6. BAC Distribution of Successfully Converted Refusers ${ }^{7}$

\begin{tabular}{lcc|cc}
\hline & \multicolumn{2}{c|}{ Daytime } & \multicolumn{2}{c}{ Nighttime } \\
\cline { 2 - 5 } BAC $\mathbf{g} / \mathbf{d L}$ & $\mathbf{N}$ & $\mathbf{\%}$ & $\mathbf{N}$ & $\%$ \\
\hline & $\mathbf{N}=\mathbf{5 2}$ & & $\mathbf{N}=\mathbf{7 0}$ \\
Zero & 48 & $94.5 \%$ & 139 & $87.0 \%$ \\
Between Zero and .08 & 3 & $5.4 \%$ & 24 & $10.6 \%$ \\
$.08+$ & 1 & $0.1 \%$ & 7 & $2.4 \%$ \\
Total & & $100 \%$ & & $100 \%$ \\
\hline
\end{tabular}

The difference in the percentage of over-the-limit at Daytime and Nighttime is non-significant. In this table, Ns are unweighted and percentages are weighted.

This distribution is very similar to that of the total nighttime participants' BAC distribution, where 12.4 percent were alcohol positive (2.2\% with a BAC of .08 or above). At first glance, the BAC distribution of daytime converted refusers appears different from the overall daytime BAC distribution. About 5.5 percent of daytime drivers that were converted had a positive BAC $(0.1 \%$ at or above .08) as compared to 1.1 percent in the general participation sample $(.02 \%$ with a BAC of .08 or above). However, because of the relatively low sample size of daytime conversions, these differences are not statistically significant.

\footnotetext{
7 In all tables similarly labeled, "zero" $=.000$ to $.004 \mathrm{~g} / \mathrm{dL}$; "between zero and $.08 "=.005$ to $.079 \mathrm{~g} / \mathrm{dL} ;$ and ".08+" $=.08 \mathrm{~g} / \mathrm{dL} "$ and higher.
} 


\section{Data Analysis}

Data analysis for this report was based on descriptive strategies aimed at estimating prevalence rates and testing differences across the four decennial roadside surveys. Prevalence rates of interest were estimated based on weights calculated to bring the raw counts to national estimates. This section describes the weighting and BAC imputation methods applied for this report.

\section{Weighting the Data}

Obtaining a random sample of all U.S. drivers on the road during survey hours is obviously impossible. Thus, as was done in the 1996 NRS, we addressed this limitation by applying a multistage sampling strategy with four nested sampling frames, including (1) selecting PSUs from which we (2) randomly selected one-square-mile sampling areas, from which we (3) selected roadway locations, and finally, from which we (4) randomly selected vehicles passing the survey locations. A weight was assigned to reflect the relative size of the driving population across geographical units. Because information about traffic volume in the PSUs does not exist for every PSU, we followed previous NRS protocol and used the annual frequency of drivers in injury crashes in the PSU as a proxy to assess the relative number of driver trips across PSUs (see Appendix B). Thus, assuming that the measure available to us (i.e., relative number of crashes at each site) is a valid proxy of the relative number of driving trips at each site, the case weights reflect the probability that any driver selected for participation in the survey would have been randomly sampled from the total driving trips occurring at each site. Within each PSU, a randomized cluster sampling strategy was used to weight the number of driver trips.

The sampling system within the PSU involved the following three levels:

1. Each PSU was divided into square-mile grids, from which five grids were randomly selected.

2. In each of these five square-mile areas, a roadway location was selected as a survey site (influenced by safety concerns for drivers and interviewers, such as adequate lighting and safe maneuvering space).

3. At each site, the number of vehicles passing the site was counted.

The result was a sampling frame in which each feasible roadway location had a probability of selection approximately equal to that of every other roadway location within the boundaries of the PSU. All driver trips passing through each selected point were treated as cluster samples, and the relative probability of any driver (or driver trip) being sampled was calculated from the trafficflow counts at each site.

Each of the various sampling stages (or frames) required a separate calculation of probability, which then became a component of the final probability computation, reflecting all levels or frames. The total weighted number $(\mathrm{N})$ of the sample was identical to the total number of eligible drivers entering the survey bays, including refusers, but was adjusted to reflect the estimated distribution of those drivers in the 48 contiguous States. Error terms for the analyses were computed by STATA (Stat Corp., 2006) to account for the differential weights, and the amount of variance attributable to the various sampling frames. Further information on the weighting of the data can be found in the Methodology Report (Lacey et al., 2009). 
Unless explicitly indicated, sample size $(\mathrm{N})$ refers to the actual, unweighted number of respondents; percentages are weighted. Sample size may vary between tables because of missing values.

\section{Imputing BAC Measures}

Missing BAC measures for the drivers for whom we did not have PBT readings were imputed based on information collected from drivers who did provide BAC samples. The validity of this strategy depends on the implicit assumption that no systematic differences exist between those who provided a BAC sample and those who refused. We tested this assumption by offering financial incentives to a sample of NRS refusers in an attempt to reverse their decisions and become participants. The results from this effort (see Lacey et al., 2009) suggest that alcohol was not a factor for the converted refusers. Although not conclusive (it could be argued that those who accepted the financial incentive form another subset of refusers), this finding supports the validity of the BAC imputation.

Because strictly parametric regression methods tend to favor and predict values closest to the mean (thus, away from the most frequently observed value $[\mathrm{BAC}=0 \mathrm{~g} / \mathrm{dL}$ ] in a highly skewed sample), we applied the following three-stage approach to impute the missing BAC values:

1. We used logistic regression to estimate the probability that a driver would have a BAC $>$ $.00 \mathrm{~g} / \mathrm{dL}$, given certain explanatory variables (e.g., PAS, time of day).

2. We used a relative operating characteristic (ROC) curve to set a suitable threshold to separate and identify drivers with positive BACs.

3. We applied a linear regression model to drivers with positive BACs and used that model to predict positive BACs from refusals (see Appendix $\mathrm{C}$ for a detailed discussion of the imputation process).

Table 7 shows the results of this imputation process. BAC unweighted distributions for the BACs actually measured and the two imputed outcomes (predicted values only and predicted values plus error) are presented. A visual inspection of this table shows similar distributions, particularly the two containing imputed BACs. Based on this similarity, we used the simpler "predicted values only" option to present the results. Table 7 also shows that a breath sample was available for 9,413 of the eligible drivers in the file; BAC was subsequently imputed in 1,296 records with missing BAC values. Because of missing PAS readings, imputation was not attempted on 200 records. Thus, of the 10,909 eligible drivers in the file, 10,709 had either an actual or imputed BAC. As a result, every case for which a BAC measure was not obtained but had another correlative, predictive measure recorded, a single BAC value was imputed as a point estimate. 
Table 7. 2007 NRS Observed and Imputed BAC Levels (Daytime and Nighttime)

\begin{tabular}{|c|c|c|c|c|c|c|c|c|c|c|c|c|}
\hline \multirow[b]{2}{*}{ BAC $(g / d L)$} & \multicolumn{4}{|c|}{ Measured BAC Only } & \multicolumn{4}{|c|}{$\begin{array}{l}\text { Measured and Imputed BAC } \\
\text { Predicted Values Only }\end{array}$} & \multicolumn{4}{|c|}{$\begin{array}{l}\text { Measured and Imputed BAC } \\
\text { Predicted Values + Error }\end{array}$} \\
\hline & $\mathbf{N}$ & $\%$ & $\begin{array}{c}\text { Cum. } \\
\mathbf{N}\end{array}$ & $\begin{array}{c}\text { Cum. } \\
\%\end{array}$ & $\mathbf{N}$ & $\%$ & $\begin{array}{c}\text { Cum. } \\
\mathbf{N}\end{array}$ & $\begin{array}{c}\text { Cum. } \\
\%\end{array}$ & $\mathbf{N}$ & $\%$ & $\begin{array}{c}\text { Cum. } \\
\mathbf{N}\end{array}$ & $\begin{array}{c}\text { Cum. } \\
\%\end{array}$ \\
\hline Zero & 8,424 & 89.5 & 8,424 & 89.5 & 9,633 & 90.0 & 9,633 & 90.0 & 9,633 & 90.0 & 9,633 & 90.0 \\
\hline $.005-.049$ & 624 & 6.6 & 9,048 & 96.1 & 663 & 6.2 & 10,296 & 96.2 & 663 & 6.2 & 10,296 & 96.2 \\
\hline $.050-.079$ & 168 & 1.8 & 9,216 & 97.9 & 183 & 1.7 & 10,479 & 97.9 & 212 & 2.0 & 10,508 & 98.2 \\
\hline $.080-.149$ & 160 & 1.7 & 9,376 & 99.6 & 183 & 1.7 & 10,662 & 99.6 & 164 & 1.5 & 10,672 & 99.7 \\
\hline $.150+$ & 37 & 0.4 & 9,413 & 100.0 & 47 & 0.4 & 10,709 & 100.0 & 37 & 0.4 & 10,709 & 100.0 \\
\hline
\end{tabular}

In this table, Ns and percentages are unweighted.

\section{Daytime versus Nighttime}

New to the 2007 NRS was the collection of data on Friday daytime drivers. The goal of this additional effort was to contrast the findings of the weekend nighttime survey with those resulting from the weekday daytime data. To achieve this goal, results in this report are presented separately for weekend nighttime drivers and Friday daytime drivers. When relevant, proper comparisons between these two sets of drivers are presented.

Note that "overall" results (i.e., daytime and nighttime combined) are not presented in this report. Although comparisons between the daytime and nighttime frames are informative, analyses based on the whole data set (i.e., daytime and nighttime combined) would be questionable, for such an "overall" data set could be erroneously viewed as a data set representative of all daytime and nighttime U.S. drivers. That will not be the case because: (1) the nighttime data are representative of the weekend nighttime U.S. drivers (excluding weekday nighttime drivers); and (2) the daytime data are representative only of Friday daytime drivers (excluding weekend daytime drivers, as well as other weekday daytime drivers). Although useful as a new source for comparisons, adding the daytime information to the nighttime information to form a single data set could yield misleading results and thus is not presented in this report. 


\section{Comparing the Results of the Four National Roadside Surveys}

This section of the report presents the results on the nighttime prevalence of drivers at various BACs in the 2007 survey as compared with those found in the previous three surveys (1973, 1986, and 1996). Unless noted otherwise, all percentages shown in the following sections of this report are weighted to represent the U.S. driver population, and all sample sizes $(\mathrm{N})$ are unweighted to show the actual number of surveyed drivers.

At the time of the first NRS survey in 1973, the BAC illegal limit in many States was .15 g/dL. At the time of the second NRS in 1986, most States had illegal limits of .10 g/dL. By the time of the third NRS in 1996, some states had lowered their illegal limit to $.08 \mathrm{~g} / \mathrm{dL}$ but other states still had a BAC illegal limit of $.10 \mathrm{~g} / \mathrm{dL}$. Thus, previous reports present tables and figures with the value of $.10 \mathrm{~g} / \mathrm{dL}$ as a cut off. To compare trends at today's illegal level, $.08 \mathrm{~g} / \mathrm{dL} \mathrm{BAC}$, we had to rely on information presented in tables of articles and reports on previous NRS studies and are limited by the detail contained therein.

The 2007 NRS included daytime data collection; however, the previous NRSs were only able to collect data at nighttime. Thus, while the nighttime survey results can be compared to the results from previous NRS, there is no comparison data for the daytime data collection.

Figure 3 shows the percentage of nighttime drivers who had been drinking $(\mathrm{BAC}>.005 \mathrm{~g} / \mathrm{dL}$, positive for alcohol) in each of the four NRS studies. There has been a steady and statistically significant decrease in drinking drivers between each of the four decades $(p<.05)$, with the 2007 level at about one-third of the 1973 level. Drivers with a BAC below the legal limit cannot be presumed to be impaired by alcohol. 


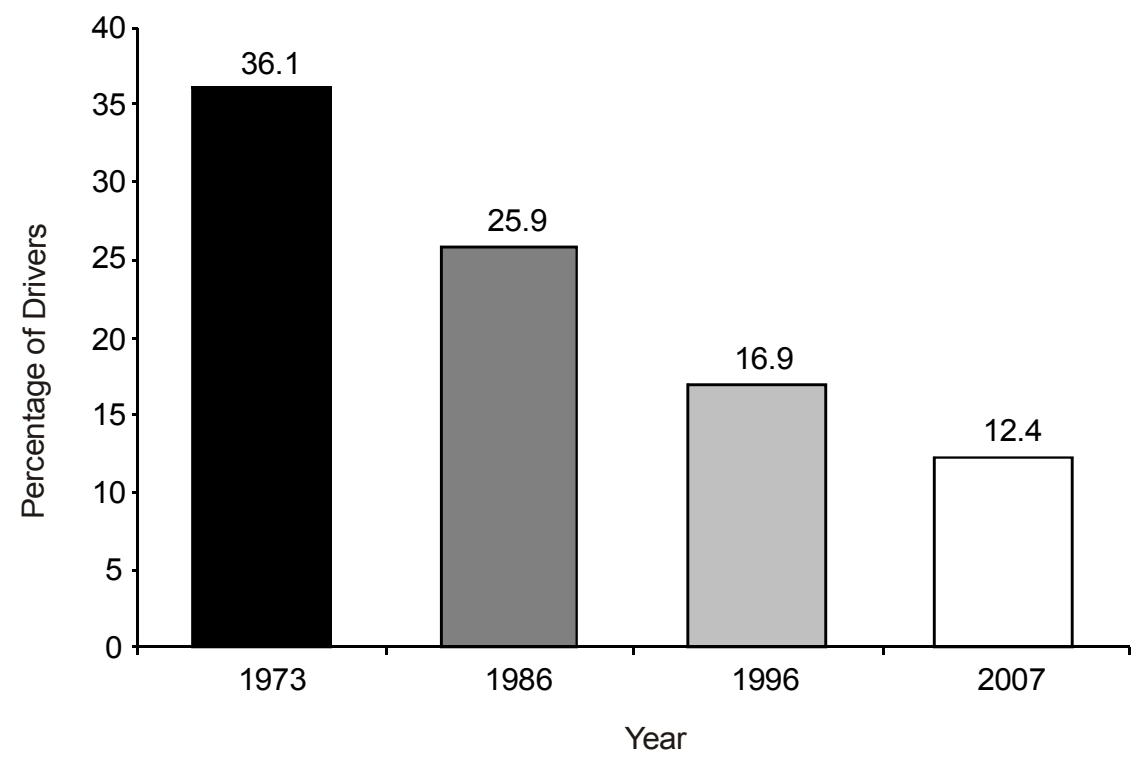

Figure 3. Percentage of Weekend Nighttime Drivers Positive for Alcohol in the Four National Roadside Surveys ${ }^{8}$

Figure 4 summarizes and compares the results of the four NRS studies of the weekend nighttime drivers. In each succeeding decade, there have been significant decreases (see Table 8) in the proportion of drivers in all BAC range categories presented, with the exception of an increase in the proportion of drivers with a BAC between .050 and $.079 \mathrm{~g} / \mathrm{dL}$ between the years 1986 and 1996. However, the overall proportion of positive BAC drivers decreased between 1986 and 1996.

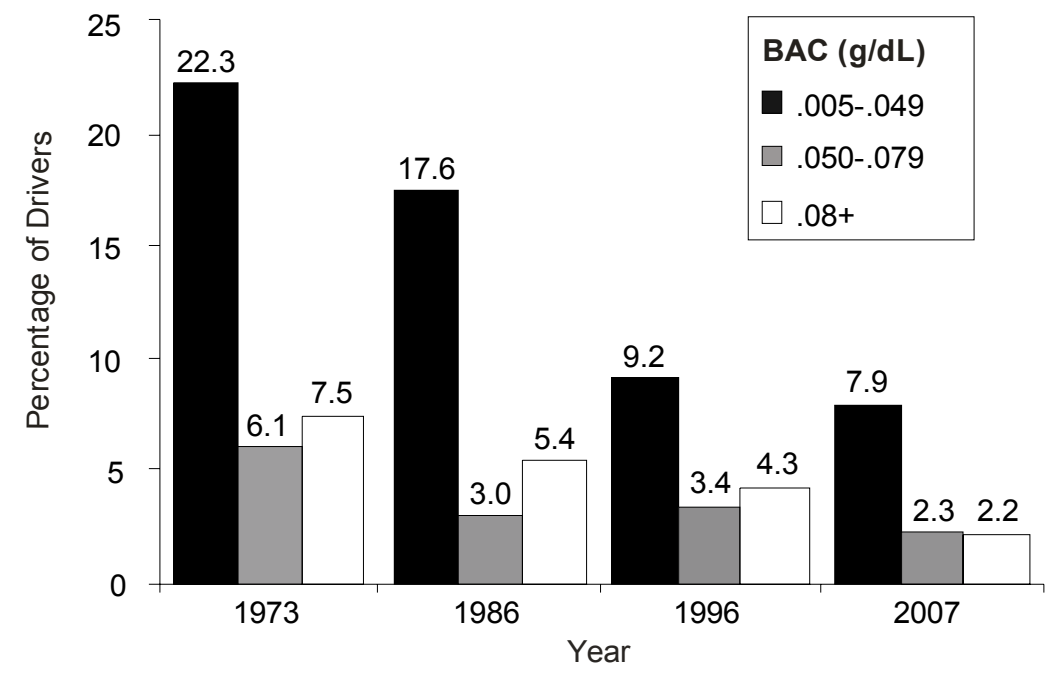

Figure 3. Percentage of Nighttime Drivers in Three BAC Categories in the Four National Roadside Surveys ${ }^{8}$

\footnotetext{
${ }^{8}$ In this figure, percentages are weighted.
} 
Table 8 shows the data displayed in Figure 4 in greater detail. The declines between the 1996 and the 2007 surveys are statistically significant in all BAC ranges except for the $.150+\mathrm{g} / \mathrm{dL}$ BAC level. Note, however, the sample size for this high BAC range is small.

Table 8. Comparison of the Percentage of Nighttime Drivers in Various BAC Categories in the Four National Roadside Surveys

\begin{tabular}{|c|c|c|c|c|c|c|c|c|c|c|}
\hline \multirow[b]{2}{*}{$B A C(g / d L)$} & \multicolumn{4}{|c|}{ Percent by Year } & \multicolumn{3}{|c|}{$\begin{array}{c}\text { Percent Differences } \\
\text { Between } 2007 \text { and } \\
\text { Previous NRS Studies }\end{array}$} & \multicolumn{3}{|c|}{$\begin{array}{c}\text { Percent Decennial } \\
\text { Differences }\end{array}$} \\
\hline & 1973 & 1986 & 1996 & 2007 & $\begin{array}{l}2007- \\
1973\end{array}$ & $\begin{array}{l}2007- \\
1986 \\
\end{array}$ & $\begin{array}{l}2007- \\
1996 \\
\end{array}$ & $\begin{array}{l}1986- \\
1973 \\
\end{array}$ & $\begin{array}{l}1996- \\
1986\end{array}$ & $\begin{array}{l}2007- \\
1996 \\
\end{array}$ \\
\hline Zero & 63.9 & 74.1 & 83.1 & 87.6 & $23.7^{*}$ & $13.5^{*}$ & $4.5^{*}$ & $10.2^{*}$ & $9.0^{*}$ & $4.5^{\star}$ \\
\hline $.005-.049$ & 22.3 & 17.6 & 9.2 & 7.9 & $-14.4^{*}$ & $-9.7^{*}$ & $-1.3^{*}$ & $-4.7^{*}$ & $-8.4^{*}$ & $-1.3^{*}$ \\
\hline $.050-.079$ & 6.1 & 3.0 & 3.4 & 2.3 & $-3.8^{*}$ & -0.7 & $-1.1^{*}$ & $-3.1^{*}$ & 0.4 & $-1.1^{*}$ \\
\hline .080 - 149 & 6.1 & 4.4 & 3.7 & 1.8 & $-4.3^{*}$ & $-2.6^{*}$ & $-1.9^{*}$ & $-1.7^{*}$ & -0.7 & $-1.9^{*}$ \\
\hline $.150+$ & 1.4 & 1.0 & 0.6 & 0.4 & $-1.0^{*}$ & -0.6 & -0.2 & -0.4 & -0.4 & -0.2 \\
\hline $\begin{array}{l}\text { Total Alcohol } \\
\text { Positive }\end{array}$ & 35.9 & 26.0 & 16.9 & 12.4 & $-23.5^{*}$ & $-13.6^{*}$ & $-4.5^{*}$ & $-9.9^{*}$ & $-9.1^{*}$ & $-4.5^{*}$ \\
\hline
\end{tabular}

Data from 1973, 1986, and 1996 were obtained from tables in previous reports.

In all tables, zero $=.000$ to $.004 \mathrm{~g} / \mathrm{dL}$.

${ }^{*}$ Denotes that the observed difference is statistically significant $\left(p<.05^{9}\right)$.

In this table, percentages are weighted.

Across the four surveys, reductions in impaired drivers in the NRS have been generally paralleled by reductions in fatal alcohol-related crashes involving drivers with a BAC of .08 or greater.

Figure 5 shows the percentage of NRS drivers and fatally injured drivers in FARS with BACs of $.08 \mathrm{~g} / \mathrm{dL}$ or higher in the years in which an NRS was conducted. Note, however, the reduction in nighttime NRS drivers with BAC .08+ g/dL from 1996 to 2007 appears to be greater than the reduction in FARS from 1996 to 2007. Figures 5 and 6 predated the FARS, which did not exist in 1973; thus, the earliest available FARS data (1982) that provided imputed BAC measures are displayed with the 1973 NRS data.

\footnotetext{
${ }^{9} p<.05$ indicates that the probability of encountering this difference by chance is less than 5 percent; $\mathrm{p}<.01$
} indicates that the probability of encountering this difference by chance is less than 1 percent. 


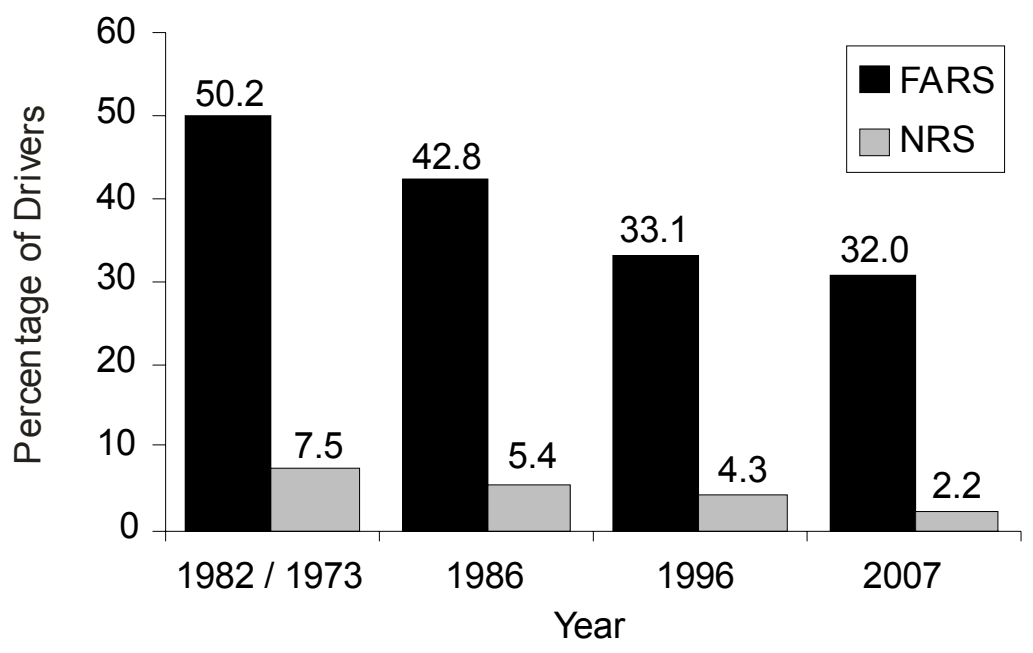

Figure 4. Comparison of FARS and National Roadside Surveys Drivers with BAC $\geq .08 \mathrm{~g} / \mathrm{dL}^{10}$

Of special interest are underage drivers (aged $\leq 20)$, a group that has been shown to be at special risk for crash involvement when drinking (Zador, Krawchuk \& Voas, 2000). Figure 6 shows that the percentage of underage drivers in the FARS with $.08 \mathrm{~g} / \mathrm{dL}$ or higher BACs decreased from 1973 to 1996. However, from 1996 FARS to 2007 FARS, there has been a slight increase. The 2007 NRS results do not show this same trend. Underage NRS drivers with .08 g/dL or higher BACs have been decreasing; however, because of the small number of such drivers in the two most recent surveys, the reduction from 1996 to 2007 is not statistically significant.

\footnotetext{
${ }^{10}$ In this figure, percentages are weighted.
} 


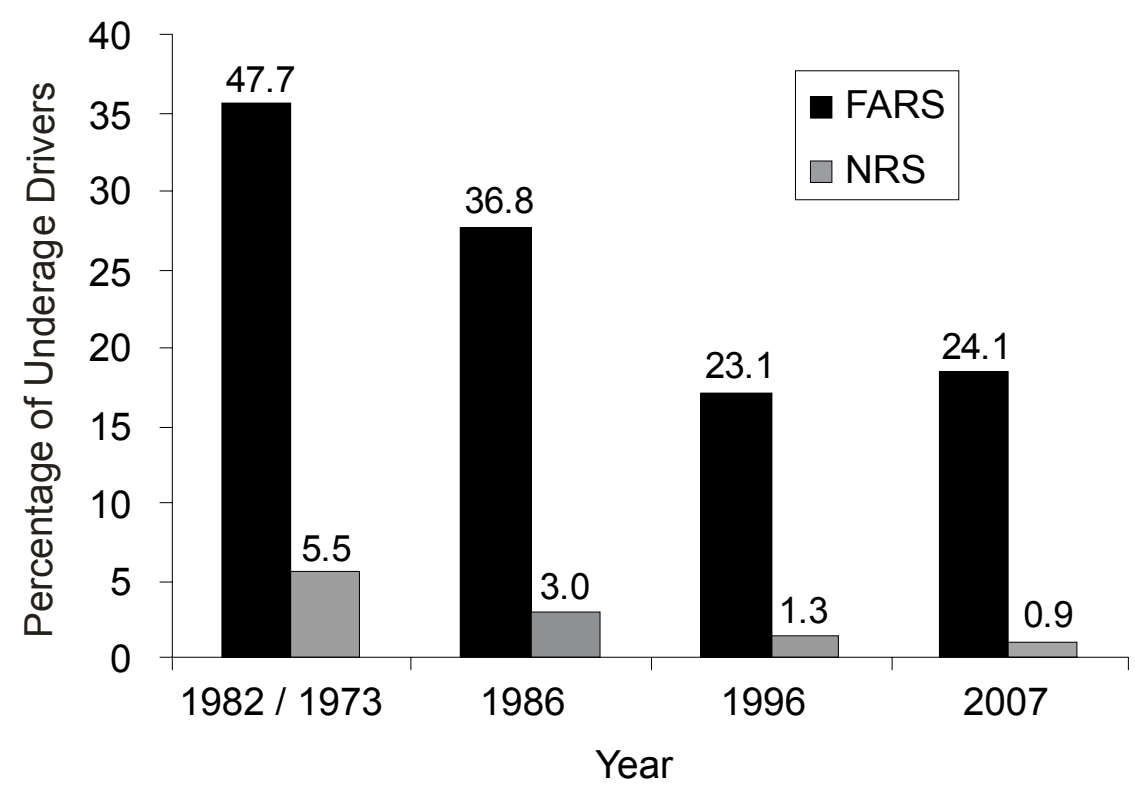

Figure 5. Comparison of FARS and National Roadside Surveys Underage (Age Under 21) Drivers with BAC $\geq .08 \mathrm{~g} / \mathrm{dL}^{11}$

Table 9 compares the BACs of drivers in the four surveys by night, Friday or Saturday, and by time of night. As in the 1996 survey, the 2007 results show lower percentages of high BAC drivers than in 1986 and 1973 at both the earlier and later hours on both weekend nights. In comparing the 2007 and the 1996 results, there were statistically significant reductions at BACs of $.05 \mathrm{~g} / \mathrm{dL}$ or higher at both the earlier and later hours on both Friday and Saturday nights. The picture is less clear for BACs of $.10 \mathrm{~g} / \mathrm{dL}$ or higher, which were not significantly different on Friday nights, but there were significantly fewer BACs of $.10 \mathrm{~g} / \mathrm{dL}$ or higher on Saturday nights.

Table 9 also displays the proportion of drivers at BACs of .08 g/dL or higher in the 2007 data set. These .08 data are not available by time of day from the previous three NRS surveys, when the prevailing legal limit in the United States was $.10 \mathrm{~g} / \mathrm{dL}$. Now that $.08 \mathrm{~g} / \mathrm{dL}$ is the legal limit in all 50 States, we are presenting 2007 NRS data with that cutoff level as well.

\footnotetext{
${ }^{11}$ In this figure, percentages are weighted.
} 
Table 9. Comparison of Driver BAC Results in Relation to Time of Night and Weekend Night

\begin{tabular}{|c|c|c|c|c|c|c|c|c|c|c|c|c|c|}
\hline & \multicolumn{3}{|c|}{1973 BAC } & \multicolumn{3}{|c|}{$1986 \mathrm{BAC}$} & \multicolumn{3}{|c|}{$1996 \mathrm{BAC}$} & \multicolumn{4}{|c|}{2007 BAC } \\
\hline & $\mathbf{N}$ & $\begin{array}{r}\geq .05 \\
(\%)\end{array}$ & $\begin{array}{r}\geq .10 \\
(\%) \\
\end{array}$ & $\mathrm{N}$ & $\begin{array}{r}\geq .05 \\
(\%)\end{array}$ & $\begin{array}{r}\geq .10 \\
(\%)\end{array}$ & $\mathbf{N}$ & $\begin{array}{r}\geq .05 \\
(\%) \\
\end{array}$ & $\begin{array}{r}\geq .10 \\
(\%) \\
\end{array}$ & $\mathbf{N}$ & $\begin{array}{l}\geq .05 \\
(\%)\end{array}$ & $\begin{array}{r}\geq .08 \\
(\%) \\
\end{array}$ & $\begin{array}{l}\geq .10 \\
(\%)\end{array}$ \\
\hline \multicolumn{14}{|l|}{ Friday } \\
\hline $\begin{array}{l}10 \text { p.m.- } \\
\text { midnight }\end{array}$ & 845 & 9.5 & 3.0 & 750 & $4.7^{*}$ & 1.6 & 1,842 & 4.2 & 1.0 & 2,123 & $2.5^{*}$ & 1.2 & 1.1 \\
\hline 1-3 a.m. & 755 & 20.6 & 7.3 & 648 & $11.9^{*}$ & 5.0 & 1,492 & 13.1 & 4.0 & 1,948 & $9.1^{*}$ & 4.8 & 2.9 \\
\hline $\begin{array}{l}\text { Total for } \\
\text { Fri. night } \\
\end{array}$ & 1,600 & 14.7 & 5.0 & 1,398 & $8.0^{*}$ & $3.2^{*}$ & 3,334 & 8.2 & 2.3 & 4,071 & $4.5^{\star}$ & 2.3 & 2.0 \\
\hline \multicolumn{14}{|l|}{ Saturday } \\
\hline $\begin{array}{l}10 \text { p.m.- } \\
\text { midnight }\end{array}$ & 841 & 9.5 & 3.4 & 833 & 6.7 & 2.8 & 1,865 & 5.3 & 2.4 & 2,280 & $2.1^{*}$ & 1.1 & $0.6^{*}$ \\
\hline 1-3 a.m. & 751 & 21.6 & 10.1 & 619 & $15.0^{*}$ & 5.5 & 1,281 & 16.4 & 6.7 & 1,876 & $9.0^{*}$ & 4.0 & $2.7^{*}$ \\
\hline $\begin{array}{l}\text { Total for } \\
\text { Sat. night }\end{array}$ & 1,592 & 15.2 & 6.6 & 1,452 & $10.2^{*}$ & 4.0 & 3,146 & 9.2 & 4.2 & 4,156 & $4.4^{*}$ & 2.0 & $1.3^{*}$ \\
\hline \multicolumn{14}{|l|}{ Total } \\
\hline $\begin{array}{l}10 \text { p.m.- } \\
3 \text { a.m. }\end{array}$ & 3,192 & 13.7 & 5.1 & 2,850 & $8.4^{*}$ & 3.2 & 6,480 & 7.7 & 2.8 & 8,227 & $4.4^{*}$ & 2.2 & $1.5^{*}$ \\
\hline
\end{tabular}

${ }^{*}$ Denotes statistically significant $(p<.05)$ when compared to previous NRS.

In this table, Ns are unweighted and percentages are weighted.

Table 10 compares driver demographic characteristics (including gender, race/ethnicity, and age) across the four surveys for drivers with BAC $\geq .05 \mathrm{~g} / \mathrm{dL}$. For the first three surveys $(1973,1986$, and 1996) the BAC categories are "greater than or equal to .05 " $(\geq .05)$ and "greater than or equal to .10 " $(\geq .10)$. The percentage indicated for $\geq .05$ includes all drivers with BACs greater than or equal to .05 . Thus, drivers at .10 or greater are included in this category as well as the " $\geq .10$ " category. For example, in 1973, 14.7 percent of males had a BAC $\geq .05$, that 14.7 percent includes the 5.5 percent who were at $\mathrm{BAC} \geq .10$. The same principle holds for the values for the 2007 survey except that we also include a category of "greater than or equal to .08" (" $\geq .08$ "). Thus, for males in 2007, 5.3 percent had a BAC of .05 or higher, which includes 2.6 percent with a BAC of .08 or higher, and in turn, the .08 group includes the 1.8 percent of drivers with a BAC of .10 or higher. Unlike the previous surveys that only included information on Whites, African Americans, and Hispanics, the 2007 survey followed the race/ethnicity categorization from the U.S. Census Bureau. Thus, there were additional response categories for race/ethnicity covering American Indian/Alaska Native, Asian, Pacific Islander, and more than one race. ${ }^{12}$

The unweighted percentage of females in the weekend nighttime sample of drivers increased from 16.5 percent in 1973 to 25.5 percent in 1986, to 30.6 percent in 1996, and to 37.1 percent in 2007 . Between 1996 and 2007, the percentage of females with BACs of .05 and above decreased. The change is statistically significant for drivers with a $.05 \mathrm{~g} / \mathrm{dL}$ or above but not for the subset of drivers with a BAC of $.10 \mathrm{~g} / \mathrm{dL}$ or higher. For males, the percentage at higher BACs also decreased. These changes were statistically significant for $\mathrm{BAC} \geq .05 \mathrm{~g} / \mathrm{dL}$, as well as for $\mathrm{BAC} \geq$ $.10 \mathrm{~g} / \mathrm{dL}$.

\footnotetext{
${ }^{12}$ Racial/Ethnic groups other than Hispanic are Non-Hispanic in this report.
} 
For race and ethnicity, the unweighted percentage of African-American drivers interviewed in the four NRS studies increased from 8 percent in 1973, to 11.5 percent in 1986, to 14.6 percent in 1996, to 16.7 percent in 2007. However, the percentage of African-American drivers with high BACs declined steadily. The percentage of African-American drivers with BACs of .05 g/dL and higher and $.10 \mathrm{~g} / \mathrm{dL}$ and higher was significantly lower in 2007 than 1996.

The unweighted percentage of Hispanic drivers interviewed in the NRS studies increased from 1.3 percent in 1973, to 4.4 percent in 1986 , to 9.4 percent in 1996 , to 18.1 percent in 2007 . In the three previous surveys, the percentage of Hispanic drivers with BACs of $.10 \mathrm{~g} / \mathrm{dL}$ or greater had increased and was twice as high in 1996 as in 1973. However, because of the relatively few Hispanic drivers in those surveys, the increases were not statistically significant. The 2007 results, in comparison to 1996, show significant decreases in the percentage of Hispanic drivers with BACs of .05 and higher and $.10 \mathrm{~g} / \mathrm{dL}$ or higher.

Table 10 also reports comparisons across age groups. The percentage of drivers in the NRS aged 20 and younger with high BACs remained low in 2007. Though there was a slight increase in the percentage of drivers aged 20 and younger with $\mathrm{BAC} \geq .10 \mathrm{~g} / \mathrm{dL}(.3 \%$ in 1996 compared to $.6 \%$ in 2007), the increase was not statistically significant. The percentage of drivers aged 21 to 34 with BACs of .05 and above declined between 1996 and 2007. This change was statistically significant at $.05 \mathrm{~g} / \mathrm{dL}$ and higher, but not at $.10 \mathrm{~g} / \mathrm{dL}$ and higher.

The most significant decreases in the percentage of high BACs occurred among 35- to 44-yearolds. The decreases were statistically significant at BACs of .05 g/dL and higher and at BACs of $.10 \mathrm{~g} / \mathrm{dL}$ and higher. The $45+$ age groups also shows decreases in the percentage of high BAC drivers; however, these differences were not statistically significant. 
Table 10. Comparison of Nighttime High BAC Drivers by Demographic Characteristics

\begin{tabular}{|c|c|c|c|c|c|c|c|c|c|c|c|c|c|}
\hline & \multicolumn{3}{|c|}{1973} & \multicolumn{3}{|c|}{1986} & \multicolumn{3}{|c|}{1996} & \multicolumn{4}{|c|}{2007} \\
\hline \multirow[t]{2}{*}{ BAC (g/dL) } & & $\geq .05$ & $\geq .10$ & & $\geq .05$ & $\geq .10$ & & $\geq .05$ & $\geq .10$ & & $\geq .05$ & $\geq .08$ & $\geq .10$ \\
\hline & $\mathbf{N}$ & $(\%)$ & $(\%)$ & $\mathbf{N}$ & $(\%)$ & $(\%)$ & $\mathbf{N}$ & $(\%)$ & $(\%)$ & $\mathbf{N}$ & $(\%)$ & $(\%)$ & $(\%)$ \\
\hline \multicolumn{14}{|l|}{ Gender } \\
\hline Male & 2,648 & 14.7 & 5.5 & 2,114 & 9.9 & 3.9 & 4,229 & 8.7 & 3.5 & 5,147 & $5.3^{*}$ & 2.6 & $1.8^{*}$ \\
\hline Female & 526 & 8.8 & 3.0 & 728 & 3.9 & 1.3 & 1,984 & 5.8 & 1.5 & 3,042 & $3.0^{*}$ & 1.5 & 1.0 \\
\hline \multicolumn{14}{|l|}{ Race/Ethnicity } \\
\hline $\begin{array}{l}\text { Am. Indian/ } \\
\text { Alaskan } \\
\end{array}$ & & & & & & & & & & 103 & 5.1 & 2.1 & 1.4 \\
\hline Asian & & & & & & & & & & 302 & 3.8 & 2.5 & 1.9 \\
\hline $\begin{array}{l}\text { Black or } \\
\text { African Am. }\end{array}$ & 256 & 16.5 & 6.0 & 328 & 13.5 & 5.9 & 947 & 9.4 & 3.6 & 1,358 & $3.4^{*}$ & 2.0 & $1.0^{*}$ \\
\hline Hispanic & 43 & 22.0 & 3.3 & 124 & 13.0 & 4.4 & 612 & 14.9 & 7.5 & 1,473 & $5.6^{*}$ & 2.1 & $1.5^{*}$ \\
\hline More than one & & & & & & & & & & 98 & 2.2 & 0.6 & 0.1 \\
\hline $\begin{array}{l}\text { Native } \mathrm{HI} / \\
\text { other PI }\end{array}$ & & & & & & & & & & 34 & 0.0 & 0.0 & 0.0 \\
\hline Other & & & & & & & & & & 107 & 2.3 & 0.6 & 0.6 \\
\hline White & 2,803 & 13.3 & 5.1 & 2,352 & 7.4 & 2.7 & 4,362 & 7.1 & 2.3 & 4,712 & 4.6 & 2.4 & 1.8 \\
\hline \multicolumn{14}{|l|}{ Age Group } \\
\hline$<21$ & 767 & 10.9 & 4.1 & 506 & 4.6 & 2.7 & 977 & 2.8 & 0.3 & 1,062 & 1.9 & 0.9 & 0.6 \\
\hline $21-34$ & 1,393 & 15.4 & 5.7 & 1,341 & 9.9 & 3.3 & 2,634 & 11.3 & 3.8 & 2,842 & $5.9^{*}$ & 3.1 & 2.2 \\
\hline $35-44$ & 419 & 15.9 & 5.8 & 497 & 9.4 & 4.7 & 1,215 & 6.9 & 3.7 & 1,253 & $3.9^{*}$ & 1.9 & $1.4^{*}$ \\
\hline $45-54$ & 339 & 13.3 & 4.7 & 245 & 9.1 & 2.2 & 747 & 5.9 & 2.3 & 968 & 4.0 & 2.2 & 1.5 \\
\hline $55-64$ & 169 & 11.0 & 3.7 & 169 & 4.4 & 0.4 & 338 & 3.9 & 1.0 & 486 & 2.2 & 0.5 & 0.5 \\
\hline $65+$ & 51 & 8.4 & 2.2 & 75 & 3.9 & 3.9 & 134 & 4.7 & 0.8 & 186 & 4.5 & 3.6 & 0.0 \\
\hline
\end{tabular}

We conducted a logistic regression analysis (Table 11) to determine the relationship of each of the variables listed in Tables 9 and 10 to the occurrence of $.05 \mathrm{~g} / \mathrm{dL}$ BAC or higher drivers, with the effects of the other factors held constant (for 2007, odds of BAC .08g/dL or higher were also estimated). The variables in Tables 9 and 10 were entered simultaneously into the prediction equation; the results are shown in Table 11, which lists the odds ratios across the survey years. Late-night drivers and males were more likely than early-evening and female drivers to have BACs of $.05 \mathrm{~g} / \mathrm{dL}$ or greater in all four surveys (with the exception of 1996, where the male/female difference was not statistically significant). Late-night drivers and males were also more likely than early-evening and female drivers to have BACs of $.08 \mathrm{~g} / \mathrm{dL}$ or greater in the 2007 survey. In 1996, Hispanics were about two-thirds more likely than Whites to have BACs of 
$.05 \mathrm{~g} / \mathrm{dL}$ or greater; however, in 2007, there was no difference between these groups. No difference was observed regarding the odds of $.08 \mathrm{~g} / \mathrm{dL}$ or greater either. For the NRS studies before 2007, race/ethnicity classification was only based on interviewer observation, whereas for the 2007 NRS, participants were directly queried about their race/ethnicity (interviewer's indication of race/ethnicity was used when such information was missing). Drivers aged 20 and younger tended to be somewhat less likely to have BACs of $.05 \mathrm{~g} / \mathrm{dL}$ or greater than those aged 45 and older, a trend that became significant in the 1996 survey and continued in the 2007 survey. The 21- to 34-year-olds tended to be higher BAC drivers than those aged 45+ in 1996; however, in 2007 , the difference was no longer significant.

Table 11. Results of Logistic Regression Models Predicting the Odds of BAC $\geq .05$ and/or BAC $\geq .08$

\begin{tabular}{|c|c|c|c|c|c|}
\hline & \multicolumn{5}{|c|}{ Odds Ratios (95\% Cl) } \\
\hline & \multirow{2}{*}{$\begin{array}{l}1973 \\
\text { BAC } \\
\geq .05\end{array}$} & \multirow{2}{*}{$\begin{array}{l}1986 \\
\text { BAC } \\
\geq .05\end{array}$} & \multirow{2}{*}{$\begin{array}{l}1996 \\
\text { BAC } \\
\geq .05\end{array}$} & \multicolumn{2}{|c|}{2007} \\
\hline & & & & $\mathrm{BAC} \geq .05$ & $\mathrm{BAC} \geq .08$ \\
\hline Saturday & 1.05 & $1.34^{*}$ & 1.22 & $0.90(0.60-1.42)$ & $0.77(0.49-1.21)$ \\
\hline $\begin{array}{l}\text { Late at night } \\
\qquad \text { Ref: Early at night }\end{array}$ & $2.66^{*}$ & $2.53^{*}$ & $3.35^{*}$ & $4.48^{*}(2.80-6.56)$ & $4.96^{*}(3.05-8.08)$ \\
\hline $\begin{array}{l}\text { Male } \\
\text { Ref: Female }\end{array}$ & $1.82^{*}$ & $2.72^{*}$ & 1.44 & $1.59^{*}(1.04-2.14)$ & $1.63^{*}(1.01-2.62)$ \\
\hline $\begin{array}{l}\text { American Indian/Alaskan } \\
\text { Asian } \\
\text { Black/ African American } \\
\text { Hispanic } \\
\text { Other } \\
\text { More than one } \\
\\
\quad \text { Ref: White }\end{array}$ & $\begin{array}{r}1.24 \\
- \\
0.95 \\
- \\
-\end{array}$ & $\begin{array}{l}1.81^{*} \\
- \\
\frac{1.65}{-} \\
-\end{array}$ & $\begin{array}{c}0.99 \\
- \\
- \\
1.67^{*} \\
- \\
-\end{array}$ & $\begin{array}{l}1.07(0.42-2.73) \\
0.50(0.25-0.99) \\
0.70(0.33-1.47) \\
1.05(0.80-1.39) \\
0.45(0.09-2.26) \\
0.40(0.11-1.41)\end{array}$ & $\begin{array}{l}0.91(0.18-4.54) \\
0.87(0.39-1.93) \\
0.80(0.22-2.98) \\
0.70(0.28-1.76) \\
0.21(0.03-1.26) \\
0.21(0.02-2.03)\end{array}$ \\
\hline $\begin{array}{l}\text { Under } 21 \\
21-34 \\
35-44\end{array}$ & $\begin{array}{l}0.82 \\
1.09 \\
1.26\end{array}$ & $\begin{array}{l}0.68 \\
1.38 \\
1.3\end{array}$ & $\begin{array}{l}0.39^{*} \\
1.82^{*} \\
1.09\end{array}$ & $\begin{array}{l}0.41^{*}(0.18-0.94) \\
1.40(0.67-2.93) \\
0.99(0.53-1.85)\end{array}$ & $\begin{array}{l}0.38(0.13-1.10) \\
1.32(0.58-3.05) \\
0.89(0.40-1.98)\end{array}$ \\
\hline
\end{tabular}




\section{Results of the 2007 NRS}

A unique feature of the 2007 NRS was the addition of data collection during two Friday daytime periods, from 9:30 a.m. to 11:30 a.m. and from 1:30 p.m. to 3:30 p.m. For the first time, we could examine the numbers and characteristics of drinking drivers on the roads during the day and the night. The daytime surveys were identical to the standard Friday and Saturday nighttime surveys with one exception: blood samples were not collected. However, as the blood sample collection comes after all other elements of the survey, its absence had no effect on the other data collected. Minor wording was also changed in some questions to conform to the daytime (e.g., "today" was substituted for "tonight").

In this section of this report, we begin by contrasting the results of Friday daytime with Friday nighttime data collection. Subsequently, we present all nighttime driver survey results, followed by the daytime driver survey results separately.

\section{Comparison of Friday Daytime and Nighttime Results}

\section{Comparison of the Demographics of Friday Daytime to Nighttime Drivers}

Before discussing the number of daytime compared to nighttime drinking drivers in this report, we first discuss the differences in the demographics of daytime compared to nighttime drivers in the survey. Demographic questions on the questionnaire included age, gender, race/ethnicity, educational achievement, employment, and vehicle type. Because both daytime and nighttime participants were randomly selected from all drivers passing the site (with responses weighted by the number of vehicles passing the site and the size of the PSU), these subjects provide a basis for estimating all drivers' characteristics on the road during the specific survey hours.

For this comparison, the two Friday daytime periods (9:30 a.m. to 11:30 a.m. and 1:30 p.m. to 3:30 p.m.) were combined and then contrasted with the two Friday nighttime periods (10 p.m. to midnight and 1 a.m. to 3 a.m.). We tested the demographic differences between daytime and nighttime Friday drivers using the Pearson chi-squared statistic. The STATA software package was applied to (1) correct for the multistage sampling design, and (2) take into account that only a subpopulation of the sampled drivers was considered (Friday drivers). The refusal rate for the drivers asked to participate in the survey was higher during the nighttime $(17.5 \%)$ than during the daytime hours $(13.9 \%)$.

Table $12^{13}$ shows a substantial difference in the age of drivers on the road during the daytime compared to nighttime on Fridays. Daytime drivers were older. It is particularly striking to note the large difference in the proportion of nighttime to daytime drivers among the two age groups: 20 and younger and 21 to 34 (those most at risk for involvement in alcohol-related crashes; Elder \& Shults, 2008).

\footnotetext{
${ }^{13}$ As noted earlier, unless explicitly indicated, sample size $(\mathrm{N})$ in this section of the report refers to the actual, unweighted number of respondents. Percentages are weighted. Sample size may vary between tables because of missing values.
} 
Table 12. Percentage of Friday Respondents by Age Category

\begin{tabular}{|c|c|c|}
\hline Age & Friday Daytime & Friday Nighttime \\
\hline & $\mathrm{N}=2,129$ & $\mathrm{~N}=3,377$ \\
\hline$<21$ & $5.1 \%$ & $13.9 \%$ \\
\hline $21-34$ & $26.4 \%$ & $44.9 \%$ \\
\hline $35-44$ & $24.5 \%$ & $18.1 \%$ \\
\hline $45-64$ & $32.5 \%$ & $20.4 \%$ \\
\hline $65+$ & $11.5 \%$ & $2.7 \%$ \\
\hline Total & $100.0 \%$ & $100.0 \%$ \\
\hline
\end{tabular}

As expected, more males than females drove at night (Table 13). Although about 55 percent of the daytime drivers were male, nearly two-thirds of the drivers on Friday night were males.

Table 13. Percentage of Male and Female Drivers during Friday Daytime and Nighttime

\begin{tabular}{lcc}
\hline Gender & Friday Daytime & Friday Nighttime \\
\hline & $\mathbf{N}=\mathbf{2 , 5 0 4}$ & $\mathbf{N}=\mathbf{4 , 1 2 4}$ \\
Male & $54.5 \%$ & $63.7 \%$ \\
Female & $45.5 \%$ & $36.3 \%$ \\
Total & $100.0 \%$ & $100.0 \%$ \\
\hline
\end{tabular}

Significant differences between day and nighttime for both sexes $(p<.001)$. In this table, Ns are unweighted and percentages are weighted.

The 2007 NRS used the race/ethnicity criteria suggested by the Office of Management and Budget (OMB) in 1997 and subsequently adopted by the U.S. Census, which required respondents to indicate first whether they regarded themselves as Hispanic or Latino, and then asked respondents to identify race. Table 14 presents the two sources of information combined. Drivers who reported being Hispanic or Latino are denoted as "Hispanic." Those who did not report being Hispanic or Latino are identified by their self-reported race membership (thus, all racial/ethnic groups other than "Hispanic" are non-Hispanic in Table 14). About one in five respondents identified themselves as Hispanic, and another fifth as Black; half of the Friday nighttime and daytime drivers identified themselves as White. The racial/ethnic distribution of the drivers did not vary significantly between daytime and nighttime participants. 
Table 14. Percentage of Race/Ethnicity of Friday Daytime and Nighttime Drivers

\begin{tabular}{lcc}
\hline Race/Ethnicity & Friday Daytime & Friday Nighttime \\
\hline & $\mathbf{N = 2 , 5 0 1}$ & $\mathbf{N = 4 , 1 1 8}$ \\
American Indian or Native Alaskan & $1.1 \%$ & $0.6 \%$ \\
Asian & $6.4 \%$ & $7.1 \%$ \\
Black or African American & $19.6 \%$ & $16.1 \%$ \\
Hispanic & $19.5 \%$ & $21.5 \%$ \\
Native Hawaiian or other Pacific Islander & $0.1 \%$ & $0.8 \%$ \\
White & $50.0 \%$ & $49.8 \%$ \\
More than one race & $0.9 \%$ & $1.7 \%$ \\
Other & $2.4 \%$ & $2.4 \%$ \\
Total & $100.0 \%$ & $100.0 \%$ \\
\hline
\end{tabular}

No significant differences between day and nighttime.

In this table, Ns are unweighted and percentages are weighted.

As is shown in Table 15, there was no significant difference in educational attainment between daytime compared to nighttime drivers. One in four of the drivers reported graduating from college, and another third reported some college attendance.

Table 15. Percentage of Educational Attainment by Friday Daytime and Nighttime Drivers

\begin{tabular}{lcc}
\hline School & Friday Daytime & Friday Nighttime \\
\hline & $\mathbf{N}=\mathbf{2 , 1 3 3}$ & $\mathbf{N}=\mathbf{3 , 3 7 9}$ \\
Not a high school graduate & $6.3 \%$ & $8.0 \%$ \\
High school graduate & $24.6 \%$ & $21.9 \%$ \\
Some college & $32.3 \%$ & $35.6 \%$ \\
College graduate & $26.1 \%$ & $23.2 \%$ \\
Some graduate work & $10.7 \%$ & $11.2 \%$ \\
Graduate school & $0.0 \%$ & $0.1 \%$ \\
Total & $100.0 \%$ & $100.0 \%$ \\
\hline
\end{tabular}

No significant differences between day and nighttime.

In this table, Ns are unweighted and percentages are weighted.

Employment status (Table 16) varied significantly between Friday daytime and nighttime drivers. More than 70 percent of daytime and more than 80 percent of nighttime drivers reported being employed. Unemployment among NRS drivers was low, and there was a lower proportion at night than during the day. There were fewer retired drivers out at night, and twice as many students were out at nighttime compared to daytime. 
Table 16. Employment Status of Friday Daytime and Nighttime Drivers

\begin{tabular}{lcc}
\hline Employment & Friday Daytime & Friday Nighttime \\
\hline & $\mathbf{N}=\mathbf{2 , 1 3 2}$ & $\mathbf{N}=\mathbf{3 , 3 8 0}$ \\
Employed/self-employed $^{* *}$ & $72.4 \%$ & $81.2 \%$ \\
Homemaker** $^{* *} \%$ & $2.3 \%$ \\
On disability & $4.9 \%$ & $0.8 \%$ \\
Retired $^{* *}$ & $1.4 \%$ & $2.7 \%$ \\
Student $^{* *}$ & $12.6 \%$ & $10.4 \%$ \\
Unemployed $^{* *}$ & $4.7 \%$ & $2.1 \%$ \\
Other $_{\text {Total }}$ & $3.7 \%$ & $0.5 \%$ \\
Tot Denotes categories that were significantly different from day to night $(p<.01)$. \\
In this table, Ns are unweighted and percentages are weighted.
\end{tabular}

The type of vehicle driven by Friday nighttime participants differed significantly from that of Friday daytime participants (Table 17). SUVs, pickups, and minivans were more frequent in the daytime. Passenger cars accounted for two-thirds of the vehicles driven by Friday nighttime respondents.

Table 17. Type of Vehicle Driven by Friday Daytime and Nighttime Drivers

\begin{tabular}{lcc}
\hline Vehicle Type & Friday Daytime & Friday Nighttime \\
\hline & $\mathbf{N}=\mathbf{2 , 5 0 7}$ & $\mathbf{N = 4 , 1 2 5}$ \\
Passenger car $^{* *}$ & $55.0 \%$ & $66.8 \%$ \\
Minivan $^{* *}$ & $7.9 \%$ & $4.4 \%$ \\
Motorcycle $^{* *}$ & $0.5 \%$ & $1.4 \%$ \\
Pickup** $^{*}$ & $7.7 \%$ \\
Sports Utility Vehicle & $* *$ \\
Van & $11.7 \%$ & $17.3 \%$ \\
Other & $23.3 \%$ & $1.8 \%$ \\
Unknown & $1.3 \%$ & $0.5 \%$ \\
Total & $0.3 \%$ & $0.2 \%$ \\
** Denotes categories that were significantly different from day to night $(p<.01)$. & $100.0 \%$ \\
In this table, Ns are unweighted and percentages are weighted.
\end{tabular}

\section{Comparison of the BACs of Friday Daytime to Friday Nighttime Drivers}

The inclusion of the daytime data collection activity in the 2007 NRS provided an opportunity to determine the variation in drivers' BACs from 9:30 a.m. through early Saturday morning. The BACs of Friday drivers during daytime (both sessions) and nighttime data collection periods are shown in Table 18. From this table, it is clear that there are fewer drinking drivers during daytime hours. 
Table 18. Percentage of Drivers in Three BAC Categories on Fridays across Three Periods

\begin{tabular}{|c|c|c|c|c|}
\hline BAC (g/dL) & $\mathbf{N}$ & Daytime & $\begin{array}{c}\text { Early } \\
\text { Nighttime }\end{array}$ & $\begin{array}{c}\text { Late } \\
\text { Nighttime }\end{array}$ \\
\hline & $\mathrm{N}=6,553$ & $\mathrm{~N}=2,482$ & $\mathrm{~N}=2,123$ & $\mathrm{~N}=1,948$ \\
\hline Zero* & 5,995 & $98.9 \%$ & $89.4 \%$ & $81.2 \%$ \\
\hline Between Zero and .08* & 447 & $0.9 \%$ & $9.5 \%$ & $14.0 \%$ \\
\hline $.08+^{*}$ & 111 & $0.2 \%$ & $1.2 \%$ & $4.8 \%$ \\
\hline Total & & $100.0 \%$ & $100.0 \%$ & $100.0 \%$ \\
\hline
\end{tabular}

\section{Nighttime Survey Results}

\section{Nighttime BAC by Demographics, Exposure, Trip, and Vehicle Type}

The prevalence of drinking drivers on roadways provides one measure of the exposure of the Nation's drivers to crash risk. As shown in Table 19, the overall prevalence of drinking drivers during the two 2007 NRS nighttime survey periods (10 p.m. to midnight and 1 a.m. to 3 a.m.), combined across both Friday and Saturday, was 12.4 percent. Slightly more than 2 percent of the drivers on the road during those periods were at illegal BACs of $.08 \mathrm{~g} / \mathrm{dL}$ or higher.

Table 19. Nighttime: BAC Distributions of Nighttime Drivers (Friday and Saturday Combined)

\begin{tabular}{lrr}
\hline BAC (g/dL) & $\mathbf{N}$ & $\%$ \\
\hline Zero & 7,207 & $87.6 \%$ \\
Between Zero and .08 & 839 & $10.2 \%$ \\
$.08+$ & 181 & $2.2 \%$ \\
Total & 8,227 & $100.0 \%$ \\
\hline In this table, Ns are unweighted and percentages are weighted.
\end{tabular}

Table 20 includes BAC by various demographic variables. The positive BAC categories are greater than .00 , greater than or equal to .05 , greater than or equal to .08 , and greater than or equal to .15. These categories overlap, for example, the category greater than .00 includes all positive BAC drivers, including those greater than or equal to .05 , greater to or equal to .08 , and greater than or equal to .15. This is the same principle described for the data displays in Table 10.

As indicated in Table 20, compared to females, males are more likely to be represented in the positive $\mathrm{BAC}$ categories $(\mathrm{BAC} \geq .00, \mathrm{BAC} \geq .05$, or $\mathrm{BAC} \geq .08 \mathrm{~g} / \mathrm{dL}$ ). Further, there are more males than females at the $\geq .15 \mathrm{BAC}$ level. However, this difference is not statistically significant in part due to the relatively small number of drivers at this BAC level ( $\geq .15 \mathrm{~g} / \mathrm{dL})$. For race and ethnicity, no statistical differences were found between non-Hispanic Whites and other racial/ethnic groups. Because of the small sample sizes for Native Hawaiians/Other PIs and/or More than One Racial/Ethnic group, we did not perform statistical tests on these groups.

The prevalence of underage drivers with positive $\mathrm{BACs}(\mathrm{BAC} \geq .00, \mathrm{BAC} \geq .05$, or $\mathrm{BAC} \geq .08$ $\mathrm{g} / \mathrm{dL})$ is significantly smaller than that of drivers 35 to 44 years old. However, this pattern 
reverses for drivers at the next age group (aged 21 to 34), where the prevalence of these drivers with positive $\mathrm{BAC}$ levels ( $\mathrm{BAC} \geq .00, \mathrm{BAC} \geq .05$, or $\mathrm{BAC} \geq .08 \mathrm{~g} / \mathrm{dL}$ ) is significantly larger than that of drivers 35 to 44 years old. No statistical difference was found between drivers aged 35 to 44 and older. Further, there were no age-based statistically significant differences associated to high BAC levels $(\geq .15 \mathrm{~g} / \mathrm{dL})$, likely due to the relative small number of BAC $\geq .15$ $\mathrm{g} / \mathrm{dL}$ drivers.

Table 20. Nighttime: BAC by Demographics (Gender, Race/Ethnicity, and Age Group)

\begin{tabular}{lrc|cccc}
\hline & & & \multicolumn{5}{|c}{ Alcohol Positive } \\
\hline BAC (g/dL) & & $\mathbf{0}$ & $>.00$ & $\mathbf{2 . 0 5}$ & $\mathbf{2 . 0 8}$ & $\mathbf{2 . 1 5}$ \\
\hline Gender & $\mathbf{N}$ & $\mathbf{( \% )}$ & $\mathbf{( \% )}$ & $\mathbf{( \% )}$ & $\mathbf{( \% )}$ & $\mathbf{( \% )}$ \\
$\quad$ Male & & & & & & \\
$\quad$ Female & 5,147 & 86.6 & $13.4^{* *}$ & $5.3^{* *}$ & $2.6^{* *}$ & 0.5 \\
\hline Race/Ethnicity & 3,042 & 89.4 & 10.6 & 3.0 & 1.5 & 0.2 \\
$\quad$ Am. Indian/Alaskan & 103 & 85.9 & 14.1 & 5.1 & 2.1 & 0.0 \\
Asian & 302 & 89.6 & 10.4 & 3.8 & 2.5 & 0.0 \\
Black or African Am. & 1,358 & 88.5 & 11.5 & 3.4 & 2.0 & 0.5 \\
Hispanic & 1,473 & 86.8 & 13.1 & 5.6 & 2.1 & 0.8 \\
Native HI/Other PI & 34 & 99.4 & 0.6 & 0.0 & 0.0 & 0.0 \\
White & 4,712 & 87.5 & 12.5 & 4.6 & 2.4 & 0.3 \\
More than one & 98 & 84.8 & 15.2 & 2.2 & 0.6 & 0.0 \\
Other & 107 & 85.5 & 14.5 & 2.3 & 0.6 & 0.0 \\
\hline Age Group & & & & & & \\
<21 & 1,062 & 92.8 & $7.2^{* *}$ & $1.9^{* *}$ & $0.9^{*}$ & 0.1 \\
21-34 & 2,842 & 84.4 & $15.6^{* *}$ & $5.9^{* *}$ & $3.1^{*}$ & 0.6 \\
35-44 & 1,253 & 89.3 & 10.7 & 3.9 & 1.9 & 0.4 \\
45-54 & 968 & 88.4 & 11.6 & 4.0 & 2.2 & 0.4 \\
55-64 & 486 & 91.2 & 8.8 & 2.2 & 0.5 & 0.3 \\
65+ & 186 & 88.7 & 11.3 & 4.5 & 3.6 & 0.0 \\
\hline
\end{tabular}

Note: Rows do not add up to $100 \%$. Data in the BAC columns overlap. (e.g., entries in > .00 also include those in the columns for $\geq .05, \geq .08$, and $\geq .15$ ). Note: $0=<.005$

${ }^{*} p<.05$ and ${ }^{* *} p<.01$ denote statistical significance between the character of interest and the reference level (female, non-Hispanic White, and age 35-44, respectively).

Because of the small sample sizes, comparisons involving Native Hawaiians/Other PIs, or "More than One" racial/ethnic group were not performed.

In this table, Ns are unweighted and percentages are weighted.

One exposure measure is the number of miles driven each year. As can be seen in Tables 21 and 22 , drivers with a zero BAC in the survey are split across the three annual mileage categories, which are "less than average," "average," and "more that average," with average having been indicated at 15,000 miles per year. Tables 21 and 22, however, show that drivers with BACs of $.08 \mathrm{~g} / \mathrm{dL}$ or higher were more likely to report less than average mileage than drivers at zero or between zero and $.08 \mathrm{~g} / \mathrm{dL}$. Drivers with intermediate BACs (between zero and $.08 \mathrm{~g} / \mathrm{dL}$ ) were more likely to report either "more than average" or "less than average" mileage than those at a zero BAC. (In other words, those who drive an "average" number of miles are also those who drive at $\mathrm{BAC}=.00)$. The lower section of Table 22 shows that about half of all the nighttime drivers reported that 20 percent or less of their driving was done at night. Compared with zero 
BAC drivers, positive BAC drivers reported driving a smaller percentage of their total miles at night.

Table 21. Nighttime: Exposure (Yearly Miles and Percentage of Day and Night Driving) by BAC (Percentages Calculated by Row)

\begin{tabular}{lcccc}
\hline & & \multicolumn{3}{c}{ BAC (g/dL) } \\
\cline { 2 - 4 } Yearly Miles (Avg = 15,000 Miles) & $\mathbf{N}$ & $\mathbf{Z}$ & $\begin{array}{c}\text { Between } \\
\text { Zero and .08 } \\
\mathbf{\%}\end{array}$ & $\mathbf{. 0 8 +}$ \\
$\quad$ Less than average & 1,904 & 86.4 & $10.5^{*}$ & $3.2^{* *}$ \\
Average & 2,152 & 89.2 & 8.8 & 2.0 \\
More than average & 2,767 & 87.3 & $11.0^{*}$ & 1.7 \\
Did not answer & 7 & 63.7 & 36.3 & 0.0 \\
Total & 6,830 & 87.6 & 10.2 & 2.2 \\
Percentage of Total Driving at Night & $\mathbf{N}$ & $\%$ & $\%$ & $\%$ \\
$0-20 \%$ & 3,035 & 85.4 & 11.6 & 3.0 \\
$21-40 \%$ & 1,763 & 89.0 & $9.3^{*}$ & $1.7^{* *}$ \\
$41-60 \%$ & 1,251 & 90.3 & $8.3^{* *}$ & $1.4^{* *}$ \\
$61-80 \%$ & 546 & 88.7 & 8.9 & 2.3 \\
$81-100 \%$ & 232 & 89.0 & 10.3 & 0.7 \\
Did not answer & 3 & 54.2 & 45.8 & 0.0 \\
Total & 6,830 & 87.6 & 10.2 & 2.2
\end{tabular}

Statistical comparisons for the first half of the table are made between the first three rows, with "Average" as the reference. For example, we tested whether the $3.2 \%$ cell is statistically different from the $2.0 \%$ cell, as well as whether $1.7 \%$ differs statistically from $2.0 \%$, or $10.5 \%$ differs from $8.8 \%$, etc.

${ }^{*} p<.05$ and ${ }^{* *} p<.01$ significance level. Statistical comparisons for the second half of the table follow a similar criteria, but using "0-20\%" as the reference level (thus, for example, we tested whether $1.7 \%$ is statistically different from $3.0 \%$, or $9.3 \%$ from $11.6 \%$, etc.).

In this table, Ns are unweighted and percentages are weighted. 
Table 22. Nighttime: Exposure (Yearly Miles and Percentage of Day and Night Driving) by BAC (Percentages Calculated by Column)

\begin{tabular}{lccc}
\hline & \multicolumn{3}{c}{ BAC (g/dL) } \\
\cline { 2 - 4 } & Zero & Between \\
& $\mathbf{N}=\mathbf{5 , 9 5 4}$ & $\mathbf{N}=\mathbf{7 0 8}$ & $\mathbf{. 0 8 +}$ \\
\hline Yearly Miles (Avg = 15,000 Miles) & $31.2 \%$ & $32.6 \%$ & $44.8 \%^{*}$ \\
Less than average & $31.8 \%$ & $26.9 \%$ & $27.8 \%$ \\
Average & $36.9 \%$ & $40.3 \%$ & $27.4 \%$ \\
More than average & $0.1 \%$ & $0.2 \%$ & $0.0 \%$ \\
Did not answer & $100.0 \%$ & $100.0 \%$ & $100.0 \%$ \\
Total & $\mathbf{N}=\mathbf{5 , 9 5 3}$ & $\mathbf{N}=\mathbf{7 0 9}$ & $\mathbf{N}=\mathbf{1 6 8}$ \\
\hline Percentage of Total Driving at Night & $44.2 \%$ & $51.7 \% * *$ & $60.3 \%{ }^{*}$ \\
$0-20 \%$ & $26.7 \%$ & $24.0 \%$ & $19.6 \%$ \\
$21-40 \%$ & $18.3 \%$ & $14.4 \%$ & $11.0 \%$ \\
$41-60 \%$ & $8.0 \%$ & $6.9 \%$ & $8.2 \%$ \\
$61-80 \%$ & $2.9 \%$ & $2.9 \%$ & $0.9 \%$ \\
$81-100 \%$ & $0.1 \%$ & $0.1 \%$ & $0.0 \%$ \\
Did not answer & $100.0 \%$ & $100.0 \%$ & $100.0 \%$ \\
Total & & & \\
\hline
\end{tabular}

Statistical comparisons are made between columns with "zero" as the reference. For example, we tested whether the $44.8 \%$ cell is statistically different from the $31.2 \%$, as well as whether $32.6 \%$ differs from $31.2 \%$, or $27.8 \%$ differs from $31.8 \%$, etc.

${ }^{*} p<.05$ significance level

${ }^{* *} p<.01$

In this table, Ns are unweighted and percentages are weighted.

Table 23 provides information on trip origin and destination by driver's BAC. In this table, the percentage of people originating from (or going to) each location, is broken into three possible BAC categories, zero, between zero and .08, and .08 and above. For example, of those drivers whose trip originated at a bar/tavern/club, 69.6 percent were at zero BAC, 25.6 percent were between zero and $.08 \mathrm{BAC}$, and 4.8 percent were at .08 or above. Table 23 shows that the four major trip origin locales were the driver's home, a restaurant, someone else's home, and work, with a relatively low number of nighttime drivers coming from hotels/motels, school/church, sport/recreation facilities, stores/gas stations, and bars/taverns/clubs. Despite the relatively low number of nighttime drivers coming from bars, taverns, or clubs, these drivers show the relatively largest proportion at high BAC levels $(.08+\mathrm{g} / \mathrm{dL})$. Table 24 shows that about 8.4 percent of these drivers registered a BAC $\geq .08$, but only 3.1 percent were at a BAC of .00 ( $p<$. 05). Thus, drivers with $\mathrm{BAC} \geq .08$ were significantly more likely to report that their trip originated at a bar or a restaurant than drivers with $\mathrm{BAC}=.00$. Drivers with BACs between zero and $.08 \mathrm{~g} / \mathrm{dL}$ were also significantly more likely to report that their trip originated at a bar or a restaurant than drivers with $\mathrm{BAC}=.00(p<.05)$. Among drivers with BACs between zero and $.08 \mathrm{~g} / \mathrm{dL}$, the prevalence of those who initiated their trips at someone else's home was also significantly higher $(p<.05)$. Thus, the data suggest that, for nighttime drivers, coming from a bar, tavern, club, or restaurant is associated with a positive BAC (either above or below the BAC $=.08$ limit), and that coming from someone else's home is also associated with moderate (underthe-limit) drinking. 
Table 24 presents the same data in a different way. In this table, the trip origin (and destination) of drivers within each BAC category are examined. For example, of the drivers at .08 or above, 23 percent were headed to someone else's home.

Table 24 also shows that, for trip destination, overall nearly 7 of 10 nighttime drivers reported that they were headed home, and another 15 percent reported heading to someone else's home. The concentration of trip destinations between these two headings makes many statistical comparisons involving the remaining trip destinations questionable. The small number of BAC $\geq$ .08 nighttime drivers heading for a bar, tavern, or club in the sample precluded meaningful comparisons involving this group. Comparisons among the $\mathrm{BAC} \geq .08$ drivers with sufficient sample size showed that drivers over the limit $(\mathrm{BAC} \geq .08)$ were more likely to report that they were headed for someone else's house than to their own homes $(p<.05)$. For moderate drinkers (between zero and $.08 \mathrm{~g} / \mathrm{dL}$ ), the destination was not significantly different from that of nondrinkers $(\mathrm{BAC}=.00)$, except for those heading to a bar, tavern, or club $(p<.05)$. 
Table 23. Nighttime: Trip Origin and Destination by BAC (Percentages Calculated by Row)

\begin{tabular}{|c|c|c|c|c|}
\hline & & \multicolumn{3}{|c|}{ BAC (g/dL) } \\
\hline & & Zero & $\begin{array}{c}\text { Between } \\
\text { Zero and } .08\end{array}$ & $.08+$ \\
\hline Trip Origin & $\mathbf{N}$ & $\%$ & $\%$ & $\%$ \\
\hline Bar/tavern/club & 330 & 69.6 & $25.6^{*}$ & $4.8^{* *}$ \\
\hline Home (own home) & 1,165 & 90.1 & 8.2 & 1.8 \\
\hline Hotel /motel & 32 & 95.2 & 1.7 & 3.1 \\
\hline Restaurant/eating place & 662 & 80.6 & $15.7^{*}$ & $3.7^{*}$ \\
\hline School/church & 133 & 97.1 & $2.9^{*}$ & 0.0 \\
\hline Someone else's home & 1,809 & 82.4 & $15.4^{*}$ & 2.2 \\
\hline Sport/rec facility/park & 303 & 92.7 & 5.6 & 1.7 \\
\hline Store/gas station & 332 & 92.3 & 4.9 & 2.8 \\
\hline Work & 1,242 & 94.2 & $3.5^{*}$ & 2.3 \\
\hline Other & 810 & 92.8 & 6.2 & 1.0 \\
\hline Total & 6,818 & 87.6 & 10.1 & 2.2 \\
\hline Trip Destination & $\mathbf{N}$ & $\%$ & $\%$ & $\%$ \\
\hline Bar/tavern/club & 131 & 78.6 & $19.1^{*}$ & $2.3^{N A}$ \\
\hline Home (own home) & 4,512 & 86.3 & 11.0 & 2.7 \\
\hline Hotel $/$ motel & 53 & 83.0 & $15.1^{N A}$ & $1.9 \mathrm{NA}$ \\
\hline Restaurant/eating place & 313 & 88.8 & 8.9 & 2.2 \\
\hline School/church & 16 & 93.8 & $6.3^{N A}$ & $0.0 \mathrm{NA}$ \\
\hline Someone else's home & 987 & 86.5 & 10.5 & 2.9 \\
\hline Sport/rec facility/park & 48 & 89.6 & 6.3 NA & $4.2^{N A}$ \\
\hline Store/gas station & 266 & 94.4 & $5.3^{*}$ & $0.4^{N A}$ \\
\hline Work & 190 & 98.4 & $1.6^{*}$ & $0.0 \mathrm{NA}$ \\
\hline Other & 298 & 91.6 & $7.4^{*}$ & $1.0 \mathrm{NA}$ \\
\hline Did not answer & 4 & 100.0 & $0.0 \mathrm{NA}$ & $0.0 \mathrm{NA}$ \\
\hline Total & 6,818 & 87.6 & 10.1 & 2.2 \\
\hline
\end{tabular}

Statistical comparisons are made between rows, with "Home (own home)" as the reference. For example, for the first half of the table, we tested whether the $4.8 \%$ cell is statistically different from the $1.8 \%$ cell, as well as whether $25.6 \%$ statistically differs from $8.2 \%$, etc. For the second half, we tested whether the $19.1 \%$ cell is statistically different from the $11.0 \%$ cell, as well as whether $8.9 \%$ statistically differs from $11.0 \%$, etc. * $p<.05$ and $^{* *}$ indicates $(p<.01)$ significance level. "NA" (not applicable) indicates a cell size too small for statistical comparisons.

In this table, Ns are unweighted and percentages are weighted. 
Table 24. Nighttime: Trip Origin and Destination by BAC (Percentages Calculated by Column)

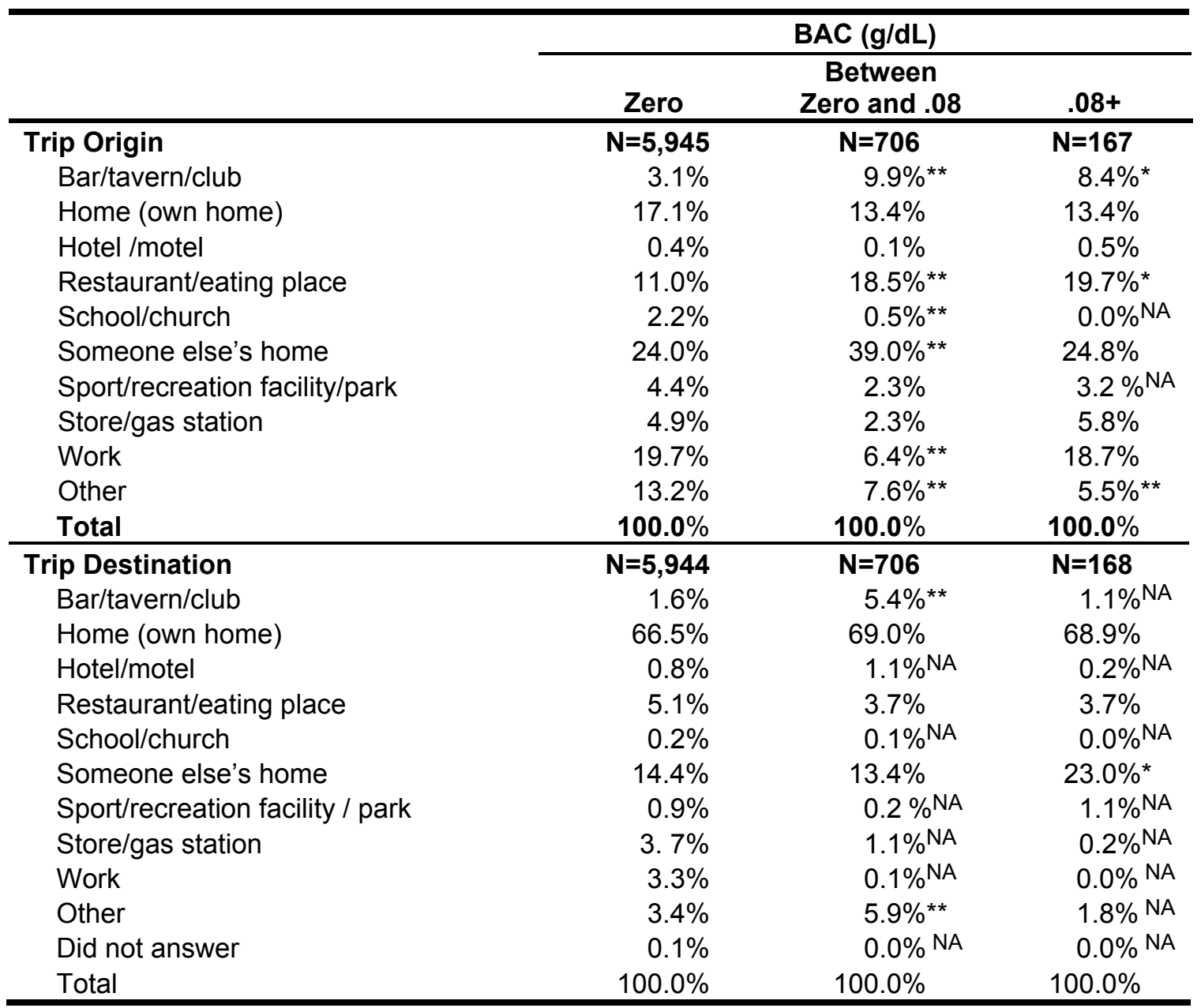

Statistical comparisons are made between columns with "zero" as the reference. More specifically,

${ }^{*} p<.05$ and ${ }^{* *} p<.01$ denote that, compared with drivers with a zero BAC, there are significant differences in the proportion of drivers of different driving origins (or destinations).

"NA" indicates a cell size too small for statistical comparisons.

In this table, Ns are unweighted and percentages are weighted.

Tables 25 and 26 show the BAC distribution found in nighttime drivers by type of vehicle. Table 25 shows that the proportion of drivers at BACs of $.08 \mathrm{~g} / \mathrm{dL}$ or higher was lower among minivan $(p<.01)$ drivers and sport utility vehicles (SUV) $(p<.05)$, than among drivers of any other vehicle type. The relatively high proportion $(5.6 \%)$ of BACs at $.08 \mathrm{~g} / \mathrm{dL}$ or higher among motorcycle riders is of note, but is not statistically significant because of the smaller sample size.

Table 26 indicates that the majority of $.08 \mathrm{~g} / \mathrm{dL}$ and above drivers were in passenger cars. The next most common vehicles were pickup trucks and SUVs. Less than 1 percent of $.08 \mathrm{~g} / \mathrm{dL}$ and above drivers were in a minivan. 
Table 25. Nighttime: Vehicle Type by BAC (Percentages Calculated by Row)

\begin{tabular}{lrccc}
\hline & & \multicolumn{3}{c}{ BAC (g/dL) } \\
\cline { 3 - 5 } Vehicle Type & $\mathbf{N}$ & Zero & $\begin{array}{c}\text { Between } \\
\text { Zero and .08 }\end{array}$ & $\mathbf{. 0 8 +}$ \\
\hline Passenger car & 5,026 & $87.7 \%$ & $10.0 \%$ & $2.3 \%$ \\
Minivan & 376 & $92.2 \%$ & $7.4 \%$ & $0.3 \%^{* *}$ \\
Motorcycle & 108 & $80.7 \%$ & $13.7 \%$ NA & $5.6 \%^{\mathrm{NA}}$ \\
Pickup & 968 & $84.7 \%$ & $12.0 \%$ & $3.3 \%$ \\
Sports Utility Vehicle & 1,550 & $87.8 \%$ & $10.8 \%$ & $1.3 \%^{*}$ \\
Van & 123 & $94.6 \%$ & $2.6 \%^{* *}$ & $2.8 \%$ \\
Other & 34 & $78.7 \%$ & $6.4 \% \mathrm{NA}$ & $14.9 \%^{\mathrm{NA}}$ \\
Unknown & 6 & $53.0 \%$ & $47.0 \% \mathrm{NA}$ & $0.0 \% \mathrm{NA}$ \\
\hline
\end{tabular}

Statistical comparisons are made between rows, with "Passenger Car" as the reference. ${ }^{*} p<.05$ and ${ }^{* *} p<.01$ denote that, compared with drivers with zero BAC, there are significant differences in the proportion of drivers of different vehicle types with those driving a "Passenger Car" $(p<.01)$.

"NA" means not applicable and indicates a cell size too small for statistical comparisons. In this table, Ns are unweighted and percentages are weighted.

Table 26. Nighttime: Vehicle Type by BAC (Percentages Calculated by Column)

\begin{tabular}{|c|c|c|c|}
\hline \multirow[b]{2}{*}{ Vehicle Type } & \multicolumn{3}{|c|}{$B A C(g / d L)$} \\
\hline & Zero & $\begin{array}{c}\text { Between } \\
\text { Zero and .08 } \\
\end{array}$ & $.08+$ \\
\hline & $N=7,153$ & $N=843$ & $N=195$ \\
\hline Passenger car & $64.87 \%$ & $63.44 \%$ & $67.38 \%$ \\
\hline Minivan & $4.98 \%$ & $3.44 \%$ & $0.75 \%$ ** \\
\hline Motorcycle & $1.07 \%$ NA & $1.57 \%$ NA & $2.97 \% \mathrm{NA}$ \\
\hline Pickup & $7.75 \%$ & $9.41 \%$ & $12.11 \% *$ \\
\hline Sports Utility Vehicle & $18.88 \%$ & $20.02 \%$ & $11.41 \%{ }^{* *}$ \\
\hline Van & $1.85 \%$ & $0.44^{* * \%}$ & $2.15 \%$ \\
\hline Other & $0.43 \%$ & $0.30 \%$ & $3.25 \%$ NA \\
\hline Unknown & $0.18 \%$ & $1.39 \%$ NA & $0.0 \% \mathrm{NA}$ \\
\hline All & $100.00 \%$ & $100.00 \%$ & $100.00 \%$ \\
\hline
\end{tabular}

\section{Nighttime Drivers Reporting Contact with the Criminal J ustice System}

Questions regarding contact with the legal system because of a previous impaired-driving arrest were added to the 2007 survey. NIJ contributed funding to the 2007 NRS to support the questionnaire items related to arrest and convictions.

Of the 5,709 NRS participants (nighttime drivers) who responded to the question "During the past 12 months, were you arrested and booked for driving under the influence of alcohol or drugs?", less than 4 percent indicated "yes" ( $n=240$ unweighted). 
Although sample sizes are small, the percentage of drivers with BACs of $.08 \mathrm{~g} / \mathrm{dL}$ or above was significantly higher $(p<.01)$ among those who reported a past arrest $(\mathrm{n}=16$ of 240$)$ than among those who did not $(n=110$ of 5,554). Thus, those who reported a prior DWI arrest were more likely to have a BAC of .08 g/dL or higher (7\%) than those who did not report a prior DWI arrest $(2 \%)$.

Of the participants who indicated "yes" to having been arrested and booked (Table 27) for driving under the influence of alcohol or drugs, more than 60 percent indicated that they had paid a fine. Twenty-five percent reported that they were required to attend an educational program, and almost 26 percent had been placed on probation. Together, more than 30 percent indicated that their driver's licenses had been either suspended or revoked, and about 24 percent reported incarceration. Community service and requirements to attend a treatment program were reported by approximately 14 percent and almost 10 percent of participants, respectively. Finally, almost 5 percent of participants reported that they received other punishments not listed because of an impaired-driving arrest.

Table 27. Nighttime: Reported Sanctions Following Arrest for Previous Impaired Driving

\begin{tabular}{|c|c|c|}
\hline Item & $\mathbf{N}$ & $\%$ \\
\hline Was your licensed suspended?. & 222 & 22.4 \\
\hline Was your licensed revoked?..... & 221 & 7.9 \\
\hline Did you serve in jail or prison? & 228 & 23.6 \\
\hline Did you pay a fine? & 225 & 61.6 \\
\hline Were you required to perform community service? .............. & 227 & 14.3 \\
\hline Were you placed in probation? & 219 & 25.8 \\
\hline Were you required to attend an educational program? ............. & 214 & 25.3 \\
\hline Were you required to attend a treatment program? .................... & 214 & 9.6 \\
\hline Other punishment? & 204 & 4.6 \\
\hline
\end{tabular}

Drivers could give multiple answers.

In this table, Ns are unweighted and percentages are weighted.

As indicated above, 16 of the 240 drivers reporting a prior DWI arrest had a BAC of .08 or above. Fourteen of them responded to the question about what sanctions they received. All 14 reported paying a fine, six reported that their license had been suspended, and 3 reported a license revocation. Four indicated that they were required to perform community service and 3 indicated receiving jail time. Three reported being placed on probation, 4 were required to attend an educational program, and 3 indicted they were required to attend treatment.

\section{Nighttime Drivers Reporting Contact with the Health System}

In addition to items relating to the criminal sanctions for drinking and drug use while driving, items related to treatment because of drug or alcohol use were included in the 2007 NRS. These items were funded by NIAAA. These questions were added to the survey to investigate potential intervention opportunities. Individuals who participated in the AUD survey were also questioned regarding their contacts with medical facilities. Thus, Tables 28 through 40 refer to a subset of the NRS respondents, those who reported drinking within the past year. The first query (see Table 28) was about any visit to a medical facility in the past year. Approximately 23 percent of the respondents indicated they had visited a medical facility in the last 12 months. That question 
contained no reference to alcohol or drugs, so the responses included visits for any health problem.

Table 28. Nighttime: "Have you visited a medical facility in the past year?"

\begin{tabular}{lcc}
\hline & $\mathbf{N}=\mathbf{4 , 4 3 0}$ & \% \\
\hline Yes & 1,081 & 22.9 \\
No & 3,349 & 77.2 \\
\hline
\end{tabular}

Question limited to drivers who drank in the last year.

In this table, Ns are unweighted and percentages are weighted.

However, as shown in Tables 29 through 40, when asked about contacts related to alcohol or drug use, about 1 percent of participant drivers in the 2007 survey reported contacts in the past year with the medical system for those reasons. Tables 29 and 30 suggest that few who acknowledged drinking in the past year received any advice about drinking from a medical person (approximately 1.3\%) and Tables 31 and 32 show that only 1.5 percent sought medical advice or assistance. Finally, about 1 percent (Tables 33 and 34) reported a visit to an emergency room for a problem related to their drinking. It is not known whether the reported visits were related to crash injuries. Interestingly, as indicated in Tables 31 and 33, the percentage of drivers with positive BACs was significantly higher among those who answered "Yes" to the questions seeking help because of drinking, and being in an emergency room because of something related to drinking $(p<.01)$.

Table 29. Nighttime: "In the past year, have you been told by a medical person you needed help for your drinking?" (Percentages Calculated by Row)

\begin{tabular}{|c|c|c|c|c|}
\hline & \multirow[b]{2}{*}{$\mathbf{N}$} & \multicolumn{3}{|c|}{ BAC (g/dL) } \\
\hline & & Zero & $\begin{array}{c}\text { Between } \\
\text { Zero and .08 }\end{array}$ & $.08+$ \\
\hline Yes & 57 & $69.4 \%$ & $28.3 \%$ & $2.3 \%$ \\
\hline No & 4,369 & $86.6 \%$ & $10.7 \%$ & $2.7 \%$ \\
\hline Total & 4,426 & $86.4 \%$ & $10.9 \%$ & $2.7 \%$ \\
\hline \multicolumn{5}{|c|}{$\begin{array}{l}\text { BAC distribution among drivers who answered "Yes" and "No" is statistically different } \\
(p<.01) . \text { Difference is limited to contrasts at the "zero" and "between zero and .08" BA } \\
\text { levels. } \\
\text { The small number of drivers who answered "Yes" precluded meaningful comparisons } \\
\text { among cells. } \\
\text { In this table, Ns are unweighted and percentages are weighted. }\end{array}$} \\
\hline
\end{tabular}


Table 30. Nighttime: "In the past year, have you been told by a medical person you needed help for your drinking?" (Percentages Calculated by Column)

\begin{tabular}{lrcc}
\hline & \multicolumn{3}{c}{ BAC (g/dL) } \\
\cline { 2 - 4 } & \multicolumn{3}{c}{ Between } \\
\hline & $\mathbf{N}=\mathbf{3 , 7 7 2}$ & $\mathbf{N}=\mathbf{5 2 4}$ & $\mathbf{N}=\mathbf{0 8 +}$ \\
Yes & $1.1 \%$ & $3.5 \%$ & $1.2 \%$ \\
No & $98.9 \%$ & $96.5 \%$ & $98.8 \%$ \\
\hline
\end{tabular}

BAC distribution among drivers who answered "Yes" and "No" is statistically different $(p<.01)$. The small number of drivers who answered "Yes" precluded other meaningful comparisons among cells.

In this table, Ns are unweighted and percentages are weighted.

Table 31. Nighttime: "In the past year, have you sought help because of your drinking?" (Percentages Calculated by Row)

\begin{tabular}{lrccc}
\hline & & \multicolumn{3}{c}{ BAC (g/dL) } \\
\cline { 3 - 5 } & $\mathbf{N}$ & Zero & Between \\
Zero and .08 & $.08+$ \\
\hline Yes & 65 & $73.8 \%$ & $19.5 \%$ & $6.7 \%$ \\
No & 4,363 & $86.5 \%$ & $10.8 \%$ & $2.7 \%$ \\
Total & 4,428 & $86.3 \%$ & $11.0 \%$ & $2.7 \%$ \\
\hline
\end{tabular}

BAC distribution among drivers who answered "Yes" and "No" is statistically different $p<.01$ ).

In this table, Ns are unweighted and percentages are weighted.

Table 32. Nighttime: "In the past year, have you sought help because of your drinking?" (Percentages Calculated by Column)

\begin{tabular}{lccc}
\hline & \multicolumn{3}{c}{ BAC $(\mathbf{g} / \mathbf{d L})$} \\
\cline { 2 - 4 } & \multicolumn{3}{c}{ Between } \\
\hline & $\mathbf{N}=\mathbf{3 , 7 7 4}$ & $\mathbf{N}=\mathbf{5 2 3}$ & $\mathbf{N}=\mathbf{0 8 +}$ \\
Yes & $1.4 \%$ & $3.0 \%$ & $4.2 \%$ \\
No & $98.6 \%$ & $97.0 \%$ & $95.8 \%$ \\
\hline
\end{tabular}

BAC distribution among drivers who answered "Yes" and "No" is statistically different $(p<.01)$. The small number of drivers who answered "Yes" precluded other meaningful comparisons among cells.

In this table, Ns are unweighted and percentages are weighted.

Table 33. Nighttime: "In the past year, have you been to an emergency room because of something related to your drinking?" (Percentages Calculated by Row)

\begin{tabular}{lrccc}
\hline & & \multicolumn{3}{c}{ BAC (g/dL) } \\
\cline { 3 - 5 } & $\mathbf{N}$ & Zero & $\begin{array}{c}\text { Between } \\
\text { Zero and .08 }\end{array}$ & .08+ \\
\hline Yes & 58 & $70.3 \%$ & $24.7 \%$ & $5.0 \%$ \\
No & 4,475 & $86.5 \%$ & $10.8 \%$ & $2.7 \%$ \\
Total & 4,533 & $86.3 \%$ & $11.0 \%$ & $2.7 \%$ \\
\hline
\end{tabular}

BAC distribution among drivers who answered "Yes" and "No" is statistically different $(p<.01)$. In this table, Ns are unweighted and percentages are weighted. 
Table 34. Nighttime: "In the past year, have you been to an emergency room because of something related to your drinking?" (Percentages Calculated by Column)

\begin{tabular}{lccr} 
& \multicolumn{4}{c}{ BAC (g/dL) } \\
\cline { 2 - 4 } & Zero & Between & .08+ \\
\hline & $\mathbf{N}=\mathbf{3 7 7 9}$ & $\mathbf{N}=\mathbf{5 2 4}$ & $\mathbf{N}=131$ \\
Yes & $1.0 \%$ & $2.7 \%$ & $2.2 \%$ \\
No & $99.0 \%$ & $97.3 \%$ & $97.8 \%$ \\
\hline
\end{tabular}

BAC distribution among drivers who answered "Yes" and "No" is statistically different $(p<.01)$. The small number of drivers who answered "Yes" precluded other meaningful comparisons among cells.

In this table, Ns are unweighted and percentages are weighted.

Reports of receiving treatment for a drinking or drug problem were equally few (Tables 35 through 40). A small percentage of the participants indicated staying overnight at an impatient or residential program (less than 1\% in Table 36) or being admitted to an outpatient program (1.9\% in Table 38), and only 1.6 percent reported receiving treatment for their drug or alcohol abuse problem through a self-help group (Table 40).

Table 35. Nighttime: "During the past 12 months, did you ever stay at least overnight in an impatient or residential drug or alcohol treatment program, for example, detox, rehab, a therapeutic community, or a hospital?" (Percentages Calculated by Row)

\begin{tabular}{lrccc}
\hline & & \multicolumn{3}{c}{ BAC (g/dL) } \\
\cline { 3 - 5 } & $\mathbf{N}$ & Zero & $\begin{array}{c}\text { Between } \\
\text { Zero and .08 }\end{array}$ \\
\hline Yes & 52 & $77.2 \%$ & $17.5 \%$ & $.08+$ \\
No & 5,548 & $88.8 \%$ & $9.0 \%$ & $5.3 \%$ \\
Total & 5,600 & $88.7 \%$ & $9.1 \%$ & $2.2 \%$ \\
\hline
\end{tabular}

BAC distribution across drivers who answered "yes" and "no" is not statistically significant. In this table, Ns are unweighted and percentages are weighted.

Table 36. Nighttime: "During the past 12 months, did you ever stay at least overnight in an impatient or residential drug or alcohol treatment program, for example, detox, rehab, a therapeutic community, or a hospital?" (Percentages Calculated by Column)

\begin{tabular}{lrcr}
\hline & \multicolumn{3}{c}{ BAC $(\mathbf{g} / \mathbf{d L})$} \\
\cline { 2 - 4 } & \multicolumn{3}{c}{ Between } \\
\hline & $\mathbf{N}=\mathbf{4 9 5 2}$ & $\mathbf{N}=\mathbf{5 2 1}$ & $\mathbf{N}=\mathbf{1 2 7}$ \\
Yes & $0.6 \%$ & $1.3 \%$ & $1.7 \%$ \\
No & $99.4 \%$ & $98.7 \%$ & $98.3 \%$ \\
\hline
\end{tabular}

BAC distribution across drivers who answered "yes" and "no" is not statistically significant. The small number of drivers who answered "Yes" precluded other meaningful comparisons among cells.

In this table, Ns are unweighted and percentages are weighted. 
Table 37. Nighttime: "Have you ever been admitted to an outpatient drug or alcohol treatment program, NOT including meetings like AA or NA?" (Percentages Calculated by Row)

\begin{tabular}{lcccc}
\hline & & \multicolumn{3}{c}{ BAC $(\mathbf{g} / \mathbf{d L})$} \\
\cline { 3 - 5 } & $\mathbf{N}$ & Zero & $\begin{array}{c}\text { Between } \\
\text { Zero and .08 }\end{array}$ & $\mathbf{. 0 8 +}$ \\
\hline Yes & 162 & $85.4 \%$ & $8.8 \%$ & $5.8 \%$ \\
No & 5,642 & $89.0 \%$ & $9.0 \%$ & $2.0 \%$ \\
Total & 5,804 & $89.0 \%$ & $9.0 \%$ & $2.0 \%$ \\
\hline
\end{tabular}

BAC distribution across drivers who answered "yes" and "no" is not statistically significant. In this table, Ns are unweighted and percentages are weighted.

Table 38. Nighttime: "Have you ever been admitted to an outpatient drug or alcohol treatment program, NOT including meetings like AA or NA?" (Percentages Calculated by Column)

\begin{tabular}{lrcr}
\hline & \multicolumn{3}{c}{ BAC (g/dL) } \\
\cline { 2 - 4 } & \multicolumn{3}{c}{ Between } \\
\hline & $\mathbf{N}=\mathbf{5 , 1 4 1}$ & $\mathbf{N}=\mathbf{5 3 3}$ & $\mathbf{N}=\mathbf{0 8 +}$ \\
Yes & $1.9 \%$ & $1.9 \%$ & $5.3 \%$ \\
No & $98.1 \%$ & $98.1 \%$ & $94.7 \%$ \\
\hline
\end{tabular}

BAC distribution across drivers who answered "yes" and "no" is not statistically significant. The small number of drivers who answered "Yes" precluded other meaningful comparisons among cells.

In this table, Ns are unweighted and percentages are weighted.

Table 39. Nighttime: "During the past 12 months, have you received treatment for your drug or alcohol use in a self-help group such as AA or NA?" (Percentages Calculated by Row)

\begin{tabular}{lcccc}
\hline & & \multicolumn{3}{c}{ BAC (g/dL) } \\
\cline { 3 - 5 } & $\mathbf{N}$ & Zero & $\begin{array}{c}\text { Between } \\
\text { Zero and .08 }\end{array}$ \\
\hline Yes & 108 & $80.4 \%$ & $15.3 \%$ & $.08+$ \\
No & 5,689 & $89.0 \%$ & $9.0 \%$ & $4.3 \%$ \\
Total & 5,797 & $88.9 \%$ & $9.0 \%$ & $2.0 \%$ \\
\hline
\end{tabular}

BAC distribution across drivers who answered "yes" and "no" is not statistically significant. In this table, Ns are unweighted and percentages are weighted. 


\section{Table 40. Nighttime: "During the past 12 months, have you received treatment for your drug or alcohol use in a self-help group such as AA or NA?" (Percentages Calculated by Column)}

\begin{tabular}{lccr}
\hline & \multicolumn{3}{c}{ BAC $(\mathbf{g} / \mathbf{d L})$} \\
\cline { 2 - 4 } & Zero & Between \\
\hline & $\mathbf{N}=\mathbf{5 , 1 3 4}$ & $\mathbf{N}=\mathbf{5 3 4}$ & $\mathbf{N}=\mathbf{0 8 +}$ \\
Yes & $1.6 \%$ & $3.1 \%$ & $3.6 \%$ \\
No & $98.4 \%$ & $96.9 \%$ & $96.4 \%$ \\
\hline
\end{tabular}

BAC distribution across drivers who answered "yes" and "no" is not statistically significant. The small number of drivers who answered "Yes" precluded other meaningful comparisons among cells.

In this table, Ns are unweighted and percentages are weighted.

\section{Observed and Reported Safety Behaviors of Nighttime Drivers}

In the 2007 NRS, interviewers observed and recorded seat belt use of drivers and, if present, front-seat passengers. Additionally, participating drivers were asked if they were acting as designated drivers ${ }^{14}$. Information on these two safety behaviors is provided for nighttime drivers in Tables 41 and 42, which reproduce the same content but show the percentages by row and by column, respectively. Table 41 indicates that of those who reported themselves as the designated driver, 13 percent had a BAC between zero and .08, and nearly 3 percent more were $.08 \mathrm{~g} / \mathrm{dL}$ or above. Ideally (if the designated driver concept had been a complete success), the proportion of BAC positives among those "designated drivers" would have been zero. Table 42 shows that about 40 percent of nighttime drivers with a BAC between zero and $.08 \mathrm{~g} / \mathrm{dL}$ and 34 percent with a BAC of .08 or higher reported being a designated driver. These are statistically different from those with drivers with a zero BAC who indicated they were designated drivers $(28 \%)$. This prevalence is statistically higher than that of drivers not reporting being a designated driver $(p<$ $.01)$. It should be noted that while our question was framed to learn if the driver was acting as a designated driver at the time of the survey, some individuals may have answered positively if they had ever served as a designated driver or may have not understood the term. In fact, we examined whether persons who reported that they were designated drivers also had passengers in the vehicle. For nighttime "designated drivers," 37.3 percent had no passengers in their vehicles, although they may have already dropped passengers off.

Regarding observed seat belt use, Table 42 shows that only about 3 percent of the drivers were not wearing a seat belt at the time of their interview. Seat belt nonuse was related to BAC level, with 5 percent of drivers with a BAC $\geq .08$ not wearing a seat belt.

14 “Tonight/Today, are you, or have you been a designated driver?" 
Table 41. Nighttime: Safety (Designated-driver Report and Seat Belt Observation) by BAC (Percentages Calculated by Row)

\begin{tabular}{|c|c|c|c|c|}
\hline & \multirow[b]{2}{*}{$\mathbf{N}$} & \multicolumn{3}{|c|}{ BAC (g/dL) } \\
\hline & & Zero & $\begin{array}{c}\text { Between } \\
\text { Zero and } .08\end{array}$ & $.08+$ \\
\hline \multicolumn{5}{|l|}{ Designated Driver } \\
\hline Yes & 1,892 & $84.0 \%$ & $13.5 \% *$ & $2.5 \% \%^{* *}$ \\
\hline (Reference) & 4,899 & $89.3 \%$ & $8.6 \%$ & $2.1 \%$ \\
\hline \multicolumn{5}{|l|}{ Driver Seat Belt Observation } \\
\hline Lap and shoulder belt & 7,493 & $87.9 \%$ & $9.9 \%$ & $2.2 \%$ \\
\hline Shoulder belt only & 401 & $85.9 \%$ & $12.8 \%$ & $1.3 \%$ \\
\hline Lap belt only & 17 & $96.9 \%$ & $3.3 \%$ & $0.0 \%$ \\
\hline No use/no belt (Reference) & 250 & $89.5 \%$ & $6.5 \%$ & $4.0 \%$ \\
\hline \multicolumn{5}{|l|}{$\begin{array}{l}\text { Passenger Seat Belt } \\
\text { Observation }\end{array}$} \\
\hline Lap and shoulder belt & 3,470 & $87.2 \%$ & $10.3 \%$ & $2.5 \%$ \\
\hline Shoulder belt only & 246 & $87.1 \%$ & $12.7 \%$ & $0.2 \%$ \\
\hline Lap belt only & 11 & $91.7 \%$ & $8.3 \%$ & $0.0 \%$ \\
\hline No use/no belt (Reference) & 217 & $86.5 \%$ & $9.7 \%$ & $3.7 \%$ \\
\hline \multicolumn{5}{|c|}{$\begin{array}{l}\text { Statistical comparisons are made between rows, with reference levels as indicated in the table. For } \\
\text { example, in the top section of the table, we tested whether the } 2.54 \% \text { cell is statistically different from the } \\
2.09 \% \text { cell, as well as whether } 13.46 \% \text { differs significantly from } 8.63 \% \text {. In the middle section of the table, } \\
\text { more than } 90 \% \text { of the drivers used a seat belt, thus leaving the number of drivers at other rows too small for } \\
\text { meaningful statistical comparisons. Similar skewed distribution occurred with the lower section of the table. } \\
* * p<01 \text { significance level. } \\
\text { In this table, Ns are unweighted and percentages are weighted. }\end{array}$} \\
\hline
\end{tabular}


Table 42. Nighttime: Safety (Designated-driver Report and Seat Belt Observation) by BAC (Percentages Calculated by Column)

\begin{tabular}{|c|c|c|c|c|}
\hline & \multicolumn{4}{|c|}{ BAC (g/dL) } \\
\hline & All & Zero & Between & $.08+$ \\
\hline Designated Driver & $N=6,791$ & $N=5,930$ & $N=696$ & $N=165$ \\
\hline Yes & $29.5 \%$ & $28.2 \%$ & $39.5^{*} \%$ & $33.8 \%$ ** \\
\hline (Reference) & $70.5 \%$ & $71.8 \%$ & $60.5 \%$ & $66.2 \%$ \\
\hline Driver Seat Belt Observation & $N=8,161$ & $\mathrm{~N}=7,131$ & $\mathrm{~N}=836$ & $\mathrm{~N}=194$ \\
\hline Lap and shoulder belt & $91.0 \%$ & $91.1 \%$ & $90.5 \%$ & $91.5 \%$ \\
\hline Shoulder belt only & $5.9 \%$ & $5.7 \%$ & $7.6 \%$ & $3.4 \%$ \\
\hline Lap belt only & $0.3 \%$ & $0.4 \%$ & $0.1 \%$ & $0.0 \%$ \\
\hline No use/no belt (Reference) & $2.8 \%$ & $2.8 \%$ & $1.8 \%$ & $5.0 \%$ \\
\hline Passenger Seat Belt & & & & \\
\hline Observation & $N=3,944$ & $N=3,453$ & $\mathrm{~N}=401$ & $\mathrm{~N}=90$ \\
\hline Lap and shoulder belt & $87.8 \%$ & $88.0 \%$ & $86.8 \%$ & $92.0 \%$ \\
\hline Shoulder belt only & $6.9 \%$ & $6.9 \%$ & $8.4 \%$ & $0.6 \%$ \\
\hline Lap belt only & $0.7 \%$ & $0.7 \%$ & $0.5 \%$ & $0.0 \%$ \\
\hline No use/no belt (Reference) & $4.7 \%$ & $4.6 \%$ & $4.3 \%$ & $7.4 \%$ \\
\hline \multicolumn{5}{|c|}{$\begin{array}{l}\text { Statistical comparisons are made between columns with "zero" as the reference. For example, we tested } \\
\text { whether the } 33.8 \% \text { cell is statistically different from the } 28.2 \% \text { cell, as well as whether } 39.5 \% \text { differs } \\
\text { significantly from } 28.2 \% \text {. In the middle section of the table, more than } 90 \% \text { of the drivers used a seat belt, } \\
\text { thus leaving the number of drivers at other rows too small for meaningful statistical comparisons. Similar } \\
\text { skewed distribution occurred with the lower section of the table. } \\
{ }^{* *} p<01 \text { significance level. } \\
\text { In this table, Ns are unweighted and percentages are weighted. }\end{array}$} \\
\hline
\end{tabular}

Tables 43 and 44 summarize helmet use among 108 nighttime motorcycle riders (operators). The tables also include information on the subset of riders who had passengers. About 66 percent of nighttime motorcycle riders were wearing a helmet (Table 44). Looking at the subset of riders with passengers to see if they differ from riders without passengers, they also had 66 percent helmet use.

Of the nighttime motorcycle riders (operators) with a BAC of $.08 \mathrm{~g} / \mathrm{dL}$ or above, 34 percent were not wearing a helmet (Table 44). 
Table 43. Nighttime: Helmet Use of Motorcycle Riders (Operators), Without and With Passengers, by Rider BAC (Percentages Calculated by Row)

\begin{tabular}{|c|c|c|c|c|}
\hline & \multirow[b]{2}{*}{$\mathbf{N}$} & \multicolumn{3}{|c|}{ BAC (g/dL) } \\
\hline & & Zero & $\begin{array}{c}\text { Between } \\
\text { Zero and } .08\end{array}$ & $.08+$ \\
\hline $\begin{array}{l}\text { Motorcycle Riders } \\
\text { (Operators) without } \\
\text { Passengers }\end{array}$ & $\mathrm{N}=108$ & $\mathrm{~N}=93$ & $\mathrm{~N}=11$ & $\mathrm{~N}=4$ \\
\hline Helmet & 81 & $83.1 \%$ & $11.2 \%$ & $5.7 \%$ \\
\hline No helmet use & 23 & $74.6 \%$ & $19.6 \%$ & $5.8 \%$ \\
\hline Unknown & 4 & $100 \%$ & $0.0 \%$ & $0.0 \%$ \\
\hline $\begin{array}{l}\text { Motorcycle Riders } \\
\text { (Operators) with } \\
\text { Passengers }\end{array}$ & $N=18$ & $\mathrm{~N}=12$ & $\mathrm{~N}=4$ & $\mathrm{~N}=2$ \\
\hline Helmet & 12 & $53.3 \%$ & $38.5 \%$ & $8.2 \%$ \\
\hline No helmet use & 5 & $67.5 \%$ & $32.5 \%$ & $0.0 \%$ \\
\hline Unknown & 1 & $74.7 \%$ & $25.3 \%$ & $0.0 \%$ \\
\hline
\end{tabular}

Table 44. Nighttime: Helmet Use for Motorcycle Rider (Operators), With and Without Passengers, by Rider BAC (Percentages Calculated by Column)

\begin{tabular}{|c|c|c|c|c|}
\hline & \multirow[b]{2}{*}{ All } & \multicolumn{3}{|c|}{$B A C(g / d L)$} \\
\hline & & Zero & $\begin{array}{c}\text { Between } \\
\text { Zero and } .08\end{array}$ & $.08+$ \\
\hline \multicolumn{5}{|l|}{$\begin{array}{l}\text { Motorcycle Riders } \\
\text { (Operators) without }\end{array}$} \\
\hline Helmet & $65.7 \%$ & $67.0 \%$ & $53.0 \%$ & $66.1 \%$ \\
\hline No helmet use & $32.9 \%$ & $30.5 \%$ & $47.0 \%$ & $33.9 \%$ \\
\hline Unknown & $1.4 \%$ & $2.5 \%$ & $0.0 \%$ & $0.0 \%$ \\
\hline \multicolumn{5}{|c|}{$\begin{array}{l}\text { Helmet Use of Motorcycle } \\
\text { Riders (Operators) with }\end{array}$} \\
\hline Helmet & $66.1 \%$ & $58.2 \%$ & $74.8 \%$ & $100.0 \%$ \\
\hline No helmet use & $26.3 \%$ & $29.3 \%$ & $25.2 \%$ & $0.0 \%$ \\
\hline Unknown & $7.6 \%$ & $12.4 \%$ & $0.0 \%$ & $0.0 \%$ \\
\hline
\end{tabular}




\section{Daytime Survey Results}

\section{Daytime BAC by Demographics, Exposure, Trip, and Vehicle Type}

As compared to the 12 percent of the nighttime drivers who had positive BACs, only 1 percent of the daytime drivers had been drinking (Table 45). This might be expected because Friday daytime is a workday, in contrast to Friday and Saturday nights, when recreational driving is predominant. The Friday afternoon data collection period ended at 3:30 p.m., before the traditional "happy hour" period began.

Table 45. Daytime: BAC Distributions of Daytime Drivers

\begin{tabular}{lrr}
\hline BAC $\mathbf{g} / \mathbf{d L}$ & $\mathbf{N}$ & $\%$ \\
\hline Zero & 2,455 & $98.9 \%$ \\
Between Zero and .08 & 22 & $0.9 \%$ \\
$.08+$ & 5 & $0.2 \%$ \\
Total & 2,482 & $100.0 \%$ \\
\hline In this table, Ns are unweighted and percentages are weighted.
\end{tabular}

Table 46 includes BAC by various demographic variables. The positive BAC categories are greater than .00 , greater than or equal to .05 , greater than or equal to .08 , and greater than or equal to .15. These categories overlap, for example, the category greater than .00 includes all positive BAC drivers, including those greater than or equal to .05 , greater to or equal to .08 , and greater than or equal to .15. This is the same principle described for the data displays in Tables 10 and 20.

As indicated in Table 46, compared to females, males are more likely to be in the BAC levels greater than zero (BAC $\geq .00 \mathrm{~g} / \mathrm{dL}$ ). No other statistically significant findings related to gender, race/ethnicity, or age were found in the daytime sample. This is likely due to the larger proportion of zero BAC drivers $(B A C=.00 \mathrm{~g} / \mathrm{dL})$ in the daytime sample and small sample size of BAC positive drivers at daytime. 
Table 46. Daytime: Demographics (Gender, Race/Ethnicity, and Age Group) by BAC

\begin{tabular}{|c|c|c|c|c|c|c|}
\hline \multirow{2}{*}{ BAC (g/dL) } & & \multirow[b]{2}{*}{0} & \multicolumn{4}{|c|}{ Alcohol Positive } \\
\hline & & & $>.00$ & $\geq .05$ & $\geq .08$ & $\geq .15$ \\
\hline & $\mathbf{N}$ & $(\%)$ & $(\%)$ & $(\%)$ & $(\%)$ & $(\%)$ \\
\hline \multicolumn{7}{|l|}{ Gender } \\
\hline Male & 1,397 & 98.5 & $1.5^{*}$ & 0.2 & 0.1 & 0.0 \\
\hline Female & 1,069 & 99.4 & 0.6 & 0.2 & 0.2 & 0.0 \\
\hline \multicolumn{7}{|l|}{ Race/Ethnicity } \\
\hline Am. Indian/Alaskan & 20 & 95.2 & 4.8 & 0.0 & 0.0 & 0.0 \\
\hline Asian & 59 & 100.0 & 0.0 & 0.0 & 0.0 & 0.0 \\
\hline Black or African Am. & 350 & 99.3 & 0.7 & 0.1 & 0.0 & 0.0 \\
\hline Hispanic & 363 & 99.1 & 0.9 & 0.4 & 0.4 & 0.0 \\
\hline Native HI/Other $\mathrm{PI}^{15}$ & 4 & 100.0 & 0.0 & 0.0 & 0.0 & 0.0 \\
\hline White & 1,615 & 98.6 & 1.4 & 0.2 & 0.2 & 0.1 \\
\hline More than one & 21 & 98.6 & 1.4 & 0.0 & 0.0 & 0.0 \\
\hline Other & 34 & 100.0 & 0.0 & 0.0 & 0.0 & 0.0 \\
\hline \multicolumn{7}{|l|}{ Age Group } \\
\hline$<21$ & 106 & 98.8 & 1.2 & 0.6 & 0.6 & 0.0 \\
\hline $21-34$ & 504 & 99.1 & 0.9 & 0.1 & 0.1 & 0.0 \\
\hline $35-44$ & 437 & 99.2 & 0.8 & 0.1 & 0.1 & 0.1 \\
\hline $45-54$ & 462 & 98.8 & 1.2 & 0.6 & 0.4 & 0.0 \\
\hline $55-64$ & 326 & 99.5 & 0.5 & 0.0 & 0.0 & 0.0 \\
\hline $65+$ & 292 & 99.9 & 0.1 & 0.1 & 0.1 & 0.0 \\
\hline
\end{tabular}

Note: Rows do not add up to $100 \%$. Data in the BAC columns overlap (e.g., entries in $>.00$ also include those in the columns for $\geq .05, \geq .08$, and $\geq .15$ ). Note: $0=<.005$.

${ }^{*} p<.05$ denotes statistical significance between the character of interest and the reference level (females). Because small sample size, comparisons involving Native Hawaiians/Other PI or More than One racial/ethnic group were not performed.

In this table, Ns are unweighted and percentages are weighted.

Tables 47 and 48 show that daytime drivers at zero BAC are split fairly evenly across the three response categories on the amount of annual mileage. Daytime drivers with BACs of .08 g/dL or higher reported the lowest annual mileage and lowest percentage of total travel occurring during the day (Table 47). However, it should be noted that only five daytime drivers had a BAC of .08 $\mathrm{g} / \mathrm{dL}$ or higher, so broad conclusions should not be drawn from these data about daytime high BAC drivers. In Tables 49 and 50, the majority of daytime drivers originated their trip from home, followed by work. Similarly, most daytime drivers reported their destination to be home, followed by work, other, and a store/gas station. Nonetheless, a weighted 68 percent of the five drivers at a BAC $.08 \mathrm{~g} / \mathrm{dL}$ or higher reported that they were coming from their homes, and none reported coming from a bar (Tables 49 and 50). Less than 10 percent reported coming from a sports facility, and 17 percent were coming from work. Because of the small sample size of BAC-positive drivers, none of these trends was statistically significant.

\footnotetext{
${ }^{15}$ Native HI/Other PI indicates Native Hawaiian or Other Pacific Islander.
} 
Table 47. Daytime: Exposure (Yearly Miles and Percentage if Daytime Driving) by BAC (Percentages Calculated by Row)

\begin{tabular}{lrrcc}
\hline & & \multicolumn{3}{c}{ BAC (g/dL) } \\
\cline { 3 - 5 } & & Zero & $\begin{array}{c}\text { Between } \\
\text { Zero and .08 }\end{array}$ & $\mathbf{. 0 8 +}$ \\
\hline Yearly Miles (Avg = 15,000 Miles) & $\mathbf{N}$ & $\%$ & $\%$ & $\%$ \\
Less than average & 715 & 99.4 & 0.3 & 0.3 \\
Average & 683 & 99.1 & 0.9 & 0.0 \\
More than average & 741 & 99.0 & 0.9 & 0.1 \\
Did not answer & 1 & 100.0 & 0.0 & 0.0 \\
Total & 2,140 & 99.2 & 0.6 & 0.2 \\
\hline Percentage of Total During the Day & & & & \\
$0-20 \%$ & 269 & 98.6 & 0.8 & 0.6 \\
$21-40 \%$ & 235 & 98.9 & 0.8 & 0.3 \\
$41-60 \%$ & 377 & 98.6 & 1.2 & 0.1 \\
$61-80 \%$ & 660 & 99.9 & 0.1 & 0.0 \\
$81-100 \%$ & 593 & 99.4 & 0.5 & 0.0 \\
Did not answer & 5 & 100.0 & 0.0 & 0.0 \\
Total & 2,139 & 99.2 & 0.6 & 0.2 \\
\hline
\end{tabular}

Small sample size for drivers with BAC $>0.00$ precluded meaningful statistical comparisons.

In this table, Ns are unweighted and percentages are weighted.

Table 48. Daytime: Exposure (Yearly Miles and Percentage of Daytime Driving) by BAC (Percentages Calculated by Column)

\begin{tabular}{lccc}
\hline & \multicolumn{3}{c}{ BAC (g/dL) } \\
\cline { 2 - 4 } & Zero & $\begin{array}{c}\text { Between } \\
\text { Zero and .08 }\end{array}$ & $\mathbf{. 0 8 +}$ \\
\hline Yearly Miles (Avg = 15,000 Miles) & & & \\
$\quad$ Less than average & $37.8 \%$ & $16.0 \%$ & $74.2 \%$ \\
Average & $29.2 \%$ & $39.2 \%$ & $0.0 \%$ \\
More than average & $33.0 \%$ & $44.8 \%$ & $25.8 \%$ \\
Did not answer & $0.0 \%$ & $0.0 \%$ & $0.0 \%$ \\
Total & $100.0 \%$ & $100.0 \%$ & $100.0 \%$ \\
Sample size & 2,113 & 22 & 5 \\
\hline Percentage of Total Driving During the Day & & & \\
$0-20 \%$ & $16.2 \%$ & $21.2 \%$ & $51.2 \%$ \\
$21-40 \%$ & $14.6 \%$ & $18.0 \%$ & $25.8 \%$ \\
$41-60 \%$ & $20.0 \%$ & $39.1 \%$ & $17.1 \%$ \\
$61-80 \%$ & $26.5 \%$ & $2.7 \%$ & $0.0 \%$ \\
$81-100 \%$ & $22.6 \%$ & $19.1 \%$ & $5.8 \%$ \\
Did not answer & $0.1 \%$ & $0.0 \%$ & $0.0 \%$ \\
Total & $100.0 \%$ & $100.0 \%$ & $100.0 \%$ \\
Sample size & 2,112 & 22 & 5 \\
\hline
\end{tabular}

Small sample size for drivers with BAC $>0.00$ precluded meaningful statistical comparisons.

In this table, Ns are unweighted and percentages are weighted. 
Table 49. Daytime: Trip Origin and Destination by BAC (Percentages Calculated by Row)

\begin{tabular}{|c|c|c|c|c|}
\hline & & \multicolumn{3}{|c|}{$B A C(g / d L)$} \\
\hline & & Zero & $\begin{array}{c}\text { Between } \\
\text { Zero and .08 }\end{array}$ & $.08+$ \\
\hline Trip Origin & $\mathbf{N}$ & $\%$ & $\%$ & $\%$ \\
\hline Bar/tavern/club & 4 & 97.5 & 2.5 & 0.0 \\
\hline Home (own home) & 790 & 99.4 & 0.2 & 0.4 \\
\hline Hotel /motel & 18 & 100.0 & 0.0 & 0.0 \\
\hline Restaurant/eating place & 98 & 96.6 & 3.4 & 0.0 \\
\hline School/church & 62 & 99.1 & 0.9 & 0.0 \\
\hline Someone else's home & 161 & 98.6 & 1.4 & 0.0 \\
\hline Sport/recreation facility/park & 30 & 98.6 & 0.0 & 1.4 \\
\hline Store/gas station & 227 & 99.8 & 0.2 & 0.0 \\
\hline Work & 452 & 98.9 & 1.0 & 0.1 \\
\hline Other & 288 & 99.8 & 0.2 & 0.1 \\
\hline Did not answer & 2 & 100.0 & 0.0 & 0.0 \\
\hline Total & 2,132 & 99.2 & 0.6 & 0.2 \\
\hline \multicolumn{5}{|l|}{ Trip Destination } \\
\hline Bar/tavern/club & 3 & 100.0 & 0.0 & 0.0 \\
\hline Home (own home) & 724 & 99.2 & 0.6 & 0.2 \\
\hline Hotel/motel & 7 & 87.7 & 12.3 & 0.0 \\
\hline Restaurant/eating place & 67 & 100.0 & 0.0 & 0.0 \\
\hline School/church & 61 & 98.9 & 1.1 & 0.0 \\
\hline Someone else's home & 190 & 98.8 & 0.9 & 0.3 \\
\hline Sport/recreation facility/park & 72 & 100.0 & 0.0 & 0.0 \\
\hline Store/gas station & 306 & 98.3 & 1.7 & 0.0 \\
\hline Work & 363 & 99.2 & 0.3 & 0.5 \\
\hline Other & 338 & 99.9 & 0.1 & 0.0 \\
\hline Did not answer & 2 & 100.0 & 0.0 & 0.0 \\
\hline Total & 2,133 & 98.7 & 1.0 & 0.2 \\
\hline
\end{tabular}

Small sample size for drivers with BAC $>0.00$ precluded meaningful statistical comparisons.

In this table, Ns are unweighted and percentages are weighted. 
Table 50. Daytime: Trip Origin and Destination by BAC (Percentages Calculated by Column)

\begin{tabular}{|c|c|c|c|}
\hline & \multicolumn{3}{|c|}{$B A C(g / d L)$} \\
\hline & Zero & $\begin{array}{c}\text { Between } \\
\text { Zero and .08 }\end{array}$ & $.08+$ \\
\hline Trip Origin & $\mathrm{N}=2,105$ & $\mathrm{~N}=22$ & $\mathrm{~N}=5$ \\
\hline Bar/tavern/club & $0.4 \%$ & $1.5 \%$ & $0.0 \%$ \\
\hline Home (own home) & $32.7 \%$ & $12.2 \%$ & $68.4 \%$ \\
\hline Hotel/motel & $1.4 \%$ & $0.0 \%$ & $0.0 \%$ \\
\hline Restaurant/eating place & $4.7 \%$ & $25.3 \%$ & $0.0 \%$ \\
\hline School/church & $4.7 \%$ & $6.3 \%$ & $0.0 \%$ \\
\hline Someone else's home & $6.7 \%$ & $14.7 \%$ & $0.0 \%$ \\
\hline Sport/recreation facility/park & $1.1 \%$ & $0.0 \%$ & $8.7 \%$ \\
\hline Store or gas station & $11.6 \%$ & $3.0 \%$ & $0.0 \%$ \\
\hline Work & $22.3 \%$ & $33.8 \%$ & $17.1 \%$ \\
\hline Other & $14.4 \%$ & $3.5 \%$ & $5.8 \%$ \\
\hline Did not answer & $0.0 \%$ & $0.0 \%$ & $0.0 \%$ \\
\hline Total & $100.0 \%$ & $100.0 \%$ & $100.0 \%$ \\
\hline Trip Destination & $\mathrm{N}=2,106$ & $\mathrm{~N}=22$ & $N=5$ \\
\hline Bar/tavern/club & $0.2 \%$ & $0.0 \%$ & $0.0 \%$ \\
\hline Home (own home) & $34.1 \%$ & $33.5 \%$ & $31.6 \%$ \\
\hline Hotel/motel & $0.1 \%$ & $1.9 \%$ & $0.0 \%$ \\
\hline Restaurant/eating place & $3.8 \%$ & $0.0 \%$ & $0.0 \%$ \\
\hline School/church & $2.6 \%$ & $4.5 \%$ & $0.0 \%$ \\
\hline Someone else's home & $9.4 \%$ & $12.4 \%$ & $17.2 \%$ \\
\hline Sport/recreation facility/park & $1.9 \%$ & $0.0 \%$ & $0.0 \%$ \\
\hline Store/gas station & $13.7 \%$ & $36.8 \%$ & $0.0 \%$ \\
\hline Work & $18.7 \%$ & $7.8 \%$ & $51.2 \%$ \\
\hline Other & $15.5 \%$ & $3.1 \%$ & $0.0 \%$ \\
\hline Did not answer & $0.0 \%$ & $0.0 \%$ & $0.0 \%$ \\
\hline Total & $100.0 \%$ & $100.0 \%$ & $100.0 \%$ \\
\hline
\end{tabular}

Small sample size for drivers with BAC $>0.00$ precluded meaningful statistical comparisons.

In this table, Ns are unweighted and percentages are weighted.

Similar to nighttime drivers, the majority of daytime drivers were in passenger cars, followed by SUVs and pickup trucks (Tables 51 and 52). Among daytime drivers with positive BACs, the majority were drivers in vans, SUVs, and motorcycles. Further, among drivers with BACs between zero and .08 and BACs at $.08 \mathrm{~g} / \mathrm{dL}$ or higher, the majority were drivers in SUVs and passenger vehicles. Because so few of the daytime drivers had positive BACs, more detailed analyses of these data are not appropriate. 
Table 51. Daytime: BAC Distribution by Vehicle Type (Percentages Calculated by Row)

\begin{tabular}{lrrcc}
\hline & & \multicolumn{3}{c}{ BAC (g/dL) } \\
\cline { 3 - 5 } Vehicle Type & \multicolumn{1}{c}{$\mathbf{N}$} & \multicolumn{1}{c}{ Zero } & $\begin{array}{c}\text { Between } \\
\text { Zero and .08 }\end{array}$ & $\mathbf{. 0 8 +}$ \\
\hline Passenger car & 1,308 & $99.2 \%$ & $0.7 \%$ & $0.1 \%$ \\
Minivan & 183 & $100.0 \%$ & $0.0 \%$ & $0.0 \%$ \\
Motorcycle & 35 & $98.9 \%$ & $1.1 \%$ & $0.0 \%$ \\
Pickup & 367 & $99.4 \%$ & $0.5 \%$ & $0.1 \%$ \\
SUV & 530 & $97.7 \%$ & $2.0 \%$ & $0.3 \%$ \\
Van & 38 & $97.0 \%$ & $3.0 \%$ & $0.0 \%$ \\
Other & 8 & $100.0 \%$ & $0.0 \%$ & $0.0 \%$ \\
\hline
\end{tabular}

Small sample size for drivers with BAC $>0.00$ precluded meaningful statistical comparisons. In this table, Ns are unweighted and percentages are weighted.

Table 52. Daytime: BAC Distribution by Vehicle Type (Percentages Calculated by Column)

\begin{tabular}{lccc}
\hline & \multicolumn{3}{c}{ BAC (g/dL) } \\
\cline { 2 - 4 } \multicolumn{1}{c}{ Vehicle Type } & Zero & Between \\
Zero and .08 & $\mathbf{. 0 8 +}$ \\
\hline Passenger car & $\mathbf{N}=\mathbf{2 , 4 3 6}$ & $\mathbf{N}=\mathbf{2 7}$ & $\mathbf{N}=\mathbf{6}$ \\
Minivan & $54.71 \%$ & $38.87 \%$ & $40.71 \%$ \\
Motorcycle & $8.08 \%$ & $0.17 \%$ & $0 \%$ \\
Pickup & $0.50 \%$ & $0.62 \%$ & $0 \%$ \\
Sports Utility Vehicle & $11.88 \%$ & $6.52 \%$ & $8.58 \%$ \\
Van & $23.21 \%$ & $49.61 \%$ & $50.71 \%$ \\
Other & $1.27 \%$ & $4.21 \%$ & $0.0 \%$ \\
Unknown & $0.35 \%$ & $0.0 \%$ & $0.0 \%$ \\
Small sample size for drivers with BAC $>0.00$ precluded meaningful statistical comparisons. & $0.0 \%$ \\
In this table, Ns are unweighted and percentages are weighted.
\end{tabular}

\section{Daytime Drivers Reporting Contact with the Criminal J ustice System}

Of the 1,828 NRS daytime participants who responded to the question "During the past 12 months, were you arrested and booked for driving under the influence of alcohol or drugs?" less than 3 percent indicated "yes" $(n=47$ unweighted). Note that the sample size of affirmative responses is very small. However, as shown in Table 53, the most frequent sanction reported was paying fines, which was reported more frequently by daytime drivers than by nighttime drivers. Other common sanctions included being placed on probation and having a license suspended. 
Table 53. Daytime Reported Sanctions Following Arrest for Previous Impaired Driving

\begin{tabular}{|c|c|c|}
\hline Item & $\mathbf{N}$ & $\%$ \\
\hline 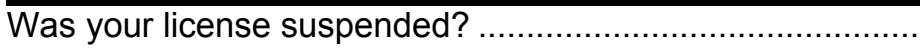 & 46 & 21.0 \\
\hline 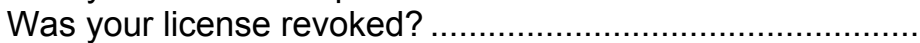 & 45 & 8.3 \\
\hline Did you serve in jail or prison?. & 47 & 21.5 \\
\hline Did you pay a fine?................... & 47 & 88.8 \\
\hline Were you required to perform community service? .............. & 47 & 15.1 \\
\hline Were you placed in probation? & 46 & 31.3 \\
\hline Were you required to attend an educational program?.......... & 45 & 11.0 \\
\hline Were you required to attend a treatment program?....... & 45 & 11.0 \\
\hline Other punishment? & 44 & 14.4 \\
\hline
\end{tabular}

Drivers could give multiple answers.

In this table, Ns are unweighted and percentages are weighted.

\section{Daytime Drivers Reporting Contacts with the Health System}

As indicated previously in this report, in addition to items relating to the criminal sanctions for drinking and drug use while driving, items related to treatment for drug or alcohol use were included in the $2007 \mathrm{NRS}$. These questions were added to the survey to investigate potential intervention opportunities. Table 54 refers to a subset of the 2007 NRS daytime respondents, those who reported drinking within the past year.

As shown in Table 54, approximately 32 percent of the daytime respondents indicated they had visited a medical facility in the last 12 months. Note that question did not contain any reference to alcohol or drugs, so the responses included visits for any health problem.

Table 54. Daytime: "Have you visited a medical facility in the past year?"

\begin{tabular}{lrr}
\hline & $\mathbf{N}$ & $\%$ \\
\hline Yes & 443 & 32.3 \\
No & 863 & 67.7 \\
Total & 1,306 & 100.0 \\
\hline
\end{tabular}

Question limited to drivers who drank in the last year.

In this table, Ns are unweighted and percentages are weighted.

When asked about contacts related to alcohol or drug use (Tables 55 through 60), less than 1 percent received any advice about drinking from a medical person (Tables 55 and 56) and less than 1 percent reported that they sought medical advice or assistance (Tables 57 and 58).

Additionally, less than 1 percent (Tables 59 through 61) reported a visit to an emergency room for a problem related to their drinking. Similar to nighttime survey results, it is not known whether the reported visits were related to crash injuries. 
Table 55. Daytime: "In the past year, have you been told by a medical person you needed help for your drinking?" (Percentage Calculated by Row)

\begin{tabular}{lrccc}
\hline & & \multicolumn{3}{c}{ BAC $(\mathbf{g} / \mathbf{d L})$} \\
\cline { 3 - 5 } & $\mathbf{N}$ & Zero & $\begin{array}{c}\text { Between } \\
\text { Zero and .08 }\end{array}$ & .08+ \\
\hline Yes & 13 & $96.5 \%$ & $3.5 \%$ & $0.0 \%$ \\
No & 1,289 & $98.7 \%$ & $1.0 \%$ & $0.3 \%$ \\
Total & 1,302 & $98.7 \%$ & $1.0 \%$ & $0.3 \%$ \\
\hline
\end{tabular}

BAC distribution among drivers who answered "Yes" and "No" cannot be statistically compared due to the small number of drivers who responded "Yes."

In this table, Ns are unweighted and percentages are weighted.

Table 56. Daytime: "In the past year, have you been told by a medical person you needed help for your drinking?" (Percentage Calculated by Column)

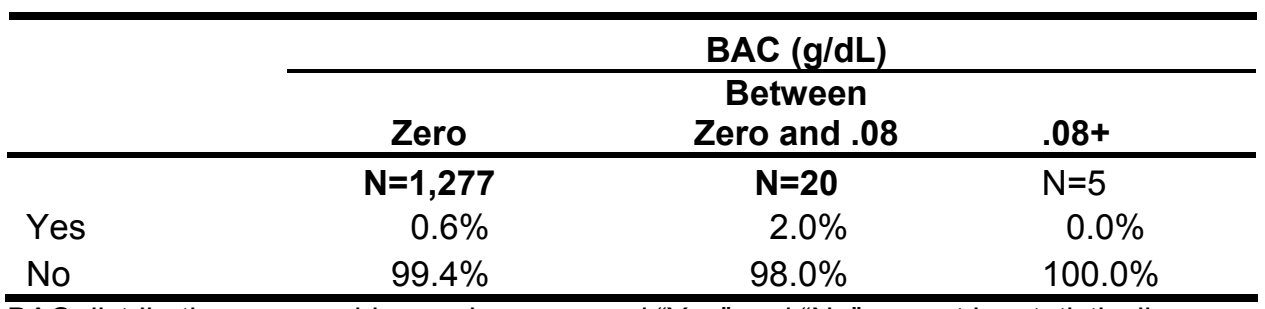

BAC distribution among drivers who answered "Yes" and "No" cannot be statistically compared due to the small number of drivers who responded "Yes."

In this table, Ns are unweighted and percentages are weighted.

Table 57. Daytime: "In the past year, have you sought help because of your drinking?" (Percentage Calculated by Row)

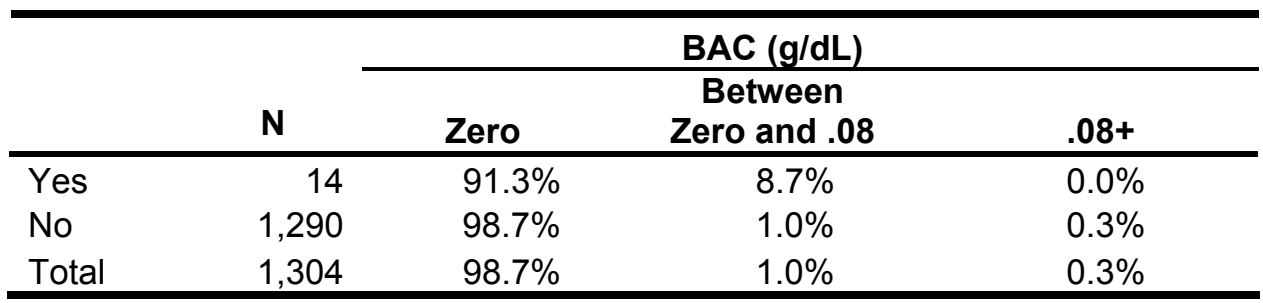

BAC distribution among drivers who answered "Yes" and "No" cannot be statistically compared due to the small number of drivers who responded "Yes."

In this table, Ns are unweighted and percentages are weighted.

Table 58. Daytime: "In the past year, have you sought help because of your drinking?" (Percentage Calculated by Column)

\begin{tabular}{|c|c|c|c|}
\hline & \multicolumn{3}{|c|}{ BAC (g/dL) } \\
\hline & Zero & $\begin{array}{c}\text { Between } \\
\text { Zero and .08 }\end{array}$ & $.08+$ \\
\hline & $\mathbf{N}=1,279$ & $\mathbf{N}=\mathbf{2 0}$ & $N=5$ \\
\hline Yes & $0.6 \%$ & $5.3 \%$ & $0.0 \%$ \\
\hline No & $99.4 \%$ & $94.7 \%$ & $100.0 \%$ \\
\hline
\end{tabular}


Table 59. Daytime: "In the past year, have you been to an emergency room because of something related to your drinking?" (Percentages Calculated by Row)

\begin{tabular}{lrlcc}
\hline & & \multicolumn{3}{c}{ BAC (g/dL) } \\
\cline { 3 - 5 } & $\mathbf{N}$ & Zero & $\begin{array}{c}\text { Between } \\
\text { Zero and .08 }\end{array}$ & $\mathbf{. 0 8 +}$ \\
\hline Yes & 9 & $94.1 \%$ & $5.9 \%$ & $0.0 \%$ \\
No & 1,293 & $98.7 \%$ & $1.0 \%$ & $0.3 \%$ \\
Total & 1,302 & $98.7 \%$ & $1.0 \%$ & $0.3 \%$ \\
\hline
\end{tabular}

BAC distribution among drivers who answered "Yes" and "No" cannot be statistically compared due to the small number of drivers who responded "Yes."

In this table, Ns are unweighted and percentages are weighted.

Table 60. Daytime: "In the past year, have you been to an emergency room because of something related to your drinking?" (Percentages Calculated by Column)

\begin{tabular}{|c|c|c|c|}
\hline & \multicolumn{3}{|c|}{ BAC $(g / d L)$} \\
\hline & Zero & $\begin{array}{c}\text { Between } \\
\text { Zero and } .08\end{array}$ & $.08+$ \\
\hline & $N=1,277$ & $\mathrm{~N}=\mathbf{2 0}$ & $\mathrm{N}=5$ \\
\hline Yes & $0.4 \%$ & $2.4 \%$ & $0.0 \%$ \\
\hline No & $99.6 \%$ & $97.6 \%$ & $100.0 \%$ \\
\hline
\end{tabular}

Reports of receiving treatment for a drinking or drug problems were also infrequent among daytime drivers (Tables 61 through 66). Note the sample sizes of affirmative answers are very small. Less than 1 percent $^{16}$ indicated they stayed at an overnight impatient or residential program (Tables 61 and 62), more than 2 percent reported receiving outpatient treatment (Tables 63 and 64), and less than 1 percent ${ }^{17}$ reported receiving treatment for their drug or alcohol abuse problem through a self-help group and all of those persons had a zero BAC level (Tables 65 and 66).

Table 61. Daytime: "During the past 12 months, did you ever stay at least overnight in an impatient or residential drug or alcohol treatment program, for example, detox, rehab, a therapeutic community, or a hospital?" (Percentages Calculated by Row)

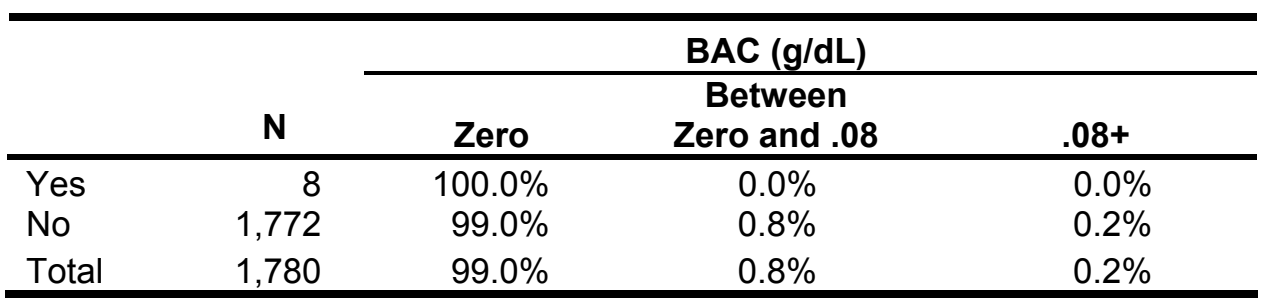

BAC distribution among drivers who answered "Yes" and "No" cannot be statistically compared due to the small number of drivers who responded "Yes."

In this table, Ns are unweighted and percentages are weighted.

\footnotetext{
${ }^{16}$ In the two tables this is indicated with " 0 "s due to rounding.

${ }^{17}$ In the two tables this is indicated with " 0 "s due to rounding.
} 
Table 62. Daytime: "During the past 12 months, did you ever stay at least overnight in an impatient or residential drug or alcohol treatment program, for example, detox, rehab, a therapeutic community, or a hospital?" (Percentages Calculated by Column)

\begin{tabular}{lccc}
\hline & \multicolumn{3}{c}{ BAC $(\mathbf{g} / \mathbf{d L})$} \\
\cline { 2 - 4 } & Zero & Between \\
& $\mathbf{N}=\mathbf{1 7 5 5}$ & $\mathbf{N}=\mathbf{2 0}$ & $\mathbf{0 8}+$ \\
\hline Yes & $0.2 \%$ & $0.0 \%$ & $\mathbf{N}=\mathbf{5}$ \\
No & $99.8 \%$ & $100.0 \%$ & $0.0 \%$ \\
\hline
\end{tabular}

BAC distribution among drivers who answered "Yes" and "No" cannot be statistically compared due to the small number of drivers who responded "Yes."

In this table, Ns are unweighted and percentages are weighted.

Table 63. Daytime: "Have you ever been admitted to an outpatient drug or alcohol treatment program, NOT including meetings like AA or NA?" (Percentages Calculated by Row)

\begin{tabular}{lrlcc}
\hline & & \multicolumn{3}{c}{ BAC $(\mathbf{g} / \mathbf{d L})$} \\
\cline { 3 - 5 } & $\mathbf{N}$ & Zero & Between \\
& Zero and .08 & .08+ \\
\hline Yes & 44 & $87.8 \%$ & $10.1 \%$ & $2.0 \%$ \\
No & 1,791 & $99.3 \%$ & $0.5 \%$ & $0.2 \%$ \\
Total & 1,835 & $99.1 \%$ & $0.7 \%$ & $0.2 \%$ \\
\hline
\end{tabular}

BAC distribution among drivers who answered "Yes" and "No" cannot be statistically compared due to the small number of drivers who responded "Yes."

In this table, Ns are unweighted and percentages are weighted.

Table 64. Daytime: "Have you ever been admitted to an outpatient drug or alcohol treatment program, NOT including meetings like AA or NA?'" (Percentages Calculated by Column)

\begin{tabular}{lrcc}
\hline & \multicolumn{3}{c}{ BAC $(\mathbf{g} / \mathbf{d L})$} \\
\cline { 2 - 4 } & \multicolumn{3}{c}{ Between } \\
& $\mathbf{N}=\mathbf{1 , 8 1 0}$ & Zero and .08 & $\mathbf{0 8 +}$ \\
Yes & $1.5 \%$ & $\mathbf{N}=\mathbf{2 0}$ & $\mathbf{N}=\mathbf{5}$ \\
No & $98.5 \%$ & $24.2 \%$ & $17.1 \%$ \\
\hline
\end{tabular}

BAC distribution among drivers who answered "Yes" and "No" cannot be statistically compared due to the small number of drivers who responded "Yes."

In this table, Ns are unweighted and percentages are weighted. 
Table 65. Daytime: "During the past 12 months, have you received treatment for your drug or alcohol use in a self-help group such as AA or NA?" (Percentage Calculated by Row)

\begin{tabular}{|c|c|c|c|c|}
\hline & \multirow[b]{2}{*}{$\mathbf{N}$} & \multicolumn{3}{|c|}{ BAC (g/dL) } \\
\hline & & Zero & $\begin{array}{c}\text { Between } \\
\text { Zero and } .08\end{array}$ & $.08+$ \\
\hline Yes & 18 & $100.0 \%$ & $0.0 \%$ & $0.0 \%$ \\
\hline No & 1,814 & $99.1 \%$ & $0.7 \%$ & $0.2 \%$ \\
\hline Total & 1,832 & $99.1 \%$ & $0.7 \%$ & $0.2 \%$ \\
\hline
\end{tabular}

BAC distribution among drivers who answered "Yes" and "No" cannot be statistically compared due to the small number of drivers who responded "Yes." In this table, Ns are unweighted and percentages are weighted.

Table 66. Daytime: "During the past 12 months, have you received treatment for your drug or alcohol use in a self-help group such as AA or NA?" (Percentage Calculated by Column)

\begin{tabular}{lrcc}
\hline & \multicolumn{3}{c}{ BAC $(\mathbf{g} / \mathbf{d L})$} \\
\cline { 2 - 4 } & Zero & Between \\
\hline & $\mathbf{N}=\mathbf{1 8 0 7}$ & $\mathbf{N}=\mathbf{2 0}$ & $\mathbf{0 8 +}$ \\
Yes & $0.9 \%$ & $0.0 \%$ & $\mathbf{N}=\mathbf{5}$ \\
No & $99.1 \%$ & $100.0 \%$ & $0.0 \%$ \\
\hline
\end{tabular}

BAC distribution among drivers who answered "Yes" and "No" cannot be statistically compared due to the small number of drivers who responded "Yes." In this table, Ns are unweighted and percentages are weighted.

\section{Observed and Reported Safety Behaviors of Daytime Drivers}

Interviewers observed and recorded seat belt use of the daytime drivers and, if present, of the front-seat passengers. Identical to the nighttime, participating daytime drivers were asked if they were acting as designated drivers. Information on these two safety behaviors is provided for daytime drivers in Tables 67 and 68. Table 68 shows that about 20 percent of the daytime drivers reported being a designated driver. As mentioned earlier, although our question was framed to learn if the driver was acting as a designated driver at the time of the survey, some individuals may have answered positively if they had ever served as a designated driver or may have not understood the term. We examined whether or not persons who reported that they were designated drivers also had passengers in the vehicle. For daytime "designated drivers," 65.1 percent had no passengers in their vehicles.

As indicated in Table 67, virtually all $(98.6 \%)$ of those reporting having been designated drivers were alcohol free. The proportion of BAC positive drivers among "designated drivers" was not statistically different from that of other drivers, although the number of daytime drivers at positive BACs was too small for meaningful statistical comparisons.

Examination of Table 68 for this variable reveals that, among drivers responding to the designated driver question with a BAC of $.08 \mathrm{~g} / \mathrm{dL}$ or above, 68 percent reported also being the designated driver. One should bear in mind that the sample size for this high BAC group is very small $(n=5)$. This is similar to the nighttime results. Regarding observed seat belt use, Table 68 shows that about 5 percent of the daytime drivers were not wearing a seat belt at the time of their interview. Again, similar to the nighttime survey results, seat belt nonuse was related to BAC level. 
Table 67. Daytime: Designated-Driver, and Seat Belt Observation by BAC (Percentage Calculated by Row)

\begin{tabular}{|c|c|c|c|c|}
\hline & \multirow[b]{2}{*}{$\mathbf{N}$} & \multicolumn{3}{|c|}{ BAC (g/dL) } \\
\hline & & Zero & $\begin{array}{c}\text { Between } \\
\text { Zero and } .08\end{array}$ & $.08+$ \\
\hline \multicolumn{5}{|l|}{ Driver as Designated Driver } \\
\hline Yes & 378 & $98.6 \%$ & $0.8 \%$ & $0.6 \%$ \\
\hline (Reference) & 1,721 & $99.2 \%$ & $0.7 \%$ & $0.2 \%$ \\
\hline \multicolumn{5}{|l|}{ Driver Seat Belt Observation } \\
\hline Lap and shoulder belt & 2,187 & $99.4 \%$ & $0.6 \%$ & $0.1 \%$ \\
\hline Shoulder belt only & 119 & $93.1 \%$ & $5.6 \%$ & $1.3 \%$ \\
\hline Lap belt only & 6 & $89.3 \%$ & $10.7 \%$ & $0.0 \%$ \\
\hline No use/no belt (Reference) & 114 & $98.2 \%$ & $1.4 \%$ & $0.3 \%$ \\
\hline \multicolumn{5}{|c|}{ Passenger Seat Belt Observation } \\
\hline Lap and shoulder belt & 634 & $98.9 \%$ & $0.9 \%$ & $0.2 \%$ \\
\hline Shoulder belt only & 41 & $86.2 \%$ & $13.8 \%$ & $0.0 \%$ \\
\hline Lap belt only & 4 & $100.0 \%$ & $0.0 \%$ & $0.0 \%$ \\
\hline No use/no belt (Reference) & 58 & $99.1 \%$ & $0.9 \%$ & $0.0 \%$ \\
\hline
\end{tabular}

Table 68. Daytime: Designated-Driver Report, and Seat Belt Observation by BAC (Percentage Calculated by Column)

\begin{tabular}{|c|c|c|c|c|}
\hline & \multirow[b]{2}{*}{ All } & \multicolumn{3}{|c|}{$B A C(g / d L)$} \\
\hline & & Zero & $\begin{array}{c}\text { Between } \\
\text { Zero and .08 }\end{array}$ & $.08+$ \\
\hline Designated Driver & $N=2,127$ & $\mathrm{~N}=2,099$ & $\mathrm{~N}=\mathbf{2 3}$ & $N=5$ \\
\hline Yes & $20.3 \%$ & $20.2 \%$ & $23.9 \%$ & $68.4 \%$ \\
\hline No $\quad$ (Reference) & $79.7 \%$ & $79.8 \%$ & $76.1 \%$ & $31.6 \%$ \\
\hline Driver Seat Belt Observation & $\mathrm{N}=2,459$ & $N=2,426$ & $\mathrm{~N}=\mathbf{2 7}$ & $\mathrm{N}=6$ \\
\hline Lap \& shoulder belt & $89.2 \%$ & $89.6 \%$ & $54.1 \%$ & $39.7 \%$ \\
\hline Shoulder belt only & $6.00 \%$ & $5.7 \%$ & $35.9 \%$ & $50.7 \%$ \\
\hline Lap belt only & $0.3 \%$ & $0.2 \%$ & $2.9 \%$ & $0.0 \%$ \\
\hline No use/no belt (Reference) & $4.6 \%$ & $4.6 \%$ & $7.1 \%$ & $9.6 \%$ \\
\hline $\begin{array}{l}\text { Passenger Seat Belt } \\
\text { Observation }\end{array}$ & $N=748$ & $N=737$ & $N=9$ & $\mathrm{~N}=2$ \\
\hline Lap and shoulder belt & $87.2 \%$ & $88.1 \%$ & $40.8 \%$ & $100.0 \%$ \\
\hline Shoulder belt only & $8.0 \%$ & $7.0 \%$ & $57.5 \%$ & $0.0 \%$ \\
\hline Lap belt only & $0.1 \%$ & $0.1 \%$ & $0.0 \%$ & $0.0 \%$ \\
\hline No use/no belt (Reference) & $4.8 \%$ & $4.8 \%$ & $2.4 \%$ & $0.0 \%$ \\
\hline
\end{tabular}

The proportion of BAC positive drivers among daytime drivers was too small for meaningful statistical comparisons. In this table, Ns are unweighted and percentages are weighted.

Tables 69 and 70 display helmet use among 35 daytime motorcycle riders (operators). The tables also include information on the subset of riders who had passengers. Seventy percent of daytime riders wore helmets. It should be noted that helmet use data were recorded only on motorcycle riders (operators) and not on passengers. 
Table 69. Daytime: Helmet Use of Motorcycle Riders (Operators), Without and With Passengers, by Rider BAC (Percentages Calculated by Row)

\begin{tabular}{|c|c|c|c|c|}
\hline & \multirow[b]{2}{*}{$\mathbf{N}$} & \multicolumn{3}{|c|}{$B A C(g / d L)$} \\
\hline & & Zero & $\begin{array}{c}\text { Between } \\
\text { Zero and .08 }\end{array}$ & $.08+$ \\
\hline \multicolumn{5}{|c|}{ Motorcycle Riders (Operators) } \\
\hline Helmet & 25 & $98.4 \%$ & $1.6 \%$ & $N A^{*}$ \\
\hline No helmet use & 9 & $100.0 \%$ & NA & NA \\
\hline Unknown & 1 & $100.0 \%$ & NA & NA \\
\hline \multicolumn{5}{|c|}{$\begin{array}{l}\text { Motorcycle Riders } \\
\text { (Operators) with Passengers }\end{array}$} \\
\hline Helmet & 1 & $100.0 \%$ & NA & NA \\
\hline No helmet use & 1 & $100.0 \%$ & NA & NA \\
\hline Unknown & 0 & NA & NA & NA \\
\hline
\end{tabular}

Table 70. Daytime: Helmet Use for Motorcycle Rider (Operators), Without and With Passengers, by Rider BAC (Percentages Calculated by Column)

\begin{tabular}{lcccc}
\hline & & \multicolumn{3}{c}{ BAC (g/dL) } \\
\cline { 3 - 5 } & All & Zero & $\begin{array}{c}\text { Between } \\
\text { Zero and .08 }\end{array}$ & .08+ \\
\hline Motorcycle Riders (Operators) & & & & $\mathbf{N}=\mathbf{1}$ \\
without Passengers & $\mathbf{N}=\mathbf{3 5}$ & $\mathbf{N}=\mathbf{3 4}$ & $\mathbf{N}=\mathbf{0}$ \\
$\quad$ Helmet & $69.7 \%$ & $69.4 \%$ & $100.0 \%$ & $\mathrm{NA}^{*}$ \\
No helmet use & $29.4 \%$ & $29.7 \%$ & $0.0 \%$ & $\mathrm{NA}$ \\
Unknown & $0.9 \%$ & $0.9 \%$ & $0.0 \%$ & $\mathrm{NA}$ \\
\hline Motorcycle Riders & & & & \\
(Operators) with Passengers & $\mathbf{N}=\mathbf{2}$ & $\mathbf{N}=\mathbf{2}$ & $\mathrm{N}=\mathbf{0}$ & $\mathrm{N}=\mathbf{0}$ \\
$\quad$ Helmet & $51.2 \%$ & $51.2 \%$ & $\mathrm{NA}$ & $\mathrm{NA}$ \\
$\quad$ No helmet use & $48.8 \%$ & $48.8 \%$ & $\mathrm{NA}$ & $\mathrm{NA}$ \\
$\quad$ Unknown & $0 \%$ & $0 \%$ & $\mathrm{NA}$ & $\mathrm{NA}$ \\
\hline
\end{tabular}

Small sample size precluded meaningful statistical comparisons.

NA = "not applicable"

In this table, Ns are unweighted and percentages are weighted. 


\section{Prevalence of Respondents with Alcohol Use Disorders (AUDs)}

\section{Background}

In its first report to the U.S. Congress in 1968, the DOT's Highway Safety Bureau (soon to become NHTSA) reported on the status of Alcohol and Highway Safety in the United States, noting that "problem drinkers" were a major factor in fatal alcohol-related crashes (USDOT, 1968). This finding became the basis of the national Alcohol Safety Action Program, sponsored by NHTSA, and stimulated research in the development of court procedures for screening and treating impaired-driving offenders believed to exhibit AUDs. Despite this attention to the role of the AUD drinker in alcohol-related crash involvement, quantification of the extent of that relationship has remained elusive.

\section{Survey Procedures}

A full description of the 2007 NRS procedures is provided in the Methodology Report (Lacey et al., 2009). As noted previously, the survey included Friday daytime data collection periods. These data are examined herein. However, AUD data from the four traditional Friday and Saturday night periods (from 10 p.m. to midnight, and 1 a.m. to 3 a.m.) are the primary focus of the analysis described below. Table 71 shows the sequence of events in the survey. The first part of the 2007 survey proceeded in the traditional manner of the three earlier roadside surveys through the collection of the breath test (item 6). At that point, the respondent was requested to provide an oral fluid sample (item 7). Those who provided informed consent placed the collection devices in their mouths and were given a questionnaire booklet containing four selfreport measures to fill out while the oral fluid collection device was filling. The four measures were (a) an inventory of their drug use, (b) a list of questions regarding their contact with the criminal justice system, (c) a drug use disorders (DUD) questionnaire, and (d) the AUD questionnaire. To determine the individual's eligibility for the screener, question 1 of the 15 on the AUD (whether respondent had had a drink in the last year) was asked at the time (item 8) the informed consent to the oral fluid test was obtained. If the respondent answered "never," the interviewer crossed out the AUD screening section of the questionnaire booklet, indicating that the driver was not eligible for participation. If the respondent answered any amount other than "never," he/she was offered a \$5 incentive to complete the AUD questionnaire (i.e., the AUD section of the questionnaire booklet). 
Table 71. Sequence of 2007 NRS Data Collection Activities

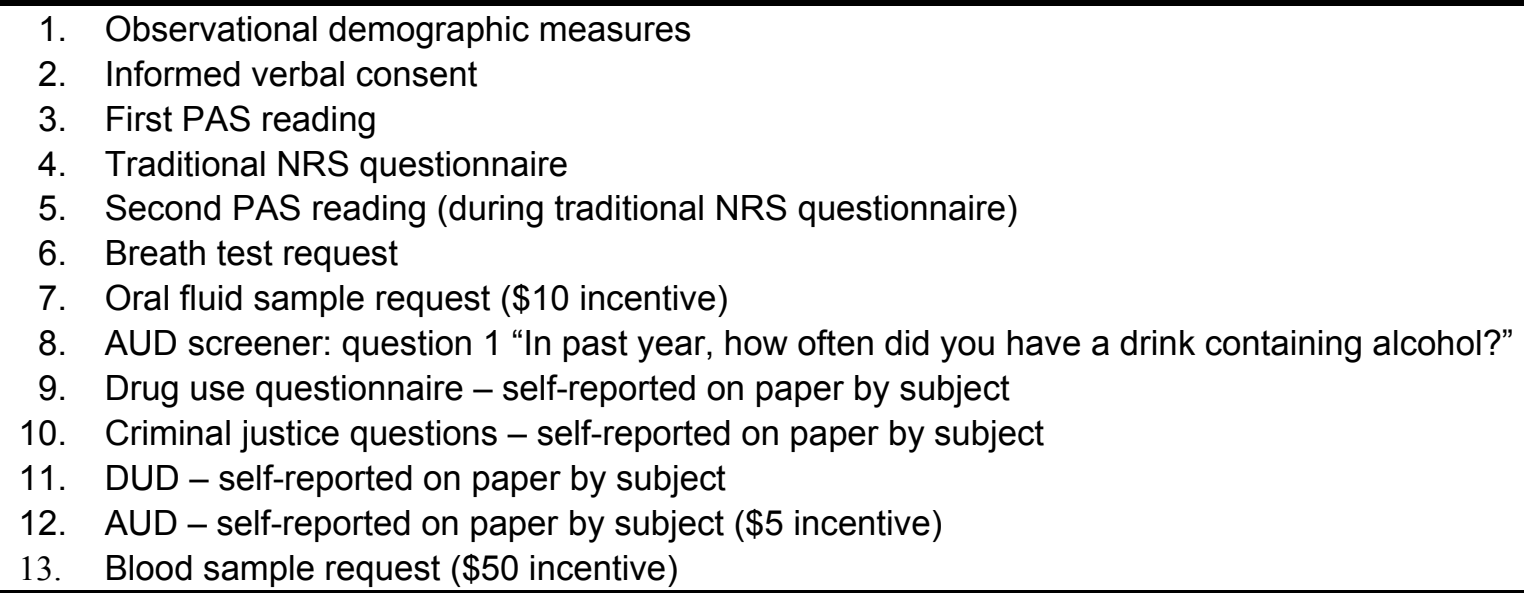

1. Observational demographic measures

2. Informed verbal consent

3. First PAS reading

4. Traditional NRS questionnaire

5. Second PAS reading (during traditional NRS questionnaire)

6. Breath test request

7. Oral fluid sample request (\$10 incentive)

8. AUD screener: question 1 "In past year, how often did you have a drink containing alcohol?"

9. Drug use questionnaire - self-reported on paper by subject

10. Criminal justice questions - self-reported on paper by subject

11. DUD - self-reported on paper by subject

12. AUD - self-reported on paper by subject ( $\$ 5$ incentive)

13. Blood sample request ( $\$ 50$ incentive)

\section{Assessing Alcohol Use Disorders}

To assess AUDs, a 15-item questionnaire was constructed from standard diagnostic instruments widely used to diagnose AUD conditions. Specifically, the Diagnostic and Statistical Manual, Fourth Edition Revised, has two classifications for AUDs, namely alcohol abuse and dependence (APA, 2008). In addition, subsyndromal drinking is most commonly characterized in the literature as high quantity and/or frequency drinking and heavy episodic drinking. We therefore define four distinct drinking groups to characterize AUDs and one to characterize drinkers who did not fall into any of these disorder groups. Those who did not fall into any of the disorder groups/categories are identified as normative drinkers. The four groups that characterize AUDs are heavy drinkers, binge drinkers, alcohol abusive drinkers, and dependent drinkers. These four disorder categories were derived from existing diagnostic instruments with known diagnostic validity and reliability and are described in the text that follows.

Heavy drinker. The first three items of the screener were scored as a unit to measure heavy drinking. They were derived from the Alcohol Use Disorders Identification Test (AUDIT) and represent the AUDIT consumption subscale, also known as the AUDIT-C (Chung, Colby, Barnett, \& Monti, 2002; Conley, 2001; Babor, de la Fuente, Saunders, \& Grant, 1992). As shown in Table 72, each of the three items is scored on a scale from 0 to 4 , making the highest possible score for all three items equal to 12 . The standard scoring system used in this study specifies that a score of 6 or more is the criterion for heavy drinking for men and a score of 5 more the criterion for women. 
Table 72. AUDIT-C Consumption Items for Measuring Heavy Drinking Questions

\begin{tabular}{|c|c|c|c|c|c|}
\hline \multirow[b]{2}{*}{1.} & \multicolumn{5}{|c|}{ In the past year, how often did you have a drink containing alcohol? } \\
\hline & never(0) & $\begin{array}{l}\text { monthly } \\
\text { or less (1) }\end{array}$ & $\begin{array}{l}2-4 \\
\text { times/month (2) }\end{array}$ & $\begin{array}{l}2-3 \\
\text { times/week (3) }\end{array}$ & $\begin{array}{l}4 \text { or more } \\
\text { times/week (4) }\end{array}$ \\
\hline \multirow[t]{2}{*}{2.} & \multicolumn{5}{|c|}{$\begin{array}{l}\text { In the past year, how many drinks containing alcohol did you have on a typical day when you were } \\
\text { drinking? }\end{array}$} \\
\hline & 1 or $2(0)$ & $2-4(1)$ & 5 or 6 & $7-9(3)$ & 10 or more (4) \\
\hline & \multicolumn{5}{|c|}{ In the past year, how often did you have six (five for a woman) or more drinks on one occasion? } \\
\hline & Never (0) & less th & monthly (1) & monthly (2) & daily/almost daily (4) \\
\hline
\end{tabular}

Binge drinker. Item 3 in Table 72, the standard binge-drinking item on the AUDIT, calls for a report on binge drinking, defined as six or more for men and five or more for women on a single occasion at least monthly in the last year.

Alcohol abusive drinker: Items 4 through 7 in Table 73 are derived from the AUDADIS (Grant \& Dawson, 1997; Cottler et al., 1997; Pull et al., 1997). The AUDADIS is constructed so that there is one item per diagnosis (based on the DSM-IV, Diagnostic and Statistical Manual Version IV) symptom. A positive response to one or more of these items was the criterion for alcohol abuse in this study.

Table 73. AUDADIS Alcohol Abuse Questions
4. Did your drinking often interfere with taking care of your home or family or cause you problems at work or school?

Did you more than once get into a situation while drinking or after drinking that increased your

5. chances of getting hurt-like driving a car or other vehicle or using heavy machinery after having had too much to drink?

\begin{tabular}{ll}
\hline 6. & Did you get arrested, held at a police station, or have legal problems because of your drinking? \\
\hline 7. & Did you continue to drink even though it was causing you trouble with your family of friends? \\
\hline
\end{tabular}

Dependent drinker. The items in Table 74 are also derived from the AUDADIS. Items 8 and 9 both relate to the domain of tolerance and were scored as a single item. Items 10 through 15 are each representative of one DSM-IV diagnostic symptom. Therefore, seven diagnostic symptoms are represented across the eight items. Three "yes" responses to any of the symptoms (Items 8 and 9 counting as one item) were the criterion for alcohol dependence. When responses to four or more of the items were not provided, the case was scored as missing unless the three available responses were "yes." Standard practice, implemented in this study, recognizes a hierarchical relationship between dependence and abuse, such that individuals who qualify for both the dependence and abuse categories are classified as dependent and are not included in the abuse classification. $^{18}$

\footnotetext{
${ }^{18}$ In this specific example, the possible categories are alcohol abuse and dependence. In total, a drinking driver could also be a heavy drinker and/or binge drinker or normative drinker. In categorizing alcohol abuse and dependence, however, if a driver is classified as alcohol dependent, that is a higher order disorder than abuse and if the driver meets criteria for both, s/he would be classified as alcohol dependent, NOT alcohol abusive.
} 
Table 74. AUDADIS Dependence Questions

8. Have you found that you have to drink more than you once did to get the effect you want?

9. Did you find that your usual number of drinks had less effect on you than it once did?

10. Did you more than once want to try to stop or cut down on your drinking, but you couldn't do it?

11. Did you end up drinking more or drinking for a longer period than you intended?

12. Did you give up or cut down on activities that were important to you or gave you pleasure in order to drink?

When the effects of alcohol were wearing off, did you experience some of the bad after effects of

13. drinking - like trouble sleeping, feeling nervous, restless, anxious, sweating or shaking, or did you have seizures or sense things that weren't really there?

14. Did you spend a lot of time drinking or getting over the bad after effects of drinking?

15. Did you continue to drink even though it was causing you to feel depressed or anxious or causing a health problem or making one worse?

Normative drinker. Respondents who qualified as current-year drinkers, but who did not provide a response that placed them in one of the four categories described above, were classified as normative drinkers. They served as a drinking comparison group for the other drinking categories.

\section{Participation in the AUD Survey}

Under this survey procedure, only respondents who completed the traditional NRS interview and provided a breath test were recruited to complete the AUD questionnaire. Figures 8 and 9 show the number of nighttime (Figure 8) and daytime (Figure 9) respondents who provided usable data at each point in the data-cleaning process (see Lacey et al., 2009, for a more complete description of the overall participant data-screening system). A total of 8,384 nighttime and 2,525 daytime drivers entered the survey site and were eligible to participate in the $2007 \mathrm{NRS}$; of those, 6,701 (83.0\%) nighttime and 2,117 (84.9\%) daytime drivers completed the traditional NRS survey questionnaire and were offered the opportunity to take the oral fluid and participate in the AUD study. Of those 6,296 (93.9\%) nighttime and 2,014 (95.1\%) daytime drivers accepted the opportunity and were screened for the AUD questionnaire.

The AUD study began with a screening question that determined whether the participant had consumed alcohol in the last year. About 26 percent of nighttime and 32 percent of daytime respondents reported that they had not had a drink in the past year (i.e., were not current drinkers) on item 1 on the AUD. This left 4,640 nighttime and 1,374 daytime participants eligible to respond to the AUD questionnaire. Of these, 0.6 percent of nighttime and 0.4 percent of daytime respondents did not complete the AUD questions. Consequently and barring some missing entries, the number of respondents providing usable data for the four AUD groups was 4,614 (99.4\% of the current drinkers) for nighttime and 1,368 (99.6\% of the current drinkers) for daytime. 


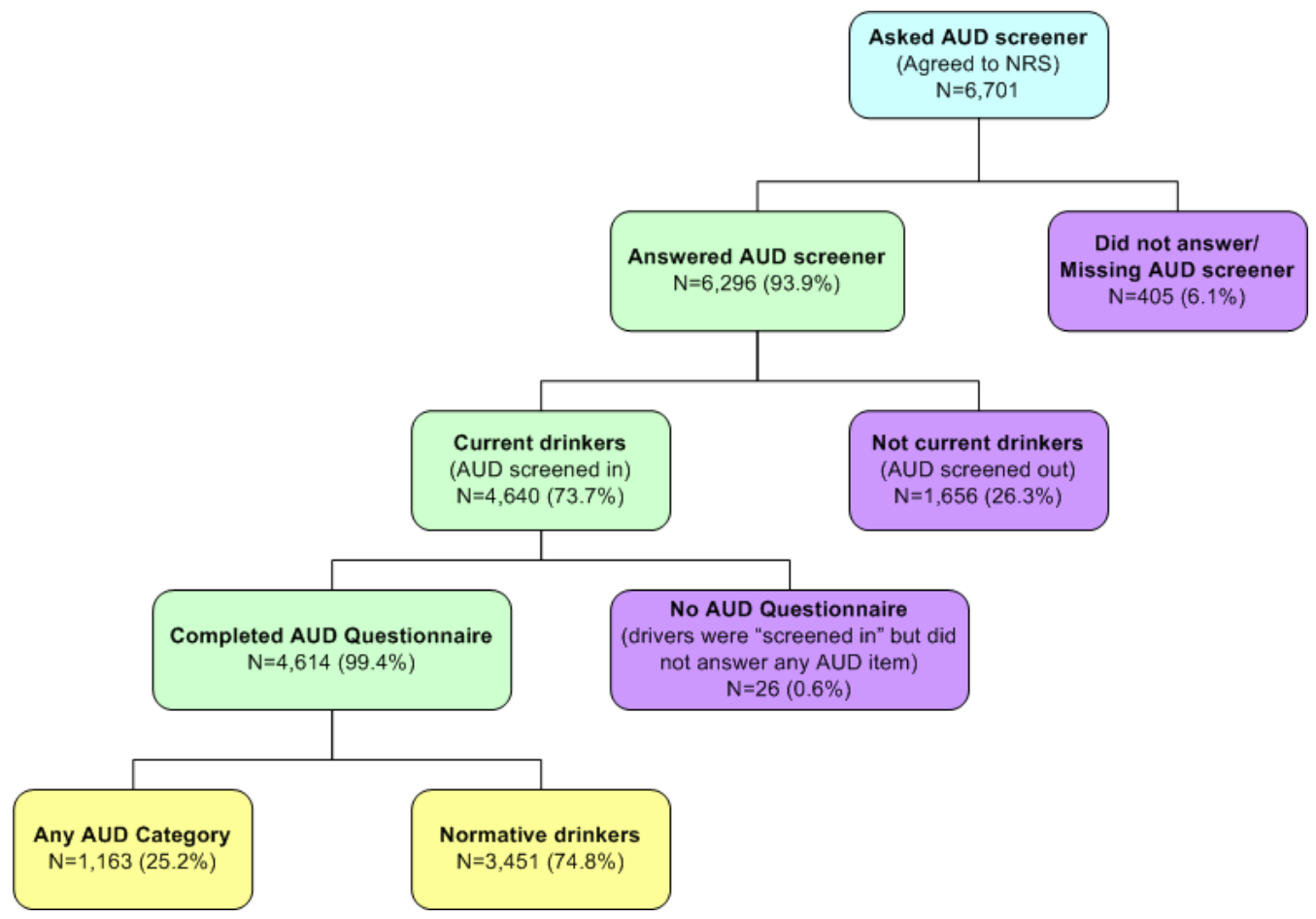

Figure 6. Development of AUD Analysis Groups, Nighttime ${ }^{19}$

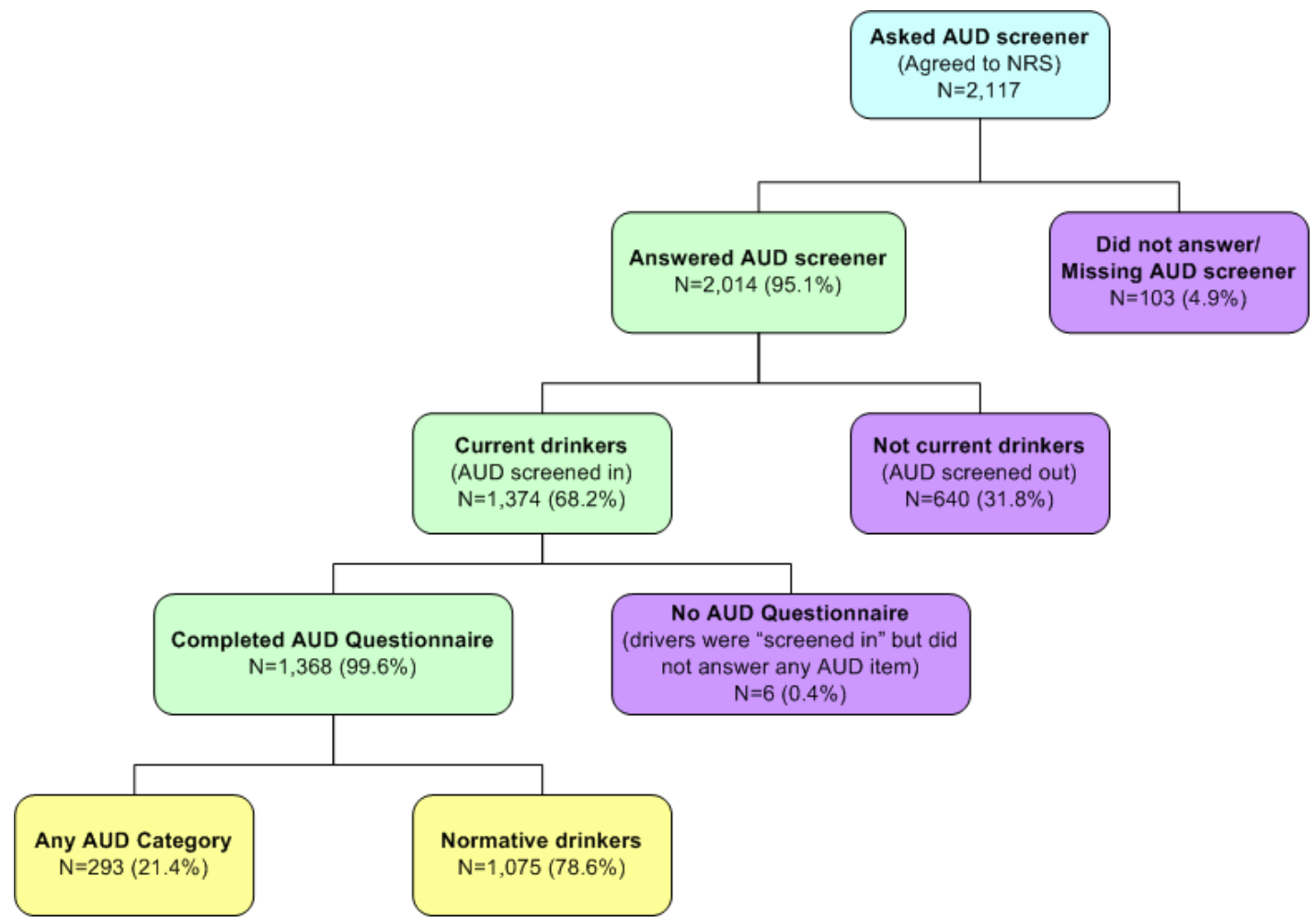

Figure 7. Development of AUD Analysis Groups, Daytime ${ }^{20}$

${ }^{19}$ In this figure, percentages are unweighted.

${ }^{20}$ In this figure, percentages are unweighted. 


\section{AUD Results}

The prevalence of the four classifications of AUD drivers in the 2007 NRS is shown in Tables 75 (nighttime) and 76 (daytime). Provided for comparison is the percentage of normative drinkers who indicated that they consumed alcohol in the last year, but were not classified in any of the four AUD categories. Note that drinking categories in Tables 75 and 76 are not completely mutually exclusive (i.e., there is some overlap between heavy drinkers, binge drinkers, dependent and abusive drinkers).

Table 75 shows that among the current drinkers in the nighttime survey, about 8 percent met the criteria for being dependent drinkers, and almost 12 percent met the criteria for an abusive drinker. About 19 percent met the criteria for being a heavy drinker and 18 percent for binge drinker. About three quarters of the current nighttime drinkers could be classified as normative drinkers. Regarding current drinking daytime drivers and comparing them against their nighttime counterparts, Table 76 shows both a higher proportion of normative drinkers in the daytime group and a reduction in the proportion of drivers with any of the other four drinking conditions (dependent drinkers, abusive drinkers, heavy drinkers, and binge drinkers).

Table 75. Number and Percentage of Respondents by Drinking Category, Nighttime

\begin{tabular}{lcc}
\hline & \multicolumn{2}{c}{ Nighttime } \\
\cline { 2 - 3 } & $\mathbf{N}$ & $\%$ \\
\hline Dependent drinker & 287 & 7.7 \\
Abusive drinker & 490 & 11.5 \\
Heavy drinker & 687 & 18.8 \\
Binge drinker & 703 & 17.6 \\
Normative drinker & 3,451 & 72.8 \\
\hline
\end{tabular}

Because of overlapping categories, columns $\mathrm{N}$ and \% add up to more than the actual number of respondents or to $100 \%$.

In this table, Ns are unweighted and percentages are weighted.

Table 76. Number and Percentage of Respondents by Drinking Category, Daytime

\begin{tabular}{lrr}
\hline & \multicolumn{2}{c}{ Daytime } \\
\cline { 2 - 3 } & $\mathbf{N}$ & $\%$ \\
\hline Dependent drinker & 49 & 2.9 \\
Abusive drinker & 110 & 7.1 \\
Heavy drinker & 191 & 13.1 \\
Binge drinker & 173 & 12.0 \\
Normative drinker & 1,075 & 80.4 \\
\hline
\end{tabular}

Because of overlapping categories, columns $\mathrm{N}$ and \% add up to more than the actual number of respondents or to $100 \%$.

In this table, Ns are unweighted and percentages are weighted.

As expected, according to the way they were defined, there is some overlapping between these categories. As noted earlier, the categories of dependent drinker and abusive drinker by definition do not overlap because the respondents who met the criteria for both were placed in the dependent category. Otherwise, there was considerable overlap between the four drinking classifications. 
Table 77 illustrates that among nighttime respondents who met the criteria for dependent drinkers, 51 percent could be classified as heavy drinkers and 53 percent as binge drinkers. Table 77 also shows that, among nighttime abusive drinkers, 36 percent could also be classified as heavy drinkers, and almost 40 percent could be classified as binge drinkers. Additionally, 77 percent of the heavy drinkers could also be classified as binge drinkers (drank $6+/ 5+$ at least once a month in the last year). The normative group, which by definition includes drinkers who did not fall into any other drinking category has no overlap with any of the four drinker categories.

Table 77. Overlap Between AUD Categories, Nighttime Respondents

\begin{tabular}{lcccc}
\hline & \multicolumn{4}{c}{ Drinking Category } \\
\cline { 2 - 4 } Drinking Category & $\begin{array}{c}\text { Dependent } \\
\text { Drinker }\end{array}$ & $\begin{array}{c}\text { Abusive } \\
\text { Drinker }\end{array}$ & $\begin{array}{c}\text { Heavy } \\
\text { Drinker }\end{array}$ & $\begin{array}{c}\text { Binge } \\
\text { Drinker }\end{array}$ \\
\cline { 2 - 4 } Dependent drinker & $100.0 \%$ & $59.9 \%$ & $51.4 \%$ & $52.8 \%$ \\
Abusive drinker & $0 \% \%^{*}$ & $100.0 \%$ & $36.1 \%$ & $39.5 \%$ \\
Heavy drinker & $20.8 \%$ & $21.1 \%$ & $100.0 \%$ & $76.9 \%$ \\
Binge drinker & $21.3 \%$ & $23.1 \%$ & $75.9 \%$ & $100.0 \%$ \\
$\quad{ }^{*}$ Respondents who are positive on both abuse and dependent items are categorized as dependent. \\
$\quad$ In this table, percentages are unweighted.
\end{tabular}

Table 78 shows an overlapping pattern for daytime drivers similar to that for nighttime drivers. The sole exception involves binge drinkers, in that daytime drivers who reported binge drinking, or heavy drinking, in the last year were significantly less likely to be diagnosed as dependent or abusive than their nighttime binge-drinking counterparts $(p<.01)$.

Table 78. Overlap between AUD Categories, Daytime Respondents

\begin{tabular}{lcccc}
\hline & \multicolumn{3}{c}{ Drinking Category } \\
\cline { 2 - 4 } Drinking Category & $\begin{array}{c}\text { Dependent } \\
\text { Drinker }\end{array}$ & $\begin{array}{c}\text { Abusive } \\
\text { Drinker }\end{array}$ & $\begin{array}{c}\text { Heavy } \\
\text { Drinker }\end{array}$ & $\begin{array}{c}\text { Binge } \\
\text { Drinker }\end{array}$ \\
\cline { 2 - 4 } Dependent drinker & $100.0 \%$ & $59.2 \%$ & $58.3 \%$ & $51.0 \%$ \\
Abusive drinker & $0 \% *$ & $100.0 \%$ & $35.8 \%$ & $32.1 \%$ \\
Heavy drinker & $14.7 \%$ & $17.9 \%$ & $100.0 \%$ & $71.7 \%$ \\
Binge drinker & $14.4 \%$ & $17.7 \%$ & $81.1 \%$ & $100.0 \%$
\end{tabular}

${ }^{*}$ Respondents who are positive on both abuse and dependent items are categorized as dependent.

In this table, percentages are unweighted.

The way these drinking categories relate to BAC levels is shown in Tables 79 and 80 (nighttime) and in Tables 81 and 82 (daytime). 
Table 79. Nighttime: BAC Distribution by Drinking Category (Percentage Calculated by Row)

\begin{tabular}{lcccc}
\hline & \multicolumn{4}{c}{ BAC(g/dL) } \\
\cline { 2 - 5 } & $\mathbf{N}$ & Zero & $\begin{array}{c}\text { Between } \\
\text { Zero and .08 }\end{array}$ & $\mathbf{. 0 8 +}$ \\
\hline Dependent drinker & 287 & $85.8 \%$ & $11.3 \%$ & $2.8 \%$ \\
Abusive drinker & 490 & $85.2 \%$ & $12.3 \%$ & $2.5 \%$ \\
Heavy drinker & 687 & $74.7 \%$ & $18.8 \%^{* *}$ & $6.4 \%^{*}$ \\
Binge drinker & 703 & $73.9 \%$ & $19.3 \%^{* *}$ & $6.8 \%^{*}$ \\
Normative drinker & 3,451 & $88.1 \%$ & $9.9 \%$ & $2.0 \%$ \\
\hline
\end{tabular}

Because of overlapping categories, column $\mathrm{N}$ adds up to more than the actual number of respondents. Statistical comparisons are made between rows with normative drinkers as the reference.

More specifically, ${ }^{*}$ and ${ }^{* *}$ denote that, compared with drivers with zero BAC, there are significant differences in the proportion of drinking drivers categories with those for "Normative Drinkers" $(p<.05$ and $p$ $<.01$, respectively).

In this table, Ns are unweighted and percentages are weighted.

Table 80. Nighttime: BAC Distribution by Drinking Category (Percentage Calculated by Column)

\begin{tabular}{|c|c|c|c|}
\hline & \multicolumn{3}{|c|}{$B A C(g / d L)$} \\
\hline & Zero & $\begin{array}{c}\text { Between } \\
\text { Zero and .08 }\end{array}$ & $.08+$ \\
\hline & $\mathrm{N}=3,897$ & $N=573$ & $N=141$ \\
\hline Dependent drinker & $7.2 \%$ & $7.0 \%$ & $7.2 \%$ \\
\hline Abusive drinker & $6.9 \%$ & $6.9 \%$ & $6.0 \%$ \\
\hline Heavy drinker & $8.3 \%$ & $4.5 \% *$ & $4.7 \%$ * \\
\hline Binge drinker & $7.6 \%$ & $19.3 \%^{*}$ & $82.0 \% *$ \\
\hline Normative drinker & $75.0 \%$ & $62.2 \%{ }^{*}$ & $50.1 \%$ * \\
\hline
\end{tabular}

Because of overlapping categories, column $\mathrm{N}$ adds up to more than the actual number of respondents. Statistical comparisons are made between columns with "zero" as the reference.

More specifically, ${ }^{*}$ denotes that, compared with drivers with a zero BAC, there are significant differences in the proportion of drinking categories $(p<.05$, respectively).

In this table, Ns are unweighted and percentages are weighted.

Notable in the nighttime data in Tables 79 and 80 is the failure of these assessments to discriminate between the drivers judged dependent and abusive by way of BAC level. Further, Table 79 shows clearly that the BAC distribution for these two types of drinking drivers does not differ from that of the normative drinkers (although Table 79 also shows that the number of normative drinkers is much larger).

Interestingly, of those drivers with BACs between zero and .08 , and $.08 \mathrm{~g} / \mathrm{dL}$ and above, the significantly largest percentage were reported by binge drinkers (Table 90).

Regarding daytime drivers, Tables 81 and 82 show once more that the proportion of drivers over the legal limit $(\mathrm{BAC} \geq .08)$ is much lower at daytime than at nighttime. Again, the proportion of alcohol abusers and dependent drivers with a $\mathrm{BAC} \geq 08$ was extremely low (there were no alcohol abusers and dependent drivers with a BAC $\geq .08$ at daytime), albeit this finding is limited by the smaller sample size at daytime. Similar to the nighttime results, of participants with BACs between zero and .08 , and $.08 \mathrm{~g} / \mathrm{dL}$ and above, the greatest percentage were heavy and binge drinkers. 
Table 81. Daytime: BAC Distribution by Drinking Category (Percentage Calculated by Row)

\begin{tabular}{lcccc}
\hline & & \multicolumn{3}{c}{ BAC $(\mathbf{g} / \mathbf{d L})$} \\
\cline { 3 - 5 } & $\mathbf{N}$ & Zero & $\begin{array}{c}\text { Between } \\
\text { Zero and .08 }\end{array}$ & $\mathbf{. 0 8 +}$ \\
\hline Dependent drinker & 49 & $98.2 \%$ & $1.8 \%$ & $0.0 \%$ \\
Abusive drinker & 110 & $98.9 \%$ & $1.1 \%$ & $0.0 \%$ \\
Heavy drinker & 191 & $95.0 \%$ & $5.0 \%$ & $0.0 \%$ \\
Binge drinker & 173 & $95.7 \%$ & $3.5 \%$ & $0.8 \%$ \\
Normative drinker & 1,075 & $99.3 \%$ & $0.5 \%$ & $0.2 \%$ \\
\hline
\end{tabular}

Because of overlapping categories, column $\mathrm{N}$ adds up to more than the actual number of respondents. Sample size of BAC-positive drivers is too small for meaningful statistical comparisons.

In this table, Ns are unweighted and percentages are weighted.

Table 82. Daytime: BAC Distribution by Drinking Category (Percentage Calculated by Column)

\begin{tabular}{lccc}
\hline & \multicolumn{3}{c}{$\mathbf{B A C}(\mathbf{g} / \mathbf{d L})$} \\
\cline { 2 - 4 } & Zero & Between \\
& $\mathbf{N}=\mathbf{1 , 3 4 4}$ & $\mathbf{N}=\mathbf{2 0}$ & $\mathbf{. 0 8 +}$ \\
\hline Dependent drinker & $2.6 \%$ & $4.8 \%$ & $\mathbf{N}=\mathbf{4}$ \\
Abusive drinker & $4.9 \%$ & $5.3 \%$ & $0.0 \%$ \\
Heavy drinker & $8.1 \%$ & $16.1 \%$ & $0.0 \%$ \\
Binge drinker & $8.6 \%$ & $31.2 \%$ & $0.0 \%$ \\
Normative drinker & $80.8 \%$ & $42.6 \%$ & $31.1 \%$ \\
\hline
\end{tabular}

Because of overlapping categories, column $\mathrm{N}$ adds up to more than the actual number of respondents. Sample size of BAC-positive drivers is too small for meaningful statistical comparisons.

In this table, Ns are unweighted and percentages are weighted. 


\section{Discussion}

The comparison of the BAC test results from the four NRS studies suggests that, during the most recent decade, there continues to be a downward trend in the proportion of drivers with positive $\mathrm{BACs}^{21}$ on U.S. roads on weekend nights, from 36.1 percent in 1973, 25.9 percent in 1986, 16.9 percent in 1996, to a low of 12.4 percent in 2007. Though the response rates we achieved in the 2007 NRS are somewhat lower than NRS studies conducted in previous decades, they are still well above those obtained with Random Digit-Dialing telephone surveys, which currently are typically lower than 50 percent (Battaglia, Frankel, \& Link, 2008). We also obtained PAS readings from well over 90 percent of these drivers who did not provide actual breath tests. This allowed us to impute BAC values for nearly every driver eligible for an interview. Since the $1996 \mathrm{NRS}$, the proportion of drivers with BACs $.08 \mathrm{~g} / \mathrm{dL}$ or above on the road has declined substantially from 4.3 percent in 1996 to 2.2 percent in 2007.

Across the four NRS surveys (1973, 1986, 1996, and 2007), reductions in .08 g/dL and above drivers in the NRS have been generally paralleled by reductions in fatal alcohol-related crashes involving drivers with a BAC of .08 or greater. The reduction in nighttime NRS drivers with BAC $.08 \mathrm{~g} / \mathrm{dL}$ or above from 1996 to 2007 appears to be greater than the reduction in FARS from 1996 to 2007 . Results from the FARS data analyses show that drivers with a $.08 \mathrm{~g} / \mathrm{dL}$ or higher in fatal crashes changed from 33.1 percent in 1996 to 32 percent in 2007, whereas the percentage of drivers at or above .08 in the 1996 NRS was 4.3 and fell to 2.2 in 2007. This is a departure from the trends observed from past NRS studies in that, from 1973 to 1986 and then from 1986 to 1996, the same pattern of reductions was observed both in fatal crashes and in the NRS.

Based on the results of the NRS, the proportion of women driving on weekend evenings has increased from 16.5 percent in 1973 to 25.5 percent in 1986, to 30.6 percent in 1996 and to 37.1 percent in 2007. Between 1996 and 2007, the percentage of females with BACs at or above .10 $\mathrm{g} / \mathrm{dL}$ significantly decreased from 1.5 to 1.0 , respectively. For males, the percentage at BAC at or above $.05 \mathrm{~g} / \mathrm{dL}$, and at BACs at or above $.10 \mathrm{~g} / \mathrm{dL}$, significantly decreased from 8.7 to 5.3 , and from 3.5 to 1.8 respectively. Thus, male drivers continue to be about 50 percent more likely to be drinking heavily than females. In the 2007 NRS, with the exception of Hispanics, non-White drivers are less likely to have a BAC at or above $.05 \mathrm{~g} / \mathrm{dL}$ than White drivers. However, the methods of collecting data on ethnicity varied across the NRS studies (some used different classifications of ethnicities and some were based on interviewer observations rather than on participant responses), so it is not clear that there has been a significant change in this pattern from the previous NRS.

The likelihood that an underage driver will have a BAC of $.05 \mathrm{~g} / \mathrm{dL}$ or higher has decreased dramatically since 1973 but has not changed significantly since the last NRS in 1996. The earlier reductions may be a result of the adoption of two laws by the States: the minimum legal drinking age 21 law and individual State zero-tolerance laws for underage drinking drivers. Graduated driver licensing laws enacted in the last decade have been shown to reduce crash involvement of

\footnotetext{
${ }^{21}$ Readers should note that all States in the U.S. have per se limits of .08 BAC. In past years, when previous roadside surveys were conducted, States' per se limits were more typically .10 BAC. Drivers with a BAC below the legal limit cannot be presumed to be impaired by alcohol. As in the past surveys, results for drivers with a BAC below the legal limit are included to provide complete data records.
} 
drivers aged 15 to 17 (Chen, Baker, \& Li, 2006), but they represent too small a percentage of underage drivers on the road on weekends to affect the overall underage drinking driver rate. The 21-to-34-year-olds are still the group most likely to have been drinking on weekend evenings.

For the first time, the 2007 NRS included the addition of data collection during two Friday daytime periods, from 9:30 a.m. to 11:30 a.m. or from 1:30 p.m. to 3:30 p.m. The daytime survey procedures were virtually identical to the standard Friday and Saturday nighttime surveys (blood samples were not collected during the daytime). Results indicate a substantial difference in the age of drivers on the road during the daytime compared to nighttime on Fridays with daytime drivers being older. Unlike the nighttime results, the number of male and female drivers is close to even during the day (as opposed to the two-thirds of the drivers on Friday nights being male). Finally, as compared to the 12 percent of the nighttime drivers who had positive BACs, only 1 percent of the daytime drivers had been drinking. This might be expected, because Friday daytime is a workday, in contrast to Friday and Saturday nights, when recreational driving is more predominant.

Another addition to the 2007 NRS was the opportunity to examine AUDs among drivers. Analyses show that among the current drinkers in the nighttime survey, about 8 percent met the criteria for being dependent drinkers, and almost 12 percent met the criteria for being an abusive drinker. About 19 percent met the criteria for being a heavy drinker and another 18 percent for binge drinker. About three quarters of the current nighttime drinkers could be classified as normative drinkers. Interestingly, of those drivers with moderate (between zero and .08) and high $(.08+) \mathrm{BACs}$, the significantly largest percentage were classified as heavy and binge drinkers.

In conclusion, the more elaborate survey protocol that involved collecting oral fluid and blood samples did not appear to account for the lower response rate for the 2007 NRS than was achieved in previous surveys. This suggests that the expanded survey procedure can be continued in future NRS studies. This expanded study has led to greater information about today's nighttime weekend drivers, as well as begun to capture information on daytime drivers. Further, the addition of the AUD screening and its results suggest that prevention programs (environmental, educational, and enforcement) should pay particular attention to individuals who drive and who report binge drinking. For example, interventions directed at reducing environmental risks, such as service to the obviously intoxicated and increased enforcement of driving-while-intoxicated laws, may be particularly effective in reducing alcohol-related crashes because of the wide prevalence of binge drinking among nighttime high BAC drivers. 


\section{References}

American Psychiatric Association. (2000). Diagnostic and Statistical Manual of Mental Disorders DSM-IV-TR Fourth Edition. Washington, DC: American Psychiatric Association.

Babor, T. F., de la Fuente, J. R., Saunders, J., \& Grant, M. (1992). AUDIT: The alcohol use disorders identification test: Guidelines for use in primary health care. Geneva, Switzerland: World Health Organization.

Battaglia, M. P., Frankel, M. R., \& Link, M. W. (2008). Improving standard poststratisfication techniques for random-digit-dialing telephone surveys. Survey Research Methods, 2(1), 11-19.

Blomberg, R., Peck, R., Moskowitz, H., Burns, M., \& Fiorentino, D. (2005). Crash Risk of Alcohol Involved Driving: A Case-Control Study. Stamford, CT: Dunlap \& Associates, Inc.

Blomberg, R. D., Peck, R. C., Moskowitz, H., Burns, M., \& Fiorentino, D. (2007). The Long Beach/Fort Lauderdale relative risk study. In B. K. Logan, D. S. Isenschmid, J. M. Walsh, D. Beirness, \& J. Morland (Eds.), Proceedings of the T2007 Joint International Meeting of TIAFT/ICADTS/IIS, August 26-30. Seattle, WA: ICADTS.

Borkenstein R. F., Crowther, R. F., Shumate, R.P., Ziel, W. B., \& Zylman, R. (1974) The role of the drinking driver in traffic accidents. Blutalkohol, 11(Supplement 1):1132.

Chen, L. H., Baker, S.P, and Li, G. (2006). "Graduated driver licensing programs and fatal crashes of 16-year-old drivers: A national evaluation.” Pediatrics 118(1): 5662.

Chung, T., Colby, S. M., Barnett, N. P., \& Monti, P. M. (2002). Alcohol use disorders identification test: Factor structure in an adolescent emergency department sample. Alcoholism: Clinical and Experimental Research, 26(2), 223-231.

Conley, T. B. (2001). Construct validity of the MAST and AUDIT with multiple offender drunk drivers. Journal of Substance Abuse Treatment, 20(4), 287-295.

Cottler, L. B., Grant, B. F., Blaine, J., Mavreas, V., Pull, C., Hasin, D., Compton, W. M., Rubio-Stipec, M., \& Mager, D. (1997). Concordance of DSM-IV alcohol and drug use disorder criteria and diagnoses as measured by AUDADIS-ADR, CIDI and SCAN. Drug and Alcohol Dependence, 47(3), 195-205.

Elder, R. W. and R. A. Shults (2002). "Involvement by young drivers in fatal alcoholrelated motor vehicle crashes - United States, 1982 - 2001.” Morbidity and Mortality Weekly Report 51(48): 1089-1091.

Federal Highway Administration (2006). Highway Statistics 2006. Retrieved June 25, 2008, from www.fhwa.dot.gov/policy/ohim/hs06/driver_licensing.htm 
Grant, B. F., \& Dawson, D. A. (1997). Prevalence and correlates of alcohol use and DSM-IV alcohol dependence in the United States: Results of the National Longitudinal Alcohol Epidemiologic Survey. Journal of Studies on Alcohol, 58(5), 464-473.

Kiger, S., Lestina, D., \& Lund, A. (1993). Passive alcohol sensors in law enforcement screening for alcohol-impaired drivers. Alcohol, Drugs and Driving, 9, 7-18.

Lacey, J., Kelley-Baker, K., Furr-Holden, C., Brainard, K., and Moore, C. (2007). Pilot Test of New Roadside Survey Methodology for Impaired Driving. (DOT HS 810 704) Washington, DC: National Highway Traffic Safety Administration.

Lacey, J. H., Kelley-Baker, T., Furr-Holden, C. D. M., Voas, R., Moore, C., Brainard, K., Tippetts, A. S., Romano, E, Torres, P., \& Berning, A. (2009 - in press). 2007 National Roadside Survey of Alcohol and Drug Use by Drivers: Methodology. Washington, DC: National Highway Traffic Safety Administration.

Lestina, D. C., Greene, M., Voas, R. B., \& Wells, J. (1999). Sampling procedures and survey methodologies for the 1996 survey with comparisons to earlier National Roadside Surveys. Evaluation Review, 23(1), 28-46.

Lund, A. K., \& Wolfe, A. C. (1991). Changes in the incidence of alcohol-impaired driving in the United States, 1973-1986. Journal of Studies on Alcohol, 52(4), 293-301.

National Highway Traffic Safety Administration. (1979). Alcohol safety action projects: Evaluation methodology and overall program impact. Washington, DC: National Highway Traffic Safety Administration.

National Highway Traffic Safety Administration. (1991). Alcohol limits for drivers: A report on the effects of alcohol and expected institutional responses to new limits. (DOT HS 807 692). Washington, DC: Department of Transportation.

National Highway Traffic Safety Administration. (1995). National automotive sampling system: Crashworthiness data system 1991-1993. Washington, DC: National Highway Traffic Safety Administration.

National Highway Traffic Safety Administration (2005). Fatality Analysis Reporting System: Fatal crash data overview. DOT HS 809 726. Washington, DC: National Highway Traffic Safety Administration.

Pull, C. B., Saunders, J. B., Mavreas, V., Cottler, L. B., Grant, B. F., Hasin, D. S., Blaine, J., Mager, D., \& Ustun, B. T. (1997). Concordance between ICD-10 alcohol and drug use disorder criteria and diagnoses as measured by the AUDADIS-ADR, CIDI and SCAN: Results of a cross-national study. Drug and Alcohol Dependence, 47(3), 207-216.

Stata Corporation. (2006). STATA (Version 9.2) [Computer Software]. College Station, TX: Stata Corporation.

Substance Abuse and Mental Health Services Administration (2004). Overview of findings from the 2003 National Survey on Drug Use and Health. Rockville, MD, Office of Applied Studies, U.S. Department of Health and Human Services. 
U.S. Department of Transportation. (1968). Alcohol and highway safety. Report to the U.S. Congress. Washington, DC: U.S. Government Printing Office.

Voas, R. B., Wells, J., Lestina, D., Williams, A., \& Greene, M. (1998). Drinking and driving in the United States: The 1996 National Roadside Survey. Accident Analysis and Prevention, 30(2), 267-275.

Wolfe, A. C. (1974). 1973 US national roadside breath testing survey: procedures and results. Ann Arbor, MI: University of Michigan Safety Research Institute.

Zador, P. L., Krawchuk, S. A., \& Voas, R. B. (2000). Alcohol-related relative risk of driver fatalities and driver involvement in fatal crashes in relation to driver age and gender: An update using 1996 data. Journal of Studies on Alcohol, 61(3), 387-395. 


\section{Appendices}

Appendix A. 2007 National Roadside Survey: Survey Instrument

Appendix B. Weighting the Data

Appendix C. Imputing Blood Alcohol Concentration (BAC) 


\section{Appendix A}

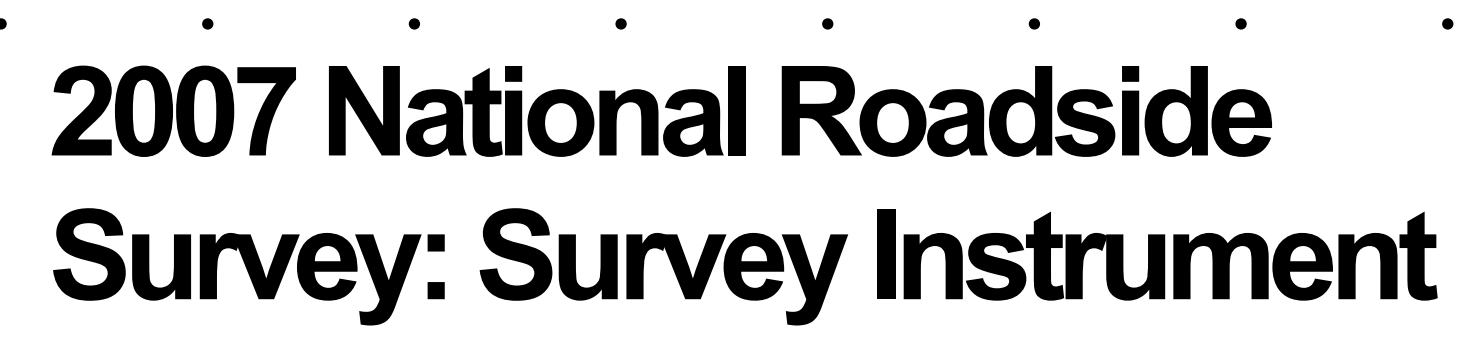




\section{Appendix A. 2007 National Roadside Survey: Survey Instrument}

\section{HOOK}

Greet subject with eye contact and smile. Use your own style to engage subjects or the one provided in the PDA.

\section{TAKE FIRST PAS READING AND RECORD IN PDA}

As you are engaging the subject to speak, take first PAS Reading and record in PDA. A reading of 6 bars or more is possible indicator of impairment and requirement to engage the Impaired Driving Protocol.

\section{ROADSIDE SURVEY Consent}

"You have not committed any violation. You have been randomly selected to participate in a voluntary and anonymous driver survey. The survey takes just a few minutes. We'd like to ask you some questions \& take a sample of your breath. You may skip any question or leave at any time. If eligible, you can earn up to $\$ 65$ (\$15 day) for completing some ADDITIONAL parts of the study. (May I begin?)"

(If subject appears to be younger than 25 years old, ask: "Are you at least 16 years of age?" If yes, continue. If no, say "Thanks, but you must be 16 to participate.")

\section{TWO Estimates on Participants and Refusers}

ESTIMATE Driver's Age:

$$
16-20(\mathrm{Y})
$$

$21-34(\mathrm{M})$

$35+(\mathrm{O})$

Observation: Driver's ethnicity: Hispanic or Latino?

Yes

No

Observation: Driver's Race

White

Black or African American

American Indian or Alaska Native

Asian

Native Hawaiian or Other Pacific Islander

More than one race

Unknown 
*REFUSERS GET YELLOW CONSENT PAPER FORM

*SIGNAL YOUR SURVEY MANAGER UPON ANY REFUSAL DURING EACH TWO HOUR COLLECTION PERIOD UNTIL INSTRUCTED OTHERWISE.

*English or Spanish?

Did you hear about this survey before you were waved in?

Yes

No

If yes: How did you hear about this survey?

Sought out Survey

Did not hunt down survey

\section{NATIONAL ROADSIDE SURVEY QUESTIONS}

1. The average driver drives about 15,000 miles a year. Would you say you drive:

More than average

Average

Less than average

Refused to answer

2. About what percent of your total driving takes place at night/during the day?

$0-20 \%$

$21-40 \%$

$\square \quad 41-60 \%$

$61-80 \%$

$\square 81-100 \%$

$\square$ Refused to answer

3. About how many miles away are you now from where you live?

$0-5$

6-10

11-20

More than 20

Refused to answer

\section{[ACTIVATE PAS for SECOND READING]}

4. Where are you coming from? (these are 2 separate questions)

Where are you headed? 


\begin{tabular}{lll} 
From & To & Place \\
\hline$\square$ & $\square$ & Own home \\
$\square$ & $\square$ & Someone else's home \\
$\square$ & $\square$ & Work \\
$\square$ & $\square$ & Restaurant/eating place \\
$\square$ & $\square$ & Bar, tavern, club \\
$\square$ & $\square$ & Sport or rec facility/park \\
$\square$ & $\square$ & School/church \\
$\square$ & $\square$ & Store or gas station \\
$\square$ & $\square$ & Hotel/Motel \\
$\square$ & $\square$ & Other \\
$\square$ & $\square$ & Refused to Answer
\end{tabular}

5. About how many miles is it between those two places?

$\square-5$

6-10

$11-15$

$16-20$

More than 20

Refused to Answer

[ASSESS ESTIMATED INTOXICATION LEVEL]

No signs of alcohol or drug use (Level 1)

Signs of use but no intoxication (Level 2)

Signs of use and Intoxication (Level 3) (Signal Supervisor)

For all subjects judged to be Level 3, a supervisor should be called over by calling out a code statement: "I need some dollars over here!" Continue asking questions while the Survey Manager observes how the subject is able to answer the questions and determine if the subject (1) has the ability to give consent AND (2) if the interview should be stopped and the Impaired Driving Protocol activated. Eight bars on the PAS requires the signaling of a Survey Manager.

\section{[RECORD PASSIVE SENSOR READING]}

$\square$ 1 green
2 green
1 yellow
2 yellow
3 yellow
4 yellow
$\square 1$ red
$\square 2$ red (Signal Supervisor)
$\square 3$ red (Signal Supervisor)
$\square 00$
0 Not used


6. Now I have a question about your use of alcohol. Do you ever drink alcoholic beverages such as beer, wine, or liquor-or are you a total abstainer?

Yes

$\square$ No, total abstainer. [GO TO Q. 13]

Refused to Answer

7. In general would you describe yourself as:

$\square$ A very light drinker

A fairly light drinker

A moderate drinker

A fairly heavy drinker

A very heavy drinker

Refused to Answer

8. About how many alcoholic beverages do you consume in an average week?

$\square 0$

$\square 1-2$

3-4

5-7

8-14

More than 14

Refused to answer

9. Have you had anything to drink today?

$\square$ Yes

No [GO TO Q. 12]

Refused to Answer [GO TO Q. 12]

10. How long ago did you finish your last drink?

Hours ___ Minutes (99 and 99 if refused)

11. Was that beer, wine, or liquor"?
Beer
Wine
Liquor
Other
Refused to answer

12. In the past 12 months, did you ever drive after drinking enough that you might be considered to be legally under the influence of alcohol?

Yes--> How many times did that happen would you say? times) ("99" if refusal) 
No

Refused to answer

13. Tonight/Today, are you, or have you been, a designated driver?

$\square$ Yes

$\square$ No

Refused to Answer

Now I have a few background questions for statistical purposes:

14. What is your age? years (“00” if refused.)

15. What is your zip code? (“00000” if refused)

16. How far have you gone in school?

Not a high school graduate

High school grad

Some college

College graduate

Some graduate work

Refused to Answer

17. Are you currently employed, unemployed, retired, on disability, a homemaker, a student, or other?

$\begin{array}{ll}\square & \text { Employed } \\ \square & \text { Unemployed } \\ \square & \text { Retired } \\ \square & \text { On disability } \\ \square & \text { Homemaker } \\ \square & \text { Student } \\ \square & \text { Other } \\ \square & \text { Refused to Answer }\end{array}$

18. Are you Hispanic or Latino?
$\square \quad$ Yes
No
Refused to answer

19. To which racial group would you say you belong?

White

Black or African American

Indian or Alaska Native

Asian

Native Hawaiian or other Pacific Islander 
More than one race

Other

Unknown

Refused to identify

The next three questions are about your general driving behavior. We are almost done with this part of the survey.

20. How many total miles will you have driven today by the end of the day?

$0-5$

6-10

$11-20$

More than 20

Refused to answer

21. How often in the past 4 weeks, have you been driving at about this same time on a Friday/Saturday.

Once

Twice

Three times

Four times

Refused to Answer

22. Have you ever been involved in a nighttime crash as a driver?

Yes

No

Refused to Answer

\section{PBT AFTER COMPLETION OF ROADSIDE SURVEY:}

Now I'd like to get an anonymous sample of your breath. Our device does not display any readings and there is no risk to you. (Show respondent PBT.) This will take just a few seconds.

\section{RECORD PBT NUMBER IN PDA ORAL FLUID/DQ CONSENT}

For $\$ 10$ cash, we are now asking you to VOLUNTARILY PARTICIPATE in two anonymous research activities about prescription and non-prescription drug use. This will take a few minutes. It involves collecting a sample of your saliva for later analysis in a lab AND filling out a questionnaire about your use of substances. As before, you may stop participating at any time.

*Read AUD Screener and then Administer Oral Fluid.

AUD SCREENER

23. In the past year, how often did you have a drink containing alcohol?

Never 
Monthly or less

2-4 times/month

2-3 times/week

4 or more times/week

Refused to Answer

[IF ANSWERS NEVER or Refuses] Respondent is ineligible. Skip AUD survey and AUD consent.

"Check "no" checkbox on AUD/DQ Booklet, cross out the AUD Questions (p. 4), hand booklet to subject, and administer oral fluid.

[IF ANSWERS anything other than NEVER, go to Consent)]

\section{AUD CONSENT}

O.K., for \$5 more, we are now asking you to VOLUNTARILY answer a few questions about your use of alcohol in the past year. Your answers to these questions CAN IN NO WAY BE ASSOCIATED WITH YOU and there is no risk to you by participating in this anonymous study. As before, you may stop participating at any time.

*Check "yes" checkbox on AUD/DQ Booklet, hand booklet to subject, and administer oral fluid.

\section{PASSENGER SURVEY (Front Seat Only - if applicable)}

We'd also like to gather some information from you as well. Please read the first paragraph and indicate whether you would like to complete the survey. If you choose to do so, I can offer you \$5 cash.

*Give Passenger Survey to front seat passenger only. They must be age 16 or older.

*While subject is completing paper forms, you may complete final Observational data.

*Give \$10 for completing Oral Fluid and Drug questionnaire

*Give \$5 for AUD if completed the paper survey.

*Collect Passenger Survey and give incentive.

*Oral Fluid Bar Codes go on tube, on Blue Card, and on AUD/DQ Booklet.

\section{BLOOD CONSENT SCRIPT}

We would like to offer you a $\$ 50$ money order to provide a quick blood sample. The purpose is to measure some blood components that may reflect alcohol or drug use. This is completely voluntary and anonymous. We have a licensed phlebotomist available who is very skilled \& it should take about 5 or 10 minutes. Would you be willing to participate in this part of the study?

NOTE: Subjects must be 18 years old in most States to provide a blood sample. The exceptions are: They must be at least age 19 in Alabama and Nebraska; They must be at least age 21 in Pennsylvania and Indiana.

YES to Blood. The DC will be have 3 bar code numbers; one blood bar code number is placed on blue card and the DC records the blood bar code number in the PDA. The 2 other bar code 
numbers will be given to the subject who will give them to the phlebotomist upon getting their blood drawn. The DC will signal the SM to escort the subject to the blood van. The

phlebotomist will place one of the remaining bar codes on the vial of blood and the other will be placed in a data log.

NO to Blood: Give subject white paper consent form. DC signals Traffic Director or SM to wave car out of the survey area.

*ALL SUBJECTS GET White CONSENT PAPER FORM

OBSERVATIONAL DATA ON VEHICLE AND PASSENGERS

Vehicle Type:

Car

SUV

Minivan

Van

Pickup

Other

Motorcycle

Unknown

Driver's Sex:

Male

Female

Unknown

Safety Belts

Driver Passenger (these are 2 separate questions)

$\begin{array}{lll}\square & \square & \text { Lap and shoulder belts (Helmet Use/Motorcycles) } \\ \square & \square & \text { Shoulder belt only } \\ \square & \square & \text { Lap belt only } \\ \square & \square & \text { No use / no belt } \\ \square & \square & \text { Unknown } \\ & \quad \text { Not applicable (no passengers) }\end{array}$

Number of Passengers (excluding driver)

$\begin{array}{lllllll}0 & 1 & 2 & 3 & 4 & 5 & 6+\end{array}$

Passengers under age 15 present:

$\square$ Yes

$\square$ No

Unknown 


\section{Appendix B}

\section{Weighting the Data}




\section{Appendix B. Weighting the Data}

This Appendix provides a detailed description of the rationale and procedures for weighting the 2007 NRS data to ensure we correctly estimate the prevalence of alcohol and drugs in the Nation's drivers in 2007. This is done both to accurately reflect the incidence of alcohol and drugged driving on our roadways and to make meaningful comparisons with previous National Roadside Surveys. We also discuss the challenges we encountered in obtaining the crash data we needed to implement this weighting process.

Because a simple random sample - in which every U.S. driver on the road during weekend latenight hours has an equal probability of being selected - was obviously impossible, a multistage sampling strategy with nested sampling frames was used. Observed cases were then weighted to reflect known distributions of the overall population. The case weight reflects the probability that any one selected and measured case would have been randomly sampled from among the total population of driving trips ${ }^{22}$ occurring during those weekend night-time hours.

At each stage of the sampling process, the sampling frame must be taken into account in computing the proper weighting factors for that stage of the sampling. These are described in the following paragraphs.

\section{Primary Sampling Units}

The first sampling stage was the selection of sizeable geographical areas in various locations around the country (though limited to the 48 contiguous States), wherein the specific survey sites would be randomly located. These geographical areas - called "Primary Sampling Units" ("PSUs," for short) - were generally either single counties, clusters of contiguous (and roughly homogenous) counties, or very large cities whose metropolitan areas were comparable to counties in size and population. Using the county and city grouping scheme that had already been developed by the National Automotive Sampling System (NASS) for the selection of their 60 PSUs that constitute the General Estimates System (GES), the population of potential PSUs included 1,193 such geographic units. PSUs needed to be selected with likelihood that is proportional to their contribution to the overall population's composition, or what is termed a "Probability Proportionate to Size" (PPS) scheme. In this manner, if equally sized random

\footnotetext{
${ }^{22}$ Driving Trips as the Units of Population: The primary purpose of the National Roadside Survey is to obtain a measure of national driving behavior (especially regarding the presence of alcohol-positive driving) that occurs during the late hours on weekend nights (i.e., when alcohol-involved driving is believed to be at its highest). Additionally, for the 2007 survey, a sample was drawn for Friday daytime drivers between 9:30-11:30 a.m. and 1:30-3:30 p.m. As such, it is important to remember the statistical population we wish to infer: not the overall U.S. population, nor geographical areas/locations per se, nor even U.S. licensed drivers generally, but rather drivers who are actually on the road traveling during those hours. The unit is defined as an action taking place (i.e., an incident). Thus, if it were possible to take a completely perfect random sample, the population of observational units to be sampled - metaphorically, the units to be shuffled and randomly drawn from a hat - from which we would hope to obtain a representative random sample of drivers would be incidents, namely, the driving trips occurring during those hours. Of course these trips (and their drivers) are linked to and correlated with population generally, and "located" (roughly, in transit) within geographically defined areas; however, the sampling frames need to be treated appropriately so as to be specifically representative of weekend nighttime driving trips (and Friday daytime trips) rather than more generally representative of population or of geography. Although that may seem like esoteric hairsplitting, it is relevant to how we treat the sampling frames, as it partially determines how the probabilities are defined and calculated. (The same holds true for the daytime drivers sampled, but we will discuss those separately. Daytime drivers are effectively a separate study population.)
} 
samples are taken within each PSU, then weighted by each case within each PSU according to the PSUs relative proportional size, the composite estimate for the entire population would approximate the distribution of individual cases that would have been sampled under an ideal (but pragmatically impossible) simple random sample.

For the 2007 National Roadside Survey, the decision was made to use a set of 60 already selected PSUs, previously chosen from a valid sampling frame that had been designed according to the principles for NASS's GES project. This decision to use the GES PSUs was partially because (a) there is an established history of cooperation from police jurisdictions in these sites, increasing the likelihood that logistical arrangements and permission could be obtained locally; (b) the PSUs for the 1996 Roadside Survey were from this group; and (c) future researchers could contrast results from the NRS survey with national crash estimates, based on the same sampling sites.

Although most of these PSUs from the GES sample did agree to participate with the NRS, there were some that declined and had to be replaced from other PSU candidates within the larger population of 1,193 geographic locales. Each replacement PSU was selected from within a limited pool of PSU candidates that had been narrowed slightly from the total 1,193 so as to match the general characteristics of the refusing PSU (i.e., by region of the country, county [or city] population size stratum, injury crash experience, and economic factors). This slightly narrowed pool from which replacements were sampled avoids replacing a site such as Los Angeles or Chicago with a locale clearly incomparable, such as Dubuque, Iowa or Boise, Idaho. This helps ensure a rough geographic and demographic comparability to the overall distribution and diversity of the original GES sites. The resulting replacement PSU that was sampled was likewise weighted in accordance with the original GES scheme for PSU weights, using the same overall PPS measure as was applied to the cooperating GES PSUs. (To account for the amount of variance, or error term, associated with sampling stage, the NRS analyses take into account the "resampling" of replacement PSUs from the overall sampling frame's population of the 1,193 geographic entities from which GES's PSUs were originally sampled.)

\section{Definition of "Size" for PSU Weighting}

In consultation with those who established the 1996 NRS methods for weighting sites, we determined that the crash experience (namely, annual frequency of drivers in injury crashes) of a particular geographic locale was a better reflection of the actual population unit ("driver incidents," namely trips) than mere population. Not only is this likely to be a much better surrogate measure or indicator of trips than population, but it also provides a smaller error term for the sampling frame (see Lestina et al., 1997). A county or city (PSU) with more crash injuries is "bigger" than another county/city (PSU) with fewer crashes; therefore, in a PPS sampling design, the cases we actually surveyed in that "bigger" PSU need to be weighted to reflect a higher probability of being in a crash than a "smaller" PSU. Just how much bigger (or smaller) must be determined via those crash injury totals.

The researchers who performed the 1996 NRS benefited from a recent national census of crash statistics that NASS had performed to revise the GES sampling. NASS had collected detailed injury crash tallies for each of the 1,195 geographical clusters that constituted the population of potential PSUs, from which the 60 PSUs were sampled. (Note that due to county border redefinitions and reclustering, there were actually two more of these geographic units in the early 1990s than there are today.) The 1996 NRS used these recently collected crash statistics for their 
PSU weighting; no recent census by county clusters had been done in the decade since then, so we obtained similar crash statistics from the States and counties for the most recent years available.

This updating of county and city crash statistics needed for PSU weighting was facilitated somewhat by the presence of State crash databases that each State collects, some of which are then shared with NHTSA for the State Data System (SDS) program. NHTSA assisted us with this critical step by sharing those State crash files that corresponded to our PSUs. In addition, PIRE had obtained other States' crash data files for various other crash analysis projects. From these State crash data files, we identified the appropriate counts of drivers involved in known injury (K,A,B coded) crashes separately for many of the geographic unit or county clusters that defined our study PSUs that were located within those States. For the remaining PSUs for which we did not have access to their States' crash files, we tracked down the statistics either from published annual reports, via direct query to State DOTs or State police officials, or on occasion, from those county or city police departments that had complete jurisdiction over the entire PSU. $^{23}$

\section{Secondary Sampling Frames (within PSUs)}

Within each PSU, ideally one would wish to take a random sample of all driver trips occurring within the time window. However, it is not possible to identify the geographic distribution of that population without knowing the location of each trip (and even if it were knowable, the process of data collection would not be possible to implement). But in a randomized cluster sampling scheme, similar in principle to the selection of PSUs throughout the country, we randomly selected four ${ }^{24}$ geographic locations within a PSU's boundaries with equal probability of selection. For each PSU separately, we divided a map of the entire PSU into square mile grids, then selected four (five) of those grids at random, and a logistically appropriate roadway location was chosen in each of those four random grids. This resulted in a sampling frame in which each specific roadway location had a probability of being selected that was equal to every other roadway location within the boundaries of the PSU. All the driver trips passing through each randomly selected point were treated as cluster samples, and the relative probability of any driver (or driver trip) being sampled was calculated from the traffic-flow counts at each site.

The information for random grid locations and traffic flow was also incorporated into the case weights to reflect both (a) the probabilities that any driver trip taking place within that cluster/location would be sampled into the survey area for data collection; and (b) the differential weights among clusters, in terms of their sheer volume of driver trips they contained (essentially, a nested level of PPS sampling within PSU). The end result of this stage of probability weights serves to reconstitute the estimated distribution of driving trips by day of week and time of night

\footnotetext{
${ }^{23}$ Some "corrections" were necessary to the crash data we obtained from some PSUs; most were available for 2006 or 2005, but others were not as recent. Using the complete 1993 and 1995 data we obtained from NHTSA respectively, plus current years' FARS totals, plus historic population changes for these counties for each year from 1990 to 2006 from the U.S. Census, we adjusted via extrapolation those crash totals from States and/or counties whose most recent crash files or reports were from years earlier than 2005/2006. This was necessary to have a comparable period for all PSUs' crashes; otherwise, cases from those States' PSUs would have been undercounted and underweighted, due to the general overall national growth in crashes over time.

${ }^{24}$ Actually, there were a total of five: one daytime location and four nighttime locations. Because the day sample and the night samples represent two different populations of interest, which will not be combined for any analysis, we treat them as though they were separate studies.
} 
within a PSU, so as to be reflective of the relative driver-trip densities, as well as reflect the differential probabilities that any given driver surveyed could be sampled. (The count of drivers being sampled was defined as any eligible driver directed into the survey bays; noncooperating and refusing drivers, as well as those who did not complete the survey but gave a single breath test only, were counted as having been sampled.)

Naturally, there were real-life situations that created slight deviations from the idealized sampling design. Not every randomly selected one-square-mile grid contained roadways with enough traffic volume to make surveying worthwhile. Some contained no roadways at all (forests, lakes, private property, mountains, etc); others may have been deemed by the local law enforcement to be unsafe for data collection. On rare occasions, some were outside of the jurisdiction of any police agency from whom we could obtain cooperation. (This was rare; in most of the PSUs, we had the participation of law enforcement agencies that covered the entire geographic area of the PSU, or at least covering all the randomly sampled squares containing usable roadway. In the few exceptions, the probabilities pertaining to random replacement gridsquares were calculated to adjust for this resampling.)

Thus, the reality of field data collection meant occasionally there had to be some replacement selection of random grid-square clusters. The fact that some PSUs - such as those in the southwest deserts of Arizona - covered vast geographic areas (and, therefore, many one-squaremile grids from which to randomly sample) but contained very few roadways, and fewer still of those with any meaningful traffic volume, meant that weighting the selection of geographic squares within that sampling frame of geography made little sense, being incongruent with reflecting the population of driver trips taking place at that hour (see first footnote). The probability that a given geographic square, randomly sampled, might contain any single driver trip, is equal for all driver trips (before the square's selection is known). The relative traffic flow density of all squares within a PSU is not known and not knowable (realistically). The traffic volume counts we obtain at the sites are the best measure of the effect of cluster at this level, and these drivers' differential probabilities of having been selected. An additional level of weighting was applied for this sampling frame to account for these cluster probabilities associated with the randomly selected squares and the traffic density within them.

\section{Intended Data Collection Numbers: Oversampled and Undersampled Quotas}

Once a PSU has been weighted for PPS, we assume that an equal number of cases will be sampled at each PSU, so that a PSU or site will not be over- or under-represented due to chance fluctuations in data collection success (such as might occur for any number of reasons; for example, more aggressive data collection teams, the bad luck of having extreme weather conditions, an anomalous event in the neighborhood, or the sheer chance of stumbling on an unusually poor / strong volume of traffic). This means that data "blocks" within each sampling frame or nested level are to be comprised of an equal quota of eligible drivers. To the extent that any PSU (or even site within PSU) had more or fewer eligible drivers sampled, the weights were adjusted to correct for oversampled or undersampled quotas.

\section{Case Weights}

For each individual driver responding to the survey, the case weight reflects the product of a joint set of probabilities, which reflect the probability that a particular driver-relative to all others whom we surveyed-would be selected for the survey from among the total pool of all 
drivers in the United States (contiguous 48 States only). The case weight is actually an inverse of the probability of being selected, relative to all other cases.

Each of the various stages (or sampling) frames that are sampled, as previously described, requires a separate calculation of probability, which then becomes a component of the final probability computation that reflects all the levels or frames. The total weighted $\mathrm{N}$ of the sample is identical to the total number of eligible drivers entering the survey bays, including refusers, but is adjusted to reflect the estimated distribution of those drivers in the 48 contiguous States. Error terms for the analyses are computed by STATA to account for the differential weights and the amount of variance attributable to the various sampling frames.

\section{Daytime Sample}

Most of the described procedures apply to the daytime survey collection as well; however, there was only one daytime site randomly selected from within each PSU, so the descriptions that pertain to accounting for and adjusting for multiple sites/locations within a PSU do not apply. The weights for daytime survey cases were calculated separately from nighttime cases, as though the daytime portion were a quasi-separate study. 


\section{Appendix C}

\section{Imputing Blood Alcohol Concentration (BAC)}




\section{Appendix C. Imputing Blood Alcohol Concentration (BAC)}

Missing BAC measures were imputed based on information collected from drivers who provided a BAC sample. The validity of this strategy depends on the implicit assumption that there are no systematic differences between those who provided a BAC sample and those who refused. We tested this assumption by offering financial incentives to a sample of NRS-refusers to reverse their refusal decisions and participate. The results from this effort (Lacey et al., 2009) suggest that alcohol was not a factor for the converted refusers. Although not conclusive (it could be argued that those who accepted the financial incentive could form another subset of refusers), this finding provides support to the validity of the BAC imputation.

To impute BAC values, and because strictly parametric regression methods tend to favor and predict values closest to the mean (and therefore, away from the most frequently observed value: $\mathrm{BAC}=0 \mathrm{~g} / \mathrm{dL}$ in a highly skewed sample), we applied a three-stage approach to impute the missing BAC values. First, we used logistic regression to estimate the probability that a driver would have a BAC $>0 \mathrm{~g} / \mathrm{dL}$, given certain explanatory variables (e.g., PAS, time of day). Then, we used a relative operating characteristic (ROC) curve approach to set a suitable threshold to separate/identify drivers with positive BACs.

In the first stage, we used a logistic model to estimate the probability of BAC $>0 \mathrm{~g} / \mathrm{dL}$, given certain predictors. The variable BAC is accordingly redefined as a binary variable (BAC2), where:

$$
\begin{aligned}
& \mathrm{BAC} 2=0 \text { if } \mathrm{BAC}=0 \\
& \mathrm{BAC} 2=1 \text { if } \mathrm{BAC}>0
\end{aligned}
$$

A subset of possible predictors for BAC2 was chosen using a forward selection method in SAS PROC LOGISTIC. Thus, the logistic model in this stage allows for the estimation of the probability of a driver having a positive BAC given certain values of the predictors.

Table 83. List of Predictors

\begin{tabular}{ll}
\hline \multicolumn{1}{c}{ Covariate } & \multicolumn{1}{c}{ Levels } \\
\hline PAS 1 reading & 0 through 8 \\
\hline PAS 2 reading & 0 through 8 \\
\multirow{2}{*}{ Session } & $1=$ Session 1 \\
& $2=$ Sessions $2 \& 4$ \\
& $3=$ Sessions 3 \& 5 \\
\hline \multirow{2}{*}{ Level of intoxication observed by } & $1=$ No Alcohol, No Drugs = Level 1, \\
data collector & $2=$ Some Alcohol or Drugs = Level 2 \\
& $3=$ Heavy Alcohol or Drugs = Level 2 \\
\hline \multirow{2}{*}{ Driver's age } & $1=$ under 22, 2=22-29, 3=30-37, 4=38-45, \\
& $5=46-53,6=54-61,7=62$ \& over \\
\hline \multirow{2}{*}{ Driver's gender } & $1=$ Male \\
& $2=$ Female \\
\hline
\end{tabular}

PAS 1 and PAS 2 denote passive alcohol sensor readings. Efforts to obtain the PAS 1 measure was attempted for all drivers entering the bay. PAS 2 was a second reading obtained later, as the interview progressed. Sessions 1, 2, 3, 4, and 5 denote the time in which the survey was taken: 
Friday daytime, Friday early at night, Friday late at night, Saturday early at night, Saturday late at night. Level of intoxication, as observed by the data collector, and the drivers' age and gender were the other explanatory variables considered in the model. Missing values in some of these variables may occur. However, for consistency with previous surveys, a PAS 1 reading was required for all imputations.

\section{Second Stage}

The logistic model used in the first-stage enables us to estimate the probability of a positive BAC: $P(B A C>0)=p$. Using a ROC approach, we subsequently established $\xi$, a threshold value chosen for predicting $\mathrm{BAC}=0 \mathrm{~g} / \mathrm{dL}$. A BAC $=0 \mathrm{~g} / \mathrm{dL}$ value is assumed each time $p$ does not reach such ROC-based threshold (i.e., $p<\xi$ ). For all other $p$ a $\mathrm{BAC}>0 \mathrm{~g} / \mathrm{dL}$ is assumed.

\section{Third Stage}

As mentioned, records with missing BAC values showing $p \geq \xi$ were assumed to have a positive BAC. The third stage focuses on imputing BAC $>0 \mathrm{~g} / \mathrm{dL}$ values to this group of drivers. Linear regression models were used for such imputation. To correct for lack of normality and improve the model's goodness of fit, the response variable was transformed (Box-Cox transformation):

$$
g(B A C)=\frac{B A C^{\lambda}-1}{\lambda}
$$

The parameter $\lambda$ was estimated according the likelihood estimated in the model, using the SAS PROC TRANSREG. The BAC imputed will be equal to $g(B A C)$ transformed back to its original scale.

Because imputation producing single predicted values from the regression models are likely to underestimate the involved variance (i.e., no residual error is assumed), we also tried stochastic regression imputation. In stochastic regression imputation, the missing values are replaced with the predicted value coming from the regression model plus its residual error. 

DOT HS 811248

December 2009

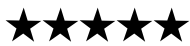

U.S. Department of Transportation National Highway Traffic Safety Administration 